\title{
EDUCACIÓN LEGAL CLÍNICA Y LITIGIO ESTRATÉGICO EN IBEROAMÉRICA
}

Beatriz Londoño Toro

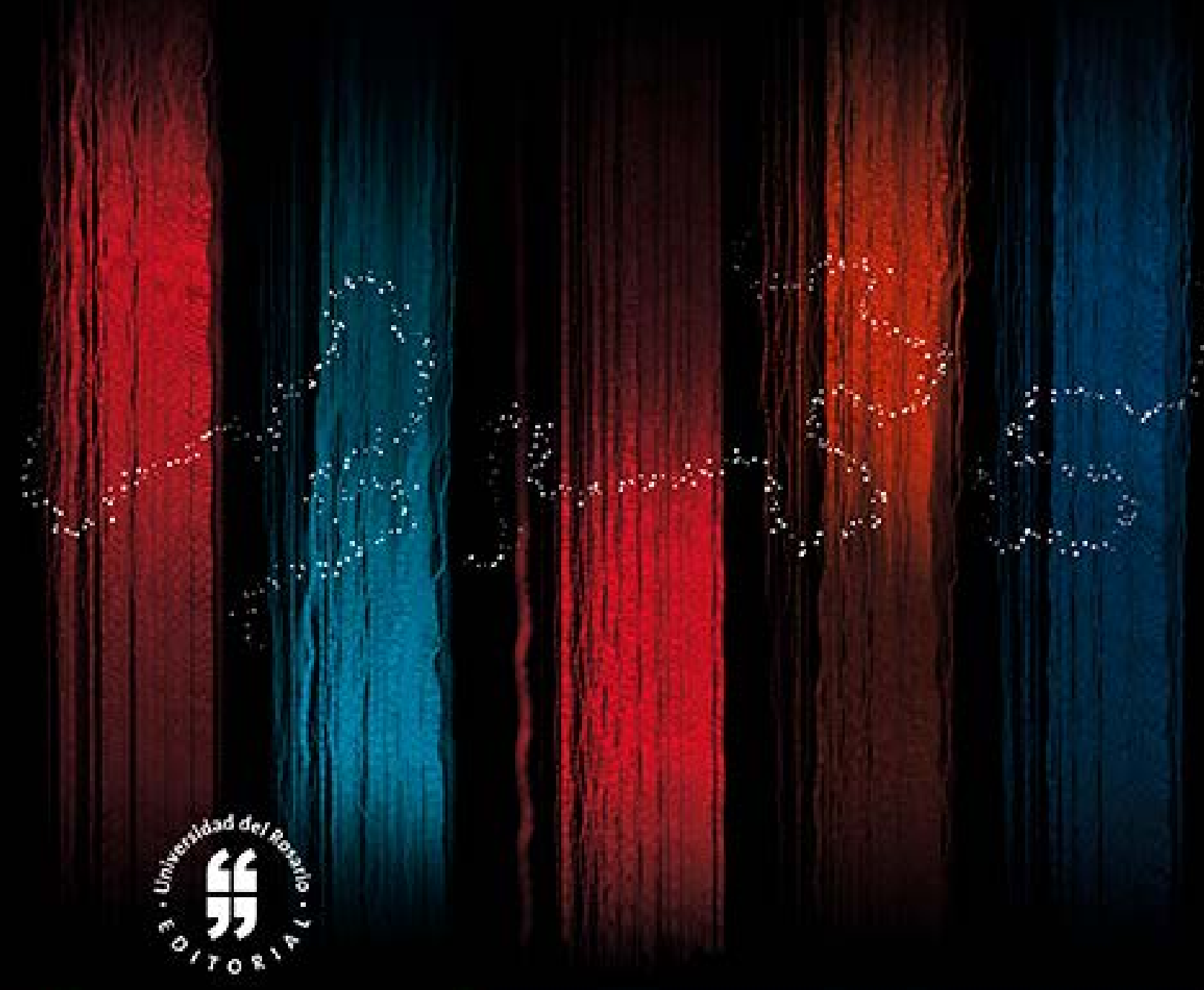



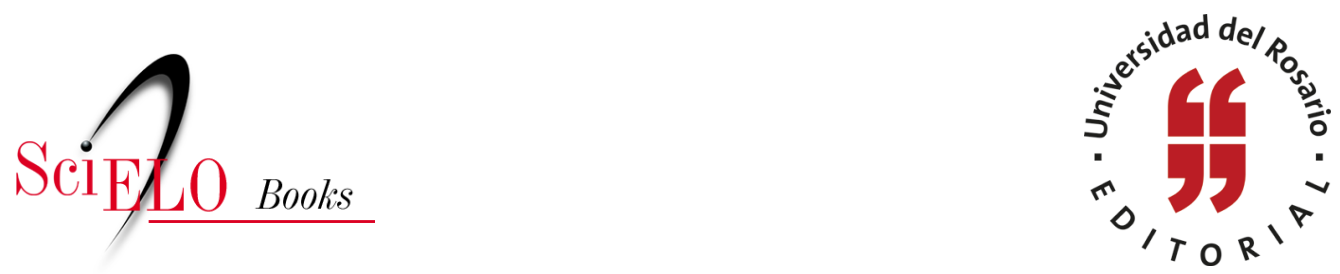

\title{
Educación legal clínica y litigio estratégico en Iberoamérica
}

\author{
Beatriz Londoño Toro
}

\section{SciELO Books / SciELO Livros / SciELO Libros}

LODOÑO TORO, B. Educación legal clínica y litigio estratégico en Iberoamérica [online]. Bogotá: Editorial Universidad del Rosario, 2015, 173 p. Textos de jurisprudencia collection. ISBN 978-958-738-624-0. https://doi.org/10.7476/9789587386240.

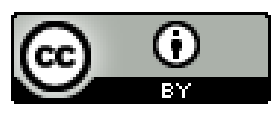

All the contents of this work, except where otherwise noted, is licensed under a Creative Commons Attribution 4.0 International license.

Todo o conteúdo deste trabalho, exceto quando houver ressalva, é publicado sob a licença Creative Commons Atribição 4.0.

Todo el contenido de esta obra, excepto donde se indique lo contrario, está bajo licencia de la licencia Creative Commons Reconocimento 4.0. 


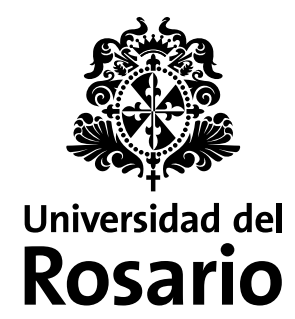




$$
\begin{gathered}
\text { Educación legal clínica } \\
\text { y litigio estratégico en Iberoamérica }
\end{gathered}
$$




\section{Londoño Toro, Beatriz}

Educación legal clínica y litigio estratégico en Iberoamérica / Beatriz Londoño Toro. - Bogotá: Editorial Universidad del Rosario, Facultad de Jurisprudencia, 2015.

xii, 174 páginas. - (Colección Textos de Jurisprudencia)

Incluye referencias bibliográficas

ISBN: 978-958-738-623-3 (rústica)

ISBN:978-958-738-624-0 (digital)

Educación superior - Métodos / Clínicas jurídicas / Derecho - Enseñanza / Derecho - Modelos de enseñanza / I. Título / II. Serie.

340.01

$$
\text { SCDD } 20
$$

Catalogación en la fuente - Universidad del Rosario. Biblioteca

amv

Hecho el depósito legal que marca el Decreto 460 de 1995 


\title{
Educación legal clínica y litigio estratégico en Iberoamérica
}

\author{
Beatriz Londoño Toro
}




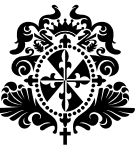

Colección Textos de Jurisprudencia

(C) Editorial Universidad del Rosario

(C) Universidad del Rosario, Facultad de Jurisprudencia

(C) Beatriz Londoño Toro

Editorial Universidad del Rosario

Carrera 7 No 12B-41, oficina 501 • Teléfono 2970200

http://editorial.urosario.edu.co
Primera edición: Bogotá D.C., julio de 2015

ISBN: 978-958-738-623-3 (rústica) ISBN: 978-958-738-624-0 (digital)

Coordinación editorial: Editorial Universidad del Rosario Corrección de estilo: Sebastián Montero

Diseño de cubierta: Miguel Ramírez, Kilka DG.

Diagramación: Martha Echeverry

Impresión: Panamericana Formas e Impresos S. A.

Impreso y hecho en Colombia

Printed and made in Colombia

Fecha de evaluación: 18 de marzo de 2015

Fecha de aceptación: 17 de abril de 2015

Todos los derechos reservados. Esta obra no puede ser reproducida sin el permiso previo por escrito de la Editorial Universidad del Rosario. 


\section{Contenido}

Agradecimientos ....................................................................................

\section{Introducción.}

Reflexiones en torno a la pregunta por la educación legal clínica y su enfoque de interés público

Un concepto inicial de clínicas jurídicas y litigio estratégico............................ 2

Litigio estratégico e interés público .................................................................. 3

\section{Educación jurídica en Iberoamérica y educación legal clínica}

A. Los principales interrogantes de la educación jurídica en Iberoamérica

1. El formalismo jurídico. ¿Qué propuestas se construyen para superarlo?

2. Desconexión entre la teoría y la realidad social........................... 17

3. La brecha entre educación jurídica y derechos humanos 20

A manera de conclusión

B. El papel de las clínicas jurídicas en la transformación de la educación legal en Iberoamérica

1. Clínicas jurídicas y Consultorios jurídicos.

Una discusión conceptual o de fondo

2. Los momentos históricos en que surgen y se desarrollan las clínicas jurídicas iberoamericanas.

Historias paralelas

La primera generación de clínicas: los primeros intentos de formación en educación legal clínica en Latinoamérica, 1960-1980

La segunda generación de clínicas jurídicas en la región (2000-2010) 
La tercera generación de clínicas (2010 hasta hoy) ............... 41

El estudio de caso de las clínicas jurídicas

colombianas....

Las clínicas de interés público y derechos humanos.

Primer movimiento de clínicas jurídicas

en Iberoamérica

La práctica de las clínicas de interés público

en diversos países iberoamericanos

3. Características de las clínicas iberoamericanas ............................ 55

El rol de los estudiantes de las clínicas

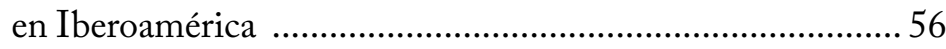

Incidencia social de las clínicas ..............................................5 59

4. Los modelos pedagógicos y la ubicación curricular

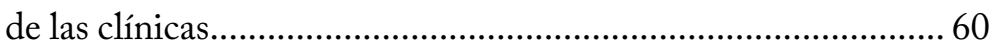

¿Las clínicas jurídicas son un nuevo modelo pedagógico? 60

¿Qué concepto de modelo pedagógico tomamos como punto de partida?

¿La educación legal clínica es un método o un modelo?

Investigación sobre el modelo pedagógico clínico

realizada por las universidades de Medellín y de Chile

¿Cómo puede incluirse la clínica en el currículo de las facultades de derecho?.

5. Logros y dificultades de la educación legal clínica en América Latina 70

El posicionamiento académico, social y político

de los temas de trabajo de las clínicas 70

Las dificultades en la educación legal clínica iberoamericana 76

\section{Posibilidades de ejercicio del litigio estratégico desde las clínicas jurídicas en Iberoamérica}

A. Evolución del concepto de litigio estratégico y algunas reflexiones sobre su relación directa con el activismo judicial. 
B. ONG, universidades e instituciones estatales de derechos humanos: alianzas estratégicas 89

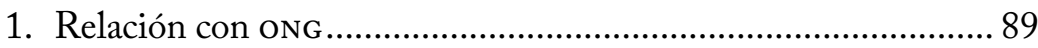

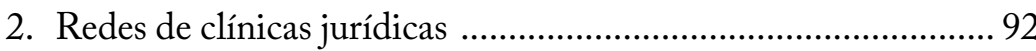

3. Relación con instituciones estatales o gubernamentales nacionales e internacionales

Las pasantías en instituciones gubernamentales nacionales e internacionales .................................................... 94

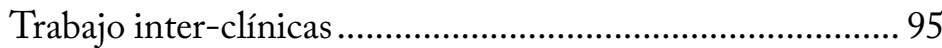

Alianzas con organizaciones pro bono ……………............. 95

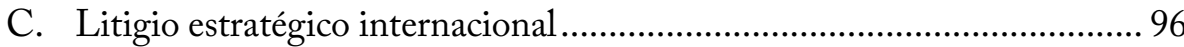

D. Las agendas de las clínicas y los temas prioritarios de derechos humanos en Iberoamérica 98

1. Prioridades en derechos civiles y políticos. Debate

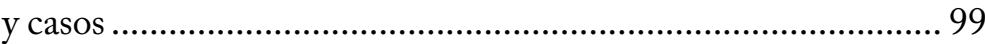

Tema 1: derechos civiles........................................................ 99

Tema 2: derechos políticos .................................................. 102

Tema 3: acceso a la información ........................................ 103

Tema 4: lucha contra la discriminación .............................. 104

Tema 5: prisión preventiva y violación de derechos ............. 105

Tema 6: objeción de conciencia frente

a la prestación del servicio militar obligatorio

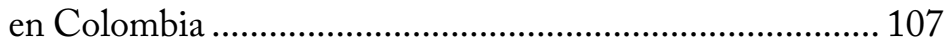

Tema 7: memoria, justicia transicional, atención

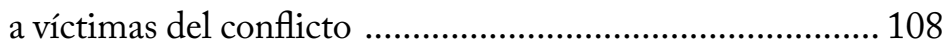

2. Propuestas novedosas en derechos económicos,

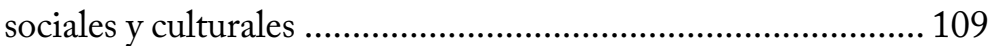

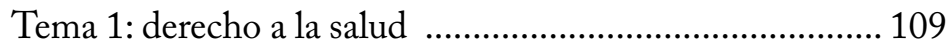

Tema 2: derecho a la alimentación para los niños y las niñas

Tema 3: derecho a la vivienda ............................................ 112

3. La defensa de los derechos colectivos a través de las clínicas...

Tema 1: derecho al ambiente sano ..................................... 112

Tema 2: derechos de los consumidores y usuarios de servicios públicos 
4. Derechos de grupos de especial protección en derechos humanos

Tema 1: derechos de las mujeres ...................................... 119

Tema 2: derechos de las personas con discapacidad ............ 120

Tema 3: derechos de los migrantes, refugiados

y desplazados

Tema 4: derechos de las personas mayores .......................... 123

Tema 5: derechos de la población LGBTI

Tema 6: derechos de pueblos indígenas,

afroamericanos y comunidades tribales

Tema 7: derechos de las víctimas de trata

de personas

Tema 8: derechos de las personas en

establecimientos de reclusión.

5. Aprendizajes del litigio estratégico

\section{Conclusiones.}

Aportes para la agenda pendiente de la educación legal clínica y el litigio estratégico en Iberoamérica

Propuesta pedagógica

\section{Anexo 1}

El diseño de una clínica jurídica.

Anexo 2

Declaración de la Red Latinoamericana de Clínicas Jurídicas.

Anexo 3

Algunas herramientas prácticas para el funcionamiento de las clínicas jurídicas, aportes desde el GAP: reglamento y ficha de viabilidad para los casos

Guía para diligenciar la ficha de viabilidad 159

Referencias 


\section{Agradecimientos}

Al finalizar este trabajo, considero que son muchos los agradecimientos que debo expresar y además reconocer que sin esos apoyos este resultado no se hubiese conseguido. De manera especial deseo agradecer:

En la Universidad del Rosario, al doctor Alejandro Venegas, ex vicerrector; al decano Antonio Aljure Salame; al Grupo de Investigación en Derechos Humanos; al Grupo de Acciones Públicas (GAP) y al Semillero de Derechos Humanos, por su apoyo en el proyecto de año sabático.

Especial mención debo hacer a los aportes de mis compañeros investigadores y supervisores en el GAP (Universidad del Rosario), María Lucía Torres, Lina Muñoz, Paola Iregui y Sebastián Senior. Su contribución fue decisiva, a través de la organización del seminario "El abogado del siglo xxi: transformaciones en la enseñanza y el ejercicio del Derecho", realizado los días 12 y 13 de junio de 2014.

En el cels, a Diego Morales, Pablo Asa, Marcos Kotliky Victoria Vigodsky.

En la Universidad Torcuato di Tella, al Profesor Hernán Güllco.

En la Universidad de Palermo, a los profesores Máximo Nino y Florencia Paulino.

En Cedha (Córdoba), a su director Juan Picolotti.

En la Universidad de Córdoba, a la Clínica Legal de Interés Público, a su coordinadora Mariela Puga y a su grupo de estudiantes.

A los integrantes de la Red Colombiana de Clínicas Jurídicas y muy especialmente a Gabriela Recalde, Paula Andrea Cerón, Erika Castro, Juan Fernando Sánchez y Beatriz Eugenia Luna de Alliaga, por sus contribuciones a esta investigación a través de los Encuentros de la Red realizados en Santa Marta, octubre de 2012; Medellín, los días 22 y 23 de abril de 2013, y Bogotá, los días 10, 11 y 12 de septiembre de 2014.

A Graciela Rodríguez por su apoyo desde México.

A Javier Ansoátegui, María del Carmen Barranco, Miguel Ángel Ramiro y Felipe González, de la Universidad Carlos III, por invitarme a su universidad 
y acogerme en una estancia que permitió acercarme a las Clínicas Jurídicas del Instituto Bartolomé de las Casas.

A los profesores Antonio Madrid y Miriam Anderson, de la Universidad de Barcelona; al profesor José García Añón, de la Universidad de Valencia; a las profesoras María Marques i Banqué y Ángeles Galiano, de la Universidad Pompei i Virgili, en Tarragona (España).

A Jaime León Durán, Mónica Andrea Avella Herrera, María Alejandra Pérez Muñoz, David Leonardo Ballesteros Rivera, Camila Villalobos Araújo y Mónica Bustamante Dumar, estudiantes del Semillero de Investigación en Derechos Humanos, línea de Educación Legal Clínica.

A Lilia Eugenia Ortiz, funcionaria del Ministerio de Justicia de Colombia, por apoyarnos en la tarea de analizar la información y encuestas sobre las clínicas jurídicas en el país. 


\section{Introducción \\ Reflexiones en torno a la pregunta por la educación legal clínica y su enfoque de interés público}

Tan importante como precisar el concepto de interés público será definir cómo hemos de enfocar la defensa de ese interés y qué lugar le corresponderá a la comunidad en el desarrollo

de esa tarea.

Víctor Abramovich

En el año 1999, el entonces decano de la Facultad de Jurisprudencia de la Universidad del Rosario, doctor Marco Gerardo Monroy Cabra, encargó a varios profesores la misión de indagar sobre la educación legal clínica en otros países y solicitó especialmente contactar a la Universidad Diego Portales, en Chile, donde se tenía conocimiento del surgimiento de la Red Sudamericana de Clínicas de Interés Público, liderada por el profesor Felipe González.

El objetivo era claro: se quería iniciar en la Universidad del Rosario una nueva experiencia que empezara a impactar socialmente y a transformar desde adentro la forma como se enseñaba el derecho. Con apoyo institucional se empezó el camino de aprendizajes y relaciones académicas que permitió fundar en Colombia la primera clínica jurídica de interés público: el Grupo de Acciones Públicas (GAP), que ha permanecido durante 15 años liderando el tema, formando a los futuros profesores de otras clínicas y sistematizando, evaluando y reinventando esta experiencia cada vez que hay oportunidad para ello.

A diferencia de otras clínicas iberoamericanas, el camino no empezó en Estados Unidos ni en sus universidades; se inició el recorrido desde el Sur, en Santiago de Chile, en diálogo con las universidades latinoamericanas, inicialmente, y en los últimos años ha habido un acercamiento interesante con clínicas norteamericanas de derechos humanos, con el movimiento pro 
bono, con el Global Alliance For Justice Education (GAJE) y con las clínicas españolas. El libro que se presenta es el resultado de una investigación propuesta como resultado de año sabático, para volver a los orígenes de este debate, propiciar un reencuentro con los actores de la educación legal clínica en Iberoamérica y, ante todo, para resaltar sus voces, sus recomendaciones, los logros, los fracasos y el gran esfuerzo de docentes y estudiantes en muchas universidades de la región.

\section{Un concepto inicial de clínicas jurídicas y litigio estratégico}

El concepto de clínicas jurídicas — que se desarrolla ampliamente en este libro- tiene su origen a comienzos del siglo xx y se atribuye a Jerome Frank, en Estados Unidos, la denominación y la argumentación crítica que desde el realismo jurídico se hizo a la forma como se enseñaba el derecho. En el trabajo denominado “¿Why Not a Legal Clinic?”, la propuesta inicial era copiar del modelo de educación de las facultades de medicina elementos tan valiosos como el trabajo directo con casos reales y los aspectos prácticos de la docencia. Pero realmente fue en los años sesenta cuando se difunde y promueve en mayor medida esta forma de educación y se asocia a criterios de justicia social (Blázquez Martín, 2006). Se señala entonces que la educación legal clínica contribuye a la enseñanza de habilidades jurídicas en un contexto reflexivo de justicia social (García Añón, 2013b, p. 35).

En los años noventa se complementa el método con criterios más específicos que apuntan al desarrollo de competencias y exigencias de la docencia clínica, como la necesidad de enfrentar a los estudiantes a problemas y situaciones reales que viven los abogados, la exigencia de trabajo de los estudiantes para solucionar dichos problemas, la interacción de los estudiantes con otras personas para buscar resolver el problema y la tipología de caos que apuntan a temas sociales y de interés público, priorizando la atención gratuita de personas que lo requieren, todo esto en un entorno de construcción de conocimiento y evaluación permanente, liderado por los docentes clínicos o supervisores (Blázquez Martín, 2006).

El concepto de litigio estratégico — que vamos a desarrollar en profundidad en el segundo capítulo — ha sido medular desde los inicios del movimiento de clínicas de interés público en Latinoamérica. Para entenderlo debemos acercarnos a sus elementos: en primer lugar: ¿cómo lo diferenciamos del litigio tradicional? Hemos agregado dos adjetivos a la noción clásica de litigio 
estratégico para diferenciarla del trabajo habitual que pueden desarrollar los abogados en ciertos casos. Para que exista este litigio se requiere trascender del caso particular o individual hacia la repercusión o impacto colectivo. De igual forma, es necesario mirar el propósito de este litigio, y este debe enfocarse en ampliar o fortalecer los estándares de protección y garantía de derechos humanos; nunca podrá enfocarse en la regresividad. Por esto lo hemos denominado progresista o garantista (Santos, 2001, p. 85).

Luego debemos entender que este litigio tiene repercusiones o impactos que inciden en su denominación. Podemos observar cómo se le denomina litigio estructural o generador de cambios jurídicos, sociopolíticos o pedagógicos.

Se trata de trabajar con casos de impacto amplio o casos emblemáticos o, incluso, apoyarse en los llamados casos testigo (casos individuales que ejemplifican graves vulneraciones a derechos humanos). En esta labor es indispensable, además de la estrategia jurídica y política, el apoyo de los medios de comunicación y la labor pedagógica y de divulgación del caso, sus resultados y su seguimiento.

Finalmente la pregunta apunta al cómo y a quiénes realizan este litigio. En la mirada de los instrumentos del litigio podemos precisar que no se realiza solamente en escenarios judiciales (aunque es el tipo de litigio más conocido); también se puede realizar litigio estratégico ante entidades administrativas o particulares, siempre y cuando se utilice el derecho y especialmente los derechos humanos como objeto de la reclamación o contenido de la labor específica. En relación con el tipo de actores de este litigio, podemos finalmente señalar que el abanico de posibilidades es enorme. Se puede hacer este litigio desde organizaciones sociales, ONG, clínicas jurídicas, bufetes de abogados que trabajan en pro bono o entidades estatales, como las defensorías del pueblo, por ejemplo.

\section{Litigio estratégico e interés público}

El término en torno al cual gira todo el debate del litigio estratégico y la educación legal clínica es el denominado interés público. Pero, ¿qué es lo público y cómo se caracteriza?

Llama la atención que este concepto no es unívoco y se usa desde diferentes enfoques disciplinarios. Pueden identificarse varios sentidos en su utilización cotidiana: en primer lugar se entiende por tal lo común y general; es igualmente sinónimo de interés político, estatal y social, y finalmente hace 
referencia a lo visible y manifiesto (Minteriaga Garaban, 2009). “[...] lo público es fundamentalmente una construcción que se disputa en un reino de referencias simbólicas [...]. En realidad aquello que se vuelve público o que deja de serlo es el resultado de un proceso de discusión, de enfrentamiento, de diferencia y de acuerdo" (p.33).

Desde la nueva mirada propuesta por las organizaciones sociales y por los teóricos del tema, lo público se asocia a la construcción de intereses colectivos en el marco de una democracia incluyente que garantice la equidad y la participación de las organizaciones y de los ciudadanos. En América Latina es cada vez más clara la distinción entre lo público y lo estatal, y desde el trabajo de litigio estratégico este ha sido uno de los pilares fundacionales.

El concepto permite construir un puente entre sociedad y Estado, entre lo privado y lo estatal, un espacio que denomina las arenas públicas, donde se busca movilizar nuevas formas de acción, representación, negociación e interlocución en torno a una agenda social construida sin monopolios y a exigencias concretas en materia económica, jurídica, política y social (Cunill Grau, 1997, p. 58).

Uno de los objetivos centrales del trabajo de ong, fundaciones y universidades es permitir el debate público sobre temas y problemas que durante mucho tiempo permanecieron ocultos, vedados al análisis y a la evidencia de su impacto colectivo.

El camino recorrido en las últimas décadas muestra avances significativos en el surgimiento de organizaciones sociales que inicialmente plantean un carácter antiestatalista y luego asumen su papel en el concepto de lo público, proponiendo los debates y reclamos en torno a los derechos colectivos; de igual forma han logrado colonizar espacios antes limitados solo a los abogados y funcionarios, como los parlamentos (a través del ejercicio del lobby parlamentario), los tribunales (a través del litigio estratégico), y el diseño, seguimiento y evaluación de políticas públicas en todos los campos del interés público.

Un debate interesante se plantea al examinar la relación entre interés público y derechos humanos, en la que consideramos que se trata de dos nociones complementarias y directamente ligadas en la medida que se avanza en la defensa de derechos económicos, sociales, culturales y colectivos. Al respecto señala González: "por lo mismo, la noción de interés público ya no se nos presenta como un elemento que limita los derechos humanos, sino que adquiere una estrecha conexión con estos, en la medida en que su protección 
aparece como uno de los aspectos centrales de la salvaguarda del interés público" (González Morales, 2004, p. 23).

En los estudios sobre educación legal clínica y litigio estratégico, el concepto central que vamos a encontrar es el de derecho de interés público. El concepto surge en Estados Unidos en la década de los sesenta del siglo pasado. No se trata de una nueva rama del derecho, sino de una forma diferente de abordar las herramientas jurídicas para defender intereses de los más desfavorecidos, superar las dificultades que se tienen en el acceso a la justicia para los más pobres y asumir causas en defensa de derechos civiles, derechos colectivos, derechos de género, entre muchas otras posibilidades. Este concepto tiene connotaciones culturales y políticas que le imprimen diversas prioridades y formas de ejercicio según la realidad a la cual se aplica (Rekosh, 2001).

En el año 1997 se realizó un simposio en Durban y allí se establecieron las siguientes prioridades:

a) Acceso a la justicia: es un tema central, en especial para aquellos sectores que carecen de recursos.

b) Educación legal clínica: como una de las contribuciones más importantes para el proceso de formación de nuevos abogados de interés público en la región.

c) Street law programs: buscan desmitificar el ejercicio del derecho y emplear la educación como una herramienta para la formación jurídica y crítica de la población.

d) Litigio de interés público: es la posibilidad de realización de litigio de alto impacto utilizando herramientas creativas en defensa de los derechos humanos y el interés público. Aún tiene debilidades y las más graves son los obstáculos que el mismo sistema jurídico establece.

e) Trabajo pro bono: estrategias de trabajo de interés público desde las firmas de abogados, a través de la donación de su tiempo y asesoría para estas causas.

f) Campañas: se estima prioritario el apoyo de medios de comunicación y el trabajo de lobby legislativo (legislative advocacy).

g) Estrategias de defensa de los derechos de las mujeres.

h) Estrategias para el litigio ante organismos internacionales (Rekosh, 2001, p. 4) 
En síntesis podría señalarse que el derecho de interés público tiene tres prioridades: acceso a la justicia, reformas normativas y de políticas públicas y empoderamiento político para generar cambios o incidir en el fortalecimiento de los derechos humanos.

Son muchas las preguntas que este trabajo busca abordar desde el punto de partida: ¿qué tipo de educación legal clínica tenemos y hacia dónde podemos avanzar? ¿Cómo encuadrar en los procesos de educación legal clínica el enfoque de interés público y derechos humanos? ¿Qué ha pasado en la región iberoamericana y cuáles son las fortalezas, debilidades, retos y oportunidades de estas experiencias?

La experiencia y el aprendizaje en torno al significado y construcción de las clínicas jurídicas en América Latina y en España permite identificar elementos comunes y hacer precisiones conceptuales que facilitan - a quienes comienzan el camino - tener claras las bases y los orígenes, pero también los derroteros. No existe una única forma de desarrollar la educación legal clínica; son numerosos los modelos posibles, la creatividad de los docentes y la innovación pedagógica es enorme en este tema.

Desde el punto de vista metodológico este proyecto se basó en la triangulación de información obtenida, en primer lugar, a través de la revisión de las fuentes teóricas documentales en los temas que se abordan. Además se aplicaron entrevistas semiestructuradas con el objetivo de examinar la percepción de los docentes clínicos en Argentina, Colombia, México, España y Perú; ${ }^{1}$ se complementó esta información con la aplicación y análisis de una encuesta dirigida a estudiantes o ex integrantes de clínicas jurídicas en la región. Dicha encuesta se aplicó entre los meses de marzo y mayo de 2013 a través de una herramienta virtual denominada Survey Monkey. Finalmente

${ }^{1}$ Los docentes entrevistados fueron:

Argentina: Pablo Asa (Clínica cels-Caref en Buenos Aires), Diego Morales (cels en Buenos Aires), Juan Picolotti (Cedha en Buenos Aires) y Mariela Puga (Universidad de Córdoba). Chile: Felipe González (Universidades Diego Portales en Santiago de Chile y Carlos III de Madrid), Elena Olea (Universidad Diego Portales en Santiago de Chile). Colombia: Érica Castro (Universidad de Medellín), Gabriela Recalde (Universidad Icesi), Isabel Goyes (Universidad de Nariño, en Pasto), Lucas Correa (Universidad de Los Andes). España: Miguel García Añón (Universidad de Valencia), Ángeles Galiana (Universidad Rovira e Virgili en Tarragona), María del Carmen Barranco (Universidad Carlos III en Madrid), Antonio Madrid (Universidad de Barcelona). México: Gabriela Rodríguez (Litiga en México D.F.), Hernán Güllco (Universidad Torcuato di Tella). Perú: Miguel Grandez (Universidad San Marcos en Lima). 
se analizaron 72 encuestas aplicadas a los decanos de facultades de derecho de Colombia por el Ministerio de Justicia.

El ámbito geográfico de este trabajo, si bien hace referencia a Iberoamérica, se ha concentrado en el estudio de las clínicas de Argentina, Chile, Perú, Colombia, México y España. En relación con el periodo examinado, nos hemos concentrado en los últimos 20 años, que además es el periodo de nacimiento y evolución de las clínicas actuales.

En la primera parte de esta investigación se examina la relación entre la educación jurídica y la educación legal clínica Iberoamérica. Se considera que el proceso de construcción de las clínicas en la región es un hito en la educación jurídica iberoamericana y existen evidencias que permiten afirmarlo. En este capítulo se realiza una profundización sobre los momentos históricos en que surgen las clínicas de la región y se observa cómo se trata de historias paralelas que se fortalecieron por los intercambios de aprendizajes y experiencias a través de las redes.

Se estudian también las características de la educación legal clínica en Iberoamérica, la realidad y los problemas en la construcción de lineamientos para un modelo pedagógico en la región, la evolución de las clínicas hacia trabajos temáticos y especializados, y se finaliza el capítulo con una sistematización de los logros y las dificultades de la educación legal clínica en los países examinados.

El segundo capítulo explora las posibilidades de ejercicio del litigio estratégico desde las clínicas jurídicas en Iberoamérica. Se desarrolla el concepto de litigio estratégico o estructural y se examina la forma cómo inciden en dicha propuesta las alianzas con oNG y en general lo que se denomina alianzas estratégicas. Luego se pasa a una profundización sobre la agenda de las clínicas y los temas prioritarios de derechos humanos en Iberoamérica. Este examen se realiza a partir de casos reales que han trabajado las clínicas. Se concluye con los temas más fuertes y en los cuales podría decirse que se han realizado aportes significativos y con los temas débiles o inexistentes, que exigirían el surgimiento de nuevas clínicas y proyectos de investigación. 


\section{Educación jurídica en Iberoamérica y educación legal clínica}

\section{A. Los principales interrogantes de la educación jurídica en Iberoamérica}

La educación jurídica tradicional en Iberoamérica ha sido marcada por problemas graves que en siglos pasados no fueron tan evidentes pero que desde comienzos del siglo $\mathrm{xx}$ han generado multitud de trabajos y propuestas, en su mayoría elaboradas por docentes universitarios.

En el último decenio se han realizado esfuerzos académicos, institucionales e informes de organismos intergubernamentales y no gubernamentales, en los que las preocupaciones se centran en aspectos como la incidencia del formalismo jurídico en la formación dogmática de los abogados, los problemas metodológicos en la educación jurídica, la desconexión entre la teoría y la realidad social enfocada como responsabilidad social universitaria, y además se examinan las graves ausencias en temas vitales como la ética profesional, la investigación y la internacionalización, entre otros aspectos que muestran la gran crisis en la forma como se educan los abogados. A continuación se profundizará no solo en los problemas centrales, sino en las alternativas que están en construcción para intentar superarlos o mitigarlos.

\section{El formalismo jurídico. ¿Qué propuestas se construyen para superarlo?}

En los programas de derecho de Iberoamérica, el estudio de la ley en sentido formal, la mitificación de la separación de poderes, la separación entre derecho y política y la equiparación de validez formal con justicia continúan siendo los ejes de las preocupaciones pedagógicas que se repiten de generación en generación (Bonilla, p. 274).

Este modelo se refleja en la educación en muchos aspectos, como el protagonismo exclusivo del profesor, la relación vertical con los alumnos, el papel pasivo de estos, la memorización y el enciclopedismo como única exigencia, y los diseños curriculares extensos y derivados de una mirada exclusivamente 
legislativa (Minagawa, 2012). Se trata de una "educación bancaria”, en términos de Freire (1999).

Se considera que en las aulas de derecho, la formación jurídica es fragmentada y reproduce formas de pensar que dificultan la integración de los contenidos y la vida real, los casos prácticos o problemáticas específicas. De esta forma el nivel de significatividad es también escaso (Minagawa, 2012, p. 61). "Se ha verificado que el sistema de enseñanza tradicional tiene una deficiencia: no integra el plano teórico con el plano práctico de la profesión, imposibilitando el desarrollo de las habilidades necesarias para ese óptimo desempeño profesional posterior anhelado"(Guevara-Paredes, 2005,p. 146).

Esta realidad se relaciona directamente con la visión de la metodología de la educación jurídica que se utiliza, en la que prevalecen la exposición y la exposición dialogada, y son escasos los vínculos entre teoría y práctica. Como lo señala Bonilla, los abogados recién graduados "se enfrentan con serias dificultades para poner en práctica el arsenal de categorías jurídicas aprendidas en la universidad" (p. 263).

Los resultados de estos procesos de formación dejan mucho que desear en las sociedades latinoamericanas y se relacionan directamente con el estereotipo de abogado que identifica la gente como un profesional que solo tiene relación con sus clientes y cuya labor nunca se orienta hacia la sociedad; como un profesional que defiende intereses privados o particulares, pero al que le es ajeno el interés público.

Las propuestas de cambios en la enseñanza-aprendizaje del derecho implican reflexión sobre cómo se asumen al interior de las facultades de derecho los cambios en el sistema educativo. Son tres las más significativas transformaciones que se han comenzado a evidenciar: "a) cambios en el enfoque del proceso de enseñanza-aprendizaje: del énfasis en la enseñanza al aprendizaje; b) cambios en los contenidos objeto de aprendizaje y de evaluación; c) cambios en la evaluación" (García Añón, 2013b, p. 17).

En muchas ocasiones se ha reafirmado la importancia de un "diálogo entre el conocimiento legal y el conocimiento pedagógico” (Seda, 2012, p. 19) y la necesidad de repensar muchas de las prácticas pedagógicas que se realizan en la educación jurídica iberoamericana.

En primer lugar debemos considerar la incorporación de nuevas formas de enseñanza del derecho. Se parte de la pregunta más simple pero retadora para quienes asumen la labor docente e investigativa en los programas de 
derecho y para quienes lideran procesos de reforma curricular, que implican también la inquietud referida: ¿tiene el derecho una característica específica que condicione su forma de enseñanza?

El derecho aporta por sí mismo una herramienta pedagógica de enorme valor: se trata de la indagación a través de la resolución de casos, las posibilidades de un debate teórico riguroso con preguntas originales, el aporte que puede hacerse a través de la elaboración de proyectos de normas o políticas públicas, en fin, las aulas jurídicas deberían ser verdaderos laboratorios de ideas (Seda, 2006, p. 21).

En las facultades de derecho de las universidades iberoamericanas se ha identificado el grave problema de las formas de enseñanza desde fines del siglo XIX y comienzos del siglo pasado, y esta situación se acentúa por la resistencia al cambio en la comunidad académica. En el diagnóstico de Giner de los Ríos en España (1889), en los trabajos de docentes argentinos como Oliver en 1918 y Eduardo en 1939, y, en México, Rafael de Pina (1955), se hacía un llamado a modificar los métodos de la educación jurídica y se proponía incursionar en los estudios de caso y en la educación legal clínica.

El profesor García Añón trae una cita interesante de Giner de los Ríos, quien en el año 1889 realiza un diagnóstico que podría estar ubicado en nuestros días:

\begin{abstract}
Pues la reforma ha de tender a concluir, severamente y cuanto antes, con el carácter actual que hoy tiene entre nosotros esa enseñanza, y cuyas notas cardinales son: $1^{\text {a }}$ Formalismo mecánico, verbal y memorista con la trivialidad y superficialidad consiguientes. $2^{\text {a }}$ Pasividad del alumno, falto de iniciativa, de personalidad, trabajo e ideas propias, y, por tanto, de gusto e interés objetivo por la verdad científica. $3^{\mathrm{a}}$ Aislamiento, sequedad e incomunicación entre profesores y alumnos, y entre cada una de estas mismas clases (Giner de los Ríos, [1889] 2003, 42) (García Añón, 2013b, p. 33).
\end{abstract}

En los años sesenta se promovió un experimento pedagógico financiado por la Fundación Ford y con enormes recursos, que finalmente resultó un fracaso. Se trataba de un trasplante del modelo educativo de los Estados Unidos que buscaba cambiar el método de la cátedra magistral por la implementación del método socrático; el recurso pedagógico que se intentó fortalecer era el 
análisis de casos. Se difundió igualmente la idea del derecho como instrumento de cambio social y un cambio en la concepción del abogado y su papel en la sociedad (Rodríguez Garavito, 2006).

En las razones de este fracaso que se exponen se plantea por el profesor Rodríguez que los proyectos no tuvieron en cuenta la cultura jurídica de los países latinoamericanos en la que se pretendían instalar y además chocaban con intereses del sistema prevalente en América Latina. "En este sentido, fue muy importante el hecho de que la experiencia en América Latina mostró que los abogados estaban mucho menos comprometidos con el cambio social que lo que se había creído en un principio y que el derecho podía ser un poderoso mecanismo conservador del statu quo" (Rodríguez Garavito, 2006, p. 417).

El aprendizaje de este movimiento en América Latina y Colombia se socializó muy poco y simplemente se manejó como un gran fracaso. Sin embargo el experimento sirvió para una transformación de la teoría y el surgimiento y fortalecimiento de la corriente de critical legal studies (cLs). En América Latina surgieron también movimientos críticos denominados:

El derecho y el otro desarrollo, el desarrollo alternativo y el derecho alternativo, con aportes significativos en la revisión crítica.

De igual forma deben reconocerse cambios significativos en los contenidos y en la forma de mirar la educación jurídica. Evolucionamos de la memoria a la investigación, de la ley a la jurisprudencia, del silogismo a la ponderación, del procedimiento (medio) al efecto (resultado), del enciclopedismo a la asociación, del enriquecimiento personal a la responsabilidad social (Fajardo, 2012).

Otra de las propuestas para hacer frente a los problemas proviene de las teorías sobre formación en competencias dentro de los programas de derecho (Carreño, 2014). En los últimos años se ha priorizado la discusión sobre las competencias que se deben formar o fortalecer en los estudiantes de derecho y en dicho debate se destacan los aportes en relación con la formación ciudadana.

En su trabajo, la profesora Goyes plantea que las propuestas curriculares deben considerarse "orientaciones del quehacer educativo". Considera que en América Latina estas ideas buscan un replanteamiento de los énfasis educativos y pretenden superar lo puramente teórico intentando, desde unos 
modelos participativos en las instituciones educativas, un mayor compromiso con la ética del saber que a su vez involucra a los docentes, estudiantes y directivas (2012, p. 138).

Los currículos de las facultades de derecho en la región buscan cumplir con tres características señaladas por Damaska (1968): (i) gramática del derecho (conceptos); (ii) visión panorámica (estudio sistemático normativo y jurisprudencial) y (iii) enseñanza de la lógica interna del derecho (dogmáticaprincipios abstractos). Estas "se combinan en una educación reduccionista, legalista y memorística” (Montoya, s.f.).

La profesora Montoya se pregunta: ¿¿cómo incluir los temas de interés público en el currículo?:

La responsabilidad social de las universidades consiste en preparar a los estudiantes para decidir por sí mismos cómo resolver los conflictos entre lo individual y lo colectivo, entre lo jurídico y lo ético, entre lo legal y lo justo, cuando la vida profesional los ponga frente a esa ineludible necesidad. La relevancia social de los estudios de derecho en América Latina se medirá por la contribución social de la profesión jurídica al mejoramiento de las condiciones de justicia de la región. No debemos olvidar que en América Latina los abogados juegan un papel preponderante a pesar de que su educación no los haya preparado adecuadamente para responder a las necesidades imperiosas de una sociedad tan necesitada de líderes capaces no solo de pensar que un mundo más justo es posible, sino de hacerlo realidad (pp. 40-41).

El concepto de competencias se redefine, tal como lo propone el estudio Tuning para América Latina: "[...] el término competencias se ha re-significado y ahora se entiende como un proceso de formación integral del estudiante para lograr 'la combinación dinámica de conocimiento, comprensión, capacidades y habilidades" (Tuning, 2007).

Para el caso colombiano existe una propuesta de competencias específicas que deberían formarse en los programas de derecho y que fueron propuestas por Acofade (2011): (i) competencia cognitiva jurídica: hace referencia a la comprensión de principios y conceptos básicos, así como a las posibilidades de su aplicación; (ii) competencia comunicativa: tiene que ver con la capacidad de redactar, argumentar e interpretar, así como con la iniciativa para buscar solu- 
ciones a problemas jurídicos que se plantean; (iii) competencia jurídica para prevenir e intervenir en un conflicto utilizando mecanismos adecuados; (iv) competencia investigativa jurídica: relacionada con el proceso de investigación científica para la solución de problemas jurídicos; y (v) competencia ética y responsabilidad jurídica: "capacidad para identificar las conductas contrarias a la lealtad, la diligencia, y la transparencia propias del ejercicio profesional de la abogacía" (Goyes, 2012, p. 141).

Sobre esta propuesta, consideramos que constituye un avance y que en la práctica ya empieza a permear las facultades de derecho, desde el momento inicial de construcción de los programas para las asignaturas y en todo el proceso pedagógico. Los sistemas de evaluación que se están diseñando en el país también incluyen estas competencias específicas, aunque la realidad es que se trata de un aprendizaje institucional y colectivo.

El profesor Lidman considera en relación con el uso de habilidades y valores en la formación de los estudiantes de derecho que en cada país, de acuerdo al sistema jurídico que se tenga, se deben definir estas habilidades y valores, teniendo en cuenta la historia, la cultura propia y la realidad que se vive (2005, p. 83).

En Estados Unidos, por ejemplo, el informe MacCrate identificó diez habilidades principales y cuatro valores fundamentales en el nuevo perfil del abogado:

a) Habilidad para solucionar problemas.

b) Habilidad de análisis y razonamiento legales.

c) Habilidad para el planteamiento de la investigación legal.

d) Habilidad para la investigación efectiva (aplicativa).

e) Habilidad comunicativa.

f) Habilidad de asesoramiento.

g) Habilidad de negociación.

h) Habilidad sobre litigios y procedimientos alternativos para la resolución de conflictos.

i) Habilidad para la organización y gerencia del trabajo legal.

j) Habilidad para el reconocimiento y resolución de dilemas éticos.

A su vez, los valores fundamentales identificados en el estudio mencionado son los siguientes: 
1) Valor relacionado con la disposición o capacidad de una representación competente.

2) Valor orientado a promover la justicia, la imparcialidad y la moralidad

3) Valor orientado a esforzarse para mejorar la profesión de abogado

4) Valor para el desarrollo profesional auto-personal (Lidman, 2005, p. 84).

Observamos, desde una perspectiva crítica, cómo estas propuestas se centran en un enfoque meramente individual del ejercicio de la profesión de abogado. El siglo xxi exige abogados con competencias de trabajo colectivo y con competencias para comprender y desarrollar labores de alto impacto en la comunidad, entre las cuales el litigio estratégico, la labor de street law o pedagogía ciudadana, el conocimiento de los instrumentos mediáticos de difusión local, regional y global de los casos o acciones y el aprendizaje formativo que implica el trabajo en redes colaborativas pueden ser nuevas herramientas que con urgencia se deben aportar en las escuelas de derecho.

Como lo afirma González:

[...] una actividad clínica centrada en casos de interés público, esto es, casos que por su misma definición son de relevancia social y, casi invariablemente, de una complejidad alta desde el punto de vista jurídico (en la medida en que generalmente implicarán poner en tela de juicio la jurisprudencia predominante reuniendo argumentos para abrir paso a una nueva jurisprudencia), resultan especialmente apropiados para entrenar a los estudiantes en una serie de destrezas argumentativas y prácticas (González Morales, 2004, p. 40).

Existen competencias específicas que desarrollan las clínicas, como el razonamiento medio-fin para poner las normas al servicio de la sociedad; la identificación, diagnóstico y solución de problemas sociales; la estructuración de casos colectivos y la generación de soluciones alternativas, entre otras (Correa, 2013, p. 22).

Una competencia central en la labor del abogado de hoy es la capacidad de trabajo en equipo. Melisa Guevara-Paredes reconoce en su trabajo que los estudiantes y profesionales del derecho tienen grandes dificultades para 
relacionarse y trabajar en equipo y que esta sería una de las competencias que deberían fortalecer los programas (2005, p. 145).

Para reformular los métodos una buena propuesta se orientaría hacia la didáctica en grupos donde exista interacción e intercambio en los procesos de construcción de conocimiento. Los grupos son un medio muy eficaz para fortalecer los objetivos comunes, promover el trabajo colaborativo y permitir los aportes de los estudiantes. El reto se encuentra en el cambio de papel del docente, que se debe convertir en un orientador y mediador de espacios de aprendizaje y reflexión (Minagawa, 2012, p. 63).

Son innumerables los rasgos positivos de las nuevas propuestas pedagógicas y en ellas se evidencia la participación activa, la incorporación permanente de nuevos temas y contenidos aportados por los alumnos y profesores, el estímulo a la curiosidad e interés investigativo en los estudiantes, el desarrollo de nuevas habilidades valiosas para el ejercicio del derecho, el apoyo del grupo y la construcción colectiva de conocimiento. Los profesores pueden también efectuar un mejor seguimiento de los procesos de aprendizaje, generar un clima activo, fomentar el trabajo grupal docente, favorecer la articulación teoría-práctica y fortalecer las competencias investigativas (Minagawa, 2012, pp. 69-70).

Existe un movimiento interesante en torno a los temas de innovación académica propuestos desde el derecho (Fortunato, 2012, pp. 42-53). En el trabajo de compilación que realizó García Añón (2013a) se realiza un llamado a la innovación pedagógica en varios frentes: (i) incorporación del tema de definición, implementación y fortalecimiento de competencias genéricas y específicas en los programas de derecho; (ii) el sistema de calidad docente; (iii) la necesidad de avanzar en propuestas sobre guías teórico-prácticas, aprendizaje experiencial, método de casos, simulación, talleres interdisciplinarios, aprendizaje colaborativo y el aprendizaje basado en problemas; (iv) la realización de aproximaciones teóricas y de experiencias en educación legal clínica; (v) las nuevas tecnologías y su impacto en el aprendizaje; (vi) la enseñanza del derecho a través del cine y la literatura; vii) la evaluación del aprendizaje; (viii) la internacionalización de la docencia y el aprendizaje de los estudiantes a través de pasantías y (ix) la divulgación científica de la actividad docente.

En relación con el aprendizaje significativo, se considera que el mayor logro será que los estudiantes sean los protagonistas de su proceso de aprendizaje y cuenten con las herramientas que aporta la teoría y las posibilidades 
de aplicación de ese conocimiento en la búsqueda de solución a problemas de su entorno, con claridad en los valores que se forman y en la responsabilidad social que se asume desde los diversos actores de la academia (Goyes, 2013, p. 82).

Un complemento importante de la formación por competencias es el debate sobre la necesidad de redefinir los sistemas de evaluación. Este es un tema pendiente en las investigaciones latinoamericanas y muy especialmente en aquellas dirigidas a la educación legal clínica. Por evaluación entendemos aquel proceso que "apunta a la innovación y a la mejora y no a la comprobación; recupera la subjetividad y tiene como garantía el diálogo, la posibilidad de crítica y la circulación. Es una evaluación situada”, en la que los criterios deben ser explícitos (Di Matteo, 2012, p. 78).

\section{Desconexión entre la teoría y la realidad social}

El área de trabajo donde las universidades ubican a las clínicas y resaltan sus logros en informes y presentaciones es el área de extensión, concepto que hoy requiere de un debate más amplio, profundo y dotado del componente ético de todo lo que realizan los docentes y estudiantes. Al respecto ArmasAlvarado señala:

La proyección social está ayudando justamente, a que el sentido original de la universidad no perezca. Consideramos que la proyección social de la universidad hacia la comunidad, no es asistencialismo ni caridad.La universidad no juega el rol de "salvador" de la comunidad. Hay más bien un beneficio mutuo. Y es que con la proyección social, la universidad se beneficia de muchas formas.

Por un lado, la universidad no puede existir de espaldas a la realidad. Por el contrario, la universidad debe desarrollar su trabajo en función de la comunidad. Este contacto con la realidad que se posibilita gracias a la proyección social, le da a la universidad mejores herramientas para desarrollar su labor (2005, p. 141).

En esta materia resulta muy importante el trabajo comparado y el examen del concepto de proyección social desde las facultades de derecho, al entender que su finalidad es "materializar la contribución del derecho en el mejoramiento de las condiciones de vida de las personas o grupos de bajos ingresos 
o marginales a los beneficios del sistema legal”. (Ortiz-Sánchez, 2005, p. 29). Esa contribución se basa en tres premisas: (i) el acceso a la justicia y la participación ciudadana como prioridades para las universidades, (ii) la tipología de acciones de los estudiantes de derecho en la sociedad y (iii) el método de enseñanza basado en aprender en la realidad (2005, pp. 24-25).

En relación con la proyección social de las facultades de derecho, ella implica acciones concretas en el entorno y no un simple activismo. Se exige direccionar lo académico hacia la solución de problemas concretos de la comunidad, y cuando se abordan los problemas de acceso a la justicia se pueden encontrar, según el autor, tres manifestaciones de injusticia: injusticia estructural, injusticia social e injusticia particular ${ }^{2}$ (2005, p. 26).

La extensión es una de las funciones misionales de las universidades y son múltiples las discusiones y trabajos que se han realizado sobre su valor e impacto en la sociedad. Existen tres premisas relacionadas con la tarea de extensión universitaria, que para el análisis de la educación legal clínica son importantes:

a) El eje de las actividades de extensión universitaria está en la formación de los estudiantes y docentes que participan.

b) La intervención en el medio social debe estar determinada por la incorporación de dispositivos innovadores de docencia e investigación.

c) La difusión de derechos constituye una labor emancipatoria, siempre que se incorpore una interpretación dinámica de las normas y una perspectiva socio-histórica (Seda, 2012, p. 177).

Los impactos del trabajo de extensión son visibles y se reconocen por los estudiantes como fuente de nuevos conocimientos; aportan además a los contenidos de las asignaturas, modifican la metodología de enseñanza-aprendizaje y aportan destrezas en los estudiantes para interactuar con diversos grupos sociales, lo cual será de enorme utilidad en su futuro profesional.

\footnotetext{
2"Injusticia estructural: principios o derechos no reconocidos en las constituciones, inexistencia de órganos jurisdiccionales rápidos y efectivos. Injusticia social: discriminación sistemática, normas no recogidas en la legislación. Injusticia particular: actos de desconocimiento de derechos subjetivos legalmente reconocidos"(Ortiz-Sánchez, 2005, p. 28).
} 
Se concluye, de acuerdo con lo anterior, que es indispensable una nueva mirada de los currículos para "[...] insertar en ellos la integralidad del saber jurídico y superar la parcialización del conocimiento” (Goyes, 2013, p. 85).

Es igualmente urgente la relación de la universidad con la comunidad y con las organizaciones sociales; el rol de la investigación acción participativa, los consultorios o servicios de asistencia jurídica y las prácticas se tendría que fortalecer para lograrlo.

Al examinar la labor que realizan las clínicas jurídicas —o las estrategias para el litigio de alto impacto-, esta se correlaciona directamente con lo que podríamos denominar la caja de nuevas herramientas para los estudiantes de derecho, con aportes significativos en materia pedagógica, investigativa y social. En la educación legal clínica se fortalecen competencias y se motiva el aprendizaje basado en problemas reales y en la búsqueda de soluciones creativas.

Una pregunta interesante que surge a todos los que trabajan en temas de extensión y responsabilidad social universitaria plantea:

¿Es válido y ético usar los problemas de las personas para satisfacer las necesidades de enseñanza de las facultades de derecho? La respuesta, sin duda, es que si solamente diseñamos el servicio con ese objetivo no será ético. Sin embargo, creemos que ello dependerá de los objetivos y finalidades que se planteen las facultades cuando intervengan en las comunidades. Nosotros consideramos que sí es posible cumplir con ambos objetivos si se constituyen y actúan como interdependientes y estableciendo claramente cuáles son las prioridades y límites en dichos objetivos (Ortiz-Sánchez, 2005, p. 30).

En la educación legal clínica, esta pregunta surge en forma permanente. En el trabajo del profesor Abramovich se plantean las exigencias para el trabajo clínico con total respeto por los derechos de las personas que se representan, la exigencia de una relación horizontal y la contribución al fortalecimiento y empoderamiento de la comunidad a través de la causa que se adelanta:

Reconstruir la práctica de representar a gente sin recursos en causas de interés público requiere restablecer una relación igualitaria entre el abogado y el cliente, asumiendo el desafío de traducir un conflicto 
social en un caso judicial sin traicionar los rasgos característicos de ese conflicto ni la imagen de sus protagonistas [...]. El dilema puede definirse así: cómo mantener desde la posición elegida una relación adecuada con los grupos o sectores que procuramos representar, para que los casos seleccionados surjan de sus verdaderos intereses y conflictos, y sirvan para fortalecer y no para debilitar su organización y el desarrollo de sus luchas sociales.

Se trata de una dura impugnación de la práctica cotidiana de las clínicas legales de interés público, similar por su peso al cuestionamiento que la educación clínica presenta a la pedagogía tradicional de las facultades de derecho (Abramovich, 1999, p. 24).

\section{La brecha entre educación jurídica y derechos humanos}

Un tercer problema, que debe convertirse en el centro de la discusión pedagógica, lo encontramos en la ausencia de una relación directa entre educación jurídica y derechos humanos. Las propuestas metodológicas indican que "la idea de construcción de ciudadanía se apoya en el ejercicio de derechos, lo cual implica incorporar necesariamente una dimensión jurídica para la comprensión profunda de las diferentes posturas y sus consecuencias" (Seda, 2012, p. 25). La relevancia social de los contenidos y casos que se trabajan, el fortalecimiento de un espíritu crítico en los estudiantes, unido a una relación horizontal de construcción de nuevo conocimiento son exigencias que complementan dicha formación.

En América Latina y el Caribe, particularmente, se necesita una educación que contribuya eficazmente a la convivencia democrática, a la tolerancia y a promover un espíritu de solidaridad y de cooperación; que construya la identidad continental; que genere oportunidades para quienes hoy no las tienen y que contribuya, con la creación del conocimiento, a la trasformación social y productiva de nuestras sociedades" (Instituto de Educación Superior de la Unesco, 2008).

En la declaración mundial sobre educación superior se precisan temas de enorme importancia para la redefinición de la educación jurídica: 
Las instituciones de educación superior, a través de sus funciones principales (investigación, docencia y proyección social), dentro del marco de la autonomía institucional y la libertad académica deben propender hacia la interdisciplinariedad y promover el pensamiento crítico, así como una participación ciudadana activa que contribuya al desarrollo sostenible, la paz, el bienestar y el respeto de los derechos humanos, incluyendo la equidad de género (Unesco, 2009).

Entre los valores que se identifican como prioritarios en el nivel personal e institucional están aquellos que son condiciones básicas para ejercer la ciudadanía, como la autonomía progresiva, la confianza, la libertad, la capacidad de tomar decisiones e incidir en ellas y la responsabilidad, entre otros (Varela, 2012, p. 34). Hoy es imposible eludir la discusión pedagógica sobre valores, relaciones sociales y prácticas (Peces-Barba, 2007).

En los aprendizajes sobre derechos humanos, lo más importante es que los saberes y la práctica de los mismos se incorporen dentro de las aulas e instituciones educativas y en la comunidad en la cual se vive, con aplicación y ejercicio cotidiano de la tolerancia y el diálogo "con miras al desarrollo de un criterio propio, autónomo e informado"(Varela, 2012, p. 35).

Las evidencias que generalmente se presentan en relación con el debilitamiento de la cultura política en América Latina son comunes y llama la atención cómo hay prioridades a trabajar desde las facultades de derecho. Entre los aspectos más estudiados e identificados están la diminución en el interés por los asuntos públicos, la desconfianza y escepticismo de las políticas públicas y el rol del Estado, el debilitamiento de los vínculos políticos y sociales, el clientelismo, la corrupción y el deterioro del vínculo representativo.

Se trata de una ciudadanía de baja intensidad, en términos de O’Donnell (2003),y, frente a este grave diagnóstico, la educación tiene retos y prioridades importantes, entre los cuales es necesario incluir cambios curriculares en los que se "promueva el conocimiento de la realidad social y la construcción de criterios de actuación frente a ella" (Fortunato, 2012, p. 42).

Si tomamos como punto de partida la exigencia de pertinencia en las instituciones de educación superior y el trabajo que deben realizar para la solución de problemas (Brunner, 2000), son muchos y diversos los retos que afrontan. El profesor Orozco señala la importancia de una toma de posición desde las instituciones: "en esta dimensión es posible plantearse interrogantes 
de naturaleza ética y política y, desde aquellos, asumir como universidades un proyecto ético político y no solo técnico instrumental"(Orozco Silva, 2010).

En el mismo artículo se plantean tareas concretas para dar respuesta a esta exigencia, y se insiste en la importancia de asumir la responsabilidad social frente al fomento de la democracia y la necesidad de promover la participación de la sociedad civil como núcleo central en el fortalecimiento de la democracia. De igual forma existe la urgencia de revisar los esquemas de formación profesional y ética de los estudiantes en coincidencia con los trabajos señalados anteriormente y, además, la prioridad de desarrollar investigación que tenga en cuenta los problemas prioritarios de cada país y región, pues ellos son el punto de partida del impacto social y real de las instituciones educativas. Finalmente se estima muy importante examinar los avances que hacen las instituciones en materia de inclusión educativa. La combinación de todas estas exigencias evitará que se siga reproduciendo el modelo de "instituciones (educativas) exitosas en sociedades fracasadas” (Orozco Silva, 2010).

\section{A manera de conclusión}

En este aparte se describieron algunos de los problemas más graves de la educación jurídica en Iberoamérica, como la incidencia del formalismo jurídico en la formación dogmática de los abogados, los problemas metodológicos, la desconexión entre la teoría y la realidad social, entre otros. De igual forma, se reconocen las propuestas que se construyen para intentar superar o mitigar estos problemas con cambios en el enfoque propuesto sobre los procesos de enseñanza-aprendizaje, cambios en relación con los contenidos y cambios en las evaluaciones.

Se observan igualmente propuestas creativas para incursionar en el campo de la innovación pedagógica desde el derecho, dar un nuevo significado al concepto de competencias y orientarlo hacia una verdadera formación integral y humanística. La reflexión también debe darse en torno al concepto de extensión universitaria y aprendizaje-servicio, así como sobre la inclusión de los derechos humanos en los planes de formación de los estudiantes.

\section{B. El papel de las clínicas jurídicas en la transformación de la educación legal en Iberoamérica}

En esta sección se realizará un análisis basado en la presentación y documentación de algunos debates en torno a la educación legal clínica en la región. 
Se busca dar elementos que permitan entender las dificultades que ha tenido en Iberoamérica la incorporación de las clínicas como espacio de formación legal, en contraste con el formalismo jurídico que ha imperado. En primer lugar se examinarán los puntos de encuentro y diferencias entre las clínicas jurídicas y otros procesos de formación, como los consultorios jurídicos y los servicios legales universitarios. El tema siguiente será el de los modelos pedagógicos y la ubicación curricular de las clínicas, planteando la reflexión sobre los diversos modelos existentes y las opciones que en el marco de la autonomía universitaria pueden escoger las facultades de derecho de Iberoamérica.

A continuación se examinará un fenómeno muy interesante que se ha presentado en los últimos años en Iberoamérica: el de la evolución de clínicas jurídicas generales hacia clínicas jurídicas especializadas. Ilustraremos este fenómeno con algunos cuadros derivados de la investigación y con el análisis complementado por las voces de los docentes que entrevistamos en las diferentes clínicas de la región. El último tema que se examinará es el de los logros y dificultades de la educación legal clínica en Iberoamérica. Allí intentaremos sistematizar los puntos comunes y las diferencias manifestadas por los docentes y estudiantes de las clínicas en las entrevistas y encuestas, asî como en los encuentros realizados en las redes y las publicaciones que en el tema se han realizado en los últimos años. Se concluye con la demostración de los temas a mejorar y las fortalezas de la región, a partir de un proceso que implicó la visita directa y el escuchar a quienes son el corazón de la educación legal clínica en Iberoamérica.

Es indudable que las clínicas jurídicas han contribuido a un cambio en la forma de entender y enseñar el derecho, su principal aporte ha sido enfrentar a los estudiantes con su realidad y su entorno para incidir en cambios jurídicos y proyectar socialmente la profesión. Los estudiantes que participan en las clínicas desarrollan un espíritu crítico, ven la necesidad de incidir en la sociedad y contribuir a solucionar problemas (Torres, 2012).

\section{Clínicas jurídicas y Consultorios jurídicos. Una discusión conceptual o de fondo}

En la experiencia iberoamericana se identifica el que podríamos denominar en forma genérica servicio jurídico de acceso a la justicia, en ocasiones prestado directamente por abogados de oficio, voluntarios o pro bono en forma inde- 
pendiente, o a través de ONG, y asumido en forma complementaria, desde los años setenta, por las facultades de derecho de algunos países.

La figura adopta diversas denominaciones: servicio de asistencia jurídica gratuita (Venezuela, España, Chile, México), consultorio jurídico (Colombia, Perú), consultorio de asistencia legal (Panamá), servicio jurídico comunitario o clínicas de asistencia jurídica voluntaria, o clínicas de asistencia legal (Venezuela, Puerto Rico) (Boueiri, 2006).

La institución fue pionera en temas de servicio social de los programas de derecho, y su impacto en materia de atención a usuarios, convenios y trabajo comunitario es visible en muchos de los países latinoamericanos.

En relación con este tipo de servicios jurídicos, en el trabajo del profesor Carrillo (2011) se opta por la denominación genérica de clinicas, diferenciando entre las que llama clínicas de servicios jurídicos gratuitos (consultorios jurídicos) y las clínicas de interés público y derechos humanos.

En el modelo de los consultorios jurídicos o clínicas de servicios legales gratuitos e individuales la función según el profesor Carrillo:

Es atender las necesidades legales básicas de personas de escasos recursos económicos - los usuarios de la clínica- mediante los servicios o asesorías de estudiantes de derecho bajo la supervisión de abogados practicantes experimentados. Elénfasis de tales clínicas está, por un lado, en brindar un servicio social importante a la comunidad y, por otro, en ofrecer a los alumnos que participan en ella una experiencia práctica de abogacía durante su formación universitaria (Carrillo, 2011, p. 36).

En relación con el segundo modelo — clínicas de derechos humanossu objetivo es:

Llevar a cabo cualquier actividad en el marco del derecho internacional de los derechos humanos (DIDH) [...]. El hilo conductor que atraviesa dichas actividades es, siempre, la finalidad de ampliar el ámbito protector del derecho, así como impulsar la efectiva implementación y cumplimiento estatal, en el orden interno, de una normativa garantista acorde con el DIDH (2011, p. 37). 
El siguiente cuadro comparativo sintetiza las diferencias propuestas por el autor:

Tabla 1. Principales diferencias entre clínicas jurídicas tradicionales y clínicas de interés público

\begin{tabular}{|l|l|l|}
\hline Enfoque & Clínicas de asistencia legal gratuita & $\begin{array}{l}\text { Clínicas de interés público y derechos } \\
\text { humanos }\end{array}$ \\
\hline Número y tipo de \\
clientes & $\begin{array}{l}\text { Personas de escasos recursos con nece- } \\
\text { sidades de asistencia legal. }\end{array}$ & $\begin{array}{l}\text { Personas o grupos a quienes se les han } \\
\text { vulnerado sistemáticamente sus dere- } \\
\text { chos. No se mira el tema cuantitativo } \\
\text { derechos y la incidencia en políticas } \\
\text { públicas. }\end{array}$ \\
\hline Benefino el cualitativo.
\end{tabular}

Fuente: elaboración basada en Carrillo (2011,pp. 39-45).

En el caso colombiano, los consultorios jurídicos surgen en 1971 con el Decreto 196, en cuyo artículo 30 se establece la obligatoriedad de dicho servicio para los estudiantes de derecho y se señalan las competencias de los mismos. La reglamentación de los consultorios se da con el Decreto 765 de 1977, y ambas normas se complementan con el artículo $1^{\circ}$ de la Ley 583 de 2000. El siguiente cuadro muestra las exigencias mínimas para este servicio: 
Tabla 2. Consultorios jurídicos y clínicas jurídicas en Colombia

\begin{tabular}{|c|c|c|}
\hline & Regulación de los consultorios jurídicos & Las clínicas jurídicas \\
\hline $\begin{array}{l}\text { Aprobación } \\
\text { para iniciar } \\
\text { funcionamiento }\end{array}$ & $\begin{array}{l}\text { La normatividad exige que el consultorio } \\
\text { sea "aprobado por el Tribunal Superior del } \\
\text { Distrito Judicial donde funcione la respectiva } \\
\text { facultad"(Ley } 583 \text { de 2000). }\end{array}$ & $\begin{array}{l}\text { Han existido diversas opciones: } \\
\text { a) Aprobación como asignatura electiva por } \\
\text { la facultad. } \\
\text { b) Trabajo voluntario. } \\
\text { c) Línea de investigación para grado } \\
\text { aprobada por la facultad. } \\
\text { d) Inclusión como parte del consultorio } \\
\text { jurídico (área o estructura similar). }\end{array}$ \\
\hline $\begin{array}{l}\text { Tipología de } \\
\text { servicio de los } \\
\text { estudiantes }\end{array}$ & $\begin{array}{l}\text { Carácter obligatorio: "la prestación del servicio } \\
\text { del consultorio jurídico en ningún caso será } \\
\text { susceptible de omisión ni homologación" (Ley } \\
583 \text { de 2000). } \\
\text { Litigio en causa ajena como abogados de } \\
\text { pobres: "los estudiantes son abogados de } \\
\text { pobres y como tales deberán verificar la } \\
\text { capacidad económica de los usuarios"(Ley } 583 \\
\text { de 2000). }\end{array}$ & $\begin{array}{l}\text { Este ha sido uno de los obstáculos para la } \\
\text { creación de clínicas en Colombia. } \\
\text { En las existentes y adscritas al consultorio, se } \\
\text { llevan casos de la clínica y del consultorio para } \\
\text { no incumplir con este requisito. } \\
\text { Los casos de interés público no pasan por este } \\
\text { filtro económico, sino por un examen sobre su } \\
\text { viabilidad como litigio de alto impacto o de } \\
\text { interés social. } \\
\text { En las clínicas los estudiantes actúan } \\
\text { como abogados de interés público y } \\
\text { derechos humanos y cumplen con labores } \\
\text { de responsabilidad social universitaria, } \\
\text { aprendizaje-servicio y extensión. }\end{array}$ \\
\hline $\begin{array}{l}\text { Dirección del } \\
\text { servicio }\end{array}$ & $\begin{array}{l}\text { E1 director del consultorio debe ser un } \\
\text { "abogado titulado dedicado exclusivamente } \\
\text { al consultorio, con experiencia en docencia } \\
\text { universitaria o práctica profesional no inferior } \\
\text { a cinco (5) años". Debe "ejercer el profesorado } \\
\text { en la facultad o ser abogado de pobres del } \\
\text { Servicio Jurídico Popular" (Decreto } 765 \text { de } \\
\text { 1977). }\end{array}$ & $\begin{array}{l}\text { La dirección de la clínica la ejerce un abogado } \\
\text { titulado, docente universitario con dedicación } \\
\text { exclusiva o parcial en algunas universidades. }\end{array}$ \\
\hline $\begin{array}{l}\text { Dirección } \\
\text { administrativa }\end{array}$ & $\begin{array}{l}\text { Si se tienen más de } 100 \text { alumnos, deben contar } \\
\text { con esta dirección. }\end{array}$ & $\begin{array}{l}\text { No la tienen, salvo que compartan la que existe } \\
\text { en el consultorio jurídico. }\end{array}$ \\
\hline $\begin{array}{l}\text { Asesores en } \\
\text { derecho público, } \\
\text { penal, privado y } \\
\text { laboral }\end{array}$ & $\begin{array}{l}\text { Estas son las áreas que tradicionalmente tienen } \\
\text { los consultorios jurídicos colombianos, aunque } \\
\text { en algunos casos se han abierto nuevas áreas. } \\
\text { En relación con los asesores se sigue la } \\
\text { directriz que señala el Decreto } 765 \text { de } 1977 \text {, } \\
\text { que exigía que fuesen "abogados titulados con } \\
\text { experiencia profesional no inferior a tres (3) } \\
\text { años". En dicha norma se exige tener un asesor } \\
\text { de tiempo completo por cada } 50 \text { estudiantes } \\
\text { o de tiempo parcial según los estudiantes que } \\
\text { coordine (nota: el Decreto } 765 \text { de } 1977 \text { ha sido } \\
\text { derogado por la Ley } 583 \text { de } 2000 \text { ). }\end{array}$ & $\begin{array}{l}\text { Se denominan supervisores y cumplen la } \\
\text { labor de asesoría directa a los estudiantes } \\
\text { en los casos que asume la clínica. Según la } \\
\text { experiencia de las clínicas se observa que } \\
\text { son abogados titulados con experiencia en el } \\
\text { área de la clínica. Se recomienda al menos un } \\
\text { supervisor de tiempo completo por cada diez } \\
\text { estudiantes. }\end{array}$ \\
\hline Monitores & $\begin{array}{l}\text { Son egresados, o alumnos de último año de la } \\
\text { carrera. Se exige uno por cada } 20 \text { alumnos. }\end{array}$ & $\begin{array}{l}\text { En los casos en que la clínica está adscrita al } \\
\text { consultorio jurídico se cuenta con un monitor. }\end{array}$ \\
\hline $\begin{array}{l}\text { Condiciones } \\
\text { locativas y } \\
\text { logísticas } \\
\text { adecuadas }\end{array}$ & $\begin{array}{l}\text { La institución debe "disponer de locales en } \\
\text { condiciones adecuadas para el trabajo de los } \\
\text { profesores, monitores y alumnos, y muebles, } \\
\text { biblioteca y equipos suficientes para el } \\
\text { funcionamiento del consultorio". }\end{array}$ & $\begin{array}{l}\text { La clínica exige de unas condiciones locativas } \\
\text { adecuadas, sala de reunión para todo el grupo, } \\
\text { equipos y recursos para la labor que adelanta. }\end{array}$ \\
\hline
\end{tabular}




\begin{tabular}{|c|c|c|}
\hline & Regulación de los consultorios jurídicos & Las clínicas jurídicas \\
\hline $\begin{array}{l}\text { Dedicación de los } \\
\text { alumnos }\end{array}$ & $\begin{array}{l}\text { Por lo menos dos semestres en los dos últimos } \\
\text { años de la carrera. }\end{array}$ & $\begin{array}{l}\text { Por lo menos dos semestres en los dos últimos } \\
\text { años de la carrera. }\end{array}$ \\
\hline Competencias & $\begin{array}{l}\text { a) En los procesos penales de que conocen } \\
\text { los jueces municipales y los fiscales } \\
\text { delegados ante estos, así como las } \\
\text { autoridades de policía, en condición de } \\
\text { apoderados de los implicados. } \\
\text { b) En los procesos penales de competencia } \\
\text { de la jurisdicción ordinaria, como } \\
\text { representantes de la parte civil. } \\
\text { c) De oficio, en los procesos penales como } \\
\text { voceros o defensores en audiencia. } \\
\text { d) En los procesos laborales en que la cuantía } \\
\text { de la pretensión no exceda de } 20 \text { salarios } \\
\text { mínimos legales mensuales vigentes } \\
\text { y en las diligencias administrativas de } \\
\text { conciliación en materia laboral. } \\
\text { e) En los procesos civiles de que conocen los } \\
\text { jueces municipales en única instancia. } \\
\text { f) En los procesos de alimentos que se } \\
\text { adelanten ante los jueces de familia. } \\
\text { g) De oficio, en los procesos disciplinarios } \\
\text { de competencia de las personerías } \\
\text { municipales y la Procuraduría General de } \\
\text { la Nación. } \\
\text { De oficio, en los procesos de } \\
\text { responsabilidad fiscal de competencia de } \\
\text { las contralorías municipales, distritales, } \\
\text { departamentales y General de la } \\
\text { República. } \\
\text { De oficio, en los procesos administrativos } \\
\text { de carácter sancionatorio que adelanten } \\
\text { las autoridades administrativas, los } \\
\text { organismos de control y las entidades } \\
\text { constitucionales autónomas" (Ley } 583 \\
\text { de 2000). } \\
\text { La Corte Constitucional en Sentencia } \\
\text { C-143-01 del } 7 \text { de febrero de } 2001 \text {, } \\
\text { Magistrado Ponente doctor José } \\
\text { Gregorio Hernández Galindo, declaró } \\
\text { condicionalmente exequible este artículo y } \\
\text { señaló que en todos los casos la exigencia } \\
\text { debe ser que: "siempre que los estudiantes } \\
\text { que actúen en su desarrollo ejerzan el } \\
\text { derecho bajo la supervisión,la guía y el } \\
\text { control de las instituciones educativas a las } \\
\text { cuales pertenecen". }\end{array}$ & 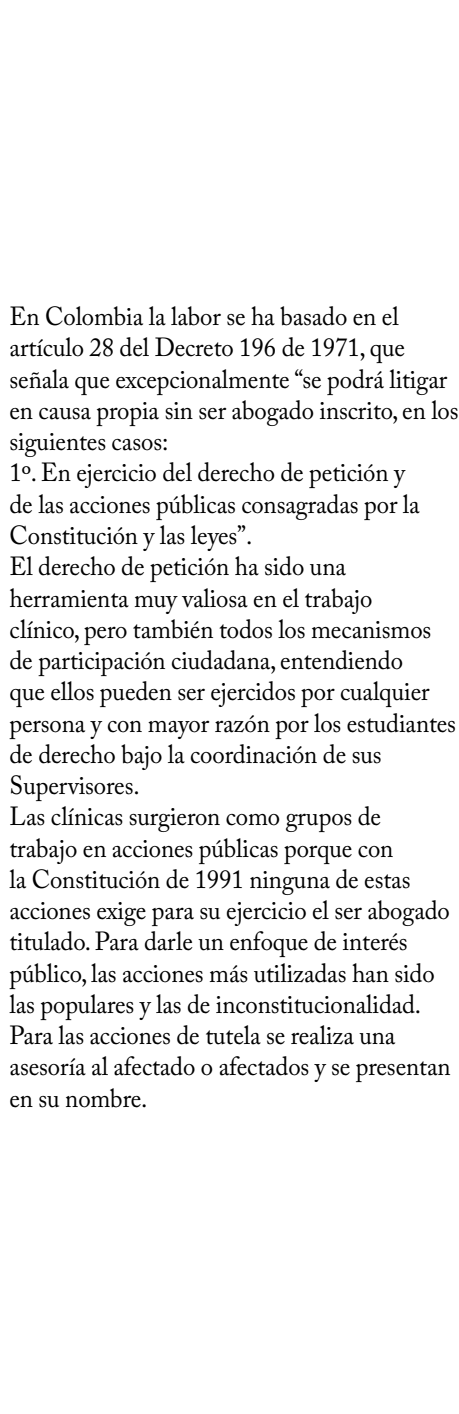 \\
\hline $\begin{array}{l}\text { Exigencia para } \\
\text { las actuaciones de } \\
\text { los estudiantes }\end{array}$ & $\begin{array}{l}\text { Autorización del consultorio jurídico para } \\
\text { realizar las respectivas actuaciones judiciales y } \\
\text { administrativas. }\end{array}$ & $\begin{array}{l}\text { Como regla general, en todas las actuaciones } \\
\text { judiciales se incluye la autorización del } \\
\text { consultorio jurídico y la mención de } \\
\text { pertenecer a la clínica jurídica. }\end{array}$ \\
\hline
\end{tabular}

Fuente: elaboración propia. 
En relación con esta regulación la Corte Constitucional colombiana se ha pronunciado en tres sentencias — su-044 de 1995, C-625 de 1996 y C-143 de 2001 - frente a los siguientes cuestionamientos:

- Garantía del debido proceso y el tema de la idoneidad de quienes actúan como defensores: $\mathrm{Al}$ respecto se señala:

Observa la Corte que la disposición últimamente transcrita, en cuanto establece que el defensor de oficio debe ser un abogado titulado, o un egresado de Facultad de Derecho oficialmente reconocida por el Estado, debidamente habilitado conforme a la ley o un estudiante miembro de consultorio jurídico, obedece a los lineamientos que la norma constitucional consagra sobre la asistencia del sindicado por un abogado dentro del proceso penal y, desde luego, en el policivo penal, el cual por su naturaleza jurídica similar, se rige por los mismos principios o garantías del debido proceso; pero se aclara, que aunque la norma permite confiar la defensa a quienes no son abogados titulados, ello no contraría el precepto del artículo 29 en referencia, pues debe entenderse que el legislador, facultado por la Constitución (art. 26) para determinar en qué casos se exigen títulos de idoneidad, ha habilitado especialmente al egresado de Facultad de Derecho que ha obtenido licencia temporal y al estudiante de derecho miembro de consultorio jurídico para actuar como defensores (Corte Constitucional, Sentencia su-044 de 1995, mp Antonio Barrera Carbonell).

- Discrecionalidad del legislador para establecer las excepciones:

De conformidad con lo previsto en el artículo 26 de la Constitución, es la ley la que puede exigir títulos de idoneidad para el ejercicio de las profesiones $y$, por lo tanto, mientras no contravenga preceptos constitucionales ni desconozca los elementos mínimos de los derechos fundamentales (como ocurre, según lo ha destacado la jurisprudencia, cuando se permite que cualquier persona sin aptitud ni preparación en el campo jurídico, asuma la defensa de un procesado), el legislador está autorizado para establecer los requisitos exigibles para el desempeño de las distintas actividades profesionales así como para 
estatuir grados o escalas de condiciones académicas según la naturaleza, contenido e importancia de los servicios que se presten en el ámbito de cada una de ellas.

Del mismo modo, será el propio legislador el que defina cuándo determinados rangos de la gestión profesional no hacen exigible un título, dando lugar a la validez de las actuaciones correspondientes si se cumplen otros requisitos que la misma legislación consagre (Corte Constitucional, Sala Plena, Sentencia C-626 del 21 de noviembre de 1996, mp José Gregorio Hernández Galindo).

- Garantía de los derechos y exigencia de supervisión y control por parte de las facultades:

La Sala concluye señalando que los numerales acusados del artículo $1^{\circ}$ de la Ley 583 de 2000, se ajustan a las disposiciones constitucionales y desarrollan principios constitucionales que garantizan derechos como el debido proceso, la solidaridad, el acceso a la administración de justicia, lo cual llevará a declarar la exequibilidad de las disposiciones demandadas [...]. Ordena: Declarar exequibles los apartes demandados de los numerales 2, 4, 5, 7,8 y 9 del artículo $1^{\circ}$ de la Ley 583 de 2000 , siempre que los estudiantes que actúen en su desarrollo ejerzan el derecho bajo la supervisión, la guía y el control de las instituciones educativas a las cuales pertenecen.

En la actualidad el debate de las universidades colombianas se centra en la necesidad de reglamentar o modificar la ley de consultorios jurídicos (Ley 583 de 2000). ${ }^{3}$

Si se opta por la reglamentación de la ley se estima importante tener en cuenta los siguientes aspectos:

- Reglamentar las circunstancias de pobreza, entendiendo que esta no solo hace referencia a falta de capacidad económica sino a situaciones

${ }^{3} \mathrm{Al}$ interior de la Red Colombiana de Clínicas Jurídicas y del Grupo de Acciones Públicos se han llevado a cabo discusiones importantes muchas de las cuales sintetizamos. 
de debilidad para la defensa del interés público o vulnerabilidad para el ejercicio de derechos o el acceso a la justicia.

- Señalar que las áreas establecidas normativamente son ejemplificativas y que en los consultorios jurídicos se puede abrir un área de interés público, desde la cual se puede coordinar el trabajo de las clínicas jurídicas.

- Se precisa incluir algún mecanismo idóneo que permita fortalecer los componentes de investigación y pedagogía formativa en los consultorios jurídicos y en las clínicas jurídicas.

- Debe buscarse la inclusión y la calidad en la atención a comunidades, grupos y colectivos como parte de la labor de las clínicas y consultorios jurídicos.

- Deben examinarse nuevas formas de intervención y legitimación por activa en los casos de consultorios y clínicas.

Si se opta por la modificación de la ley, figura con la cual estamos en mayor acuerdo, se recomendaría:

- Incluir las definiciones claras de consultorio jurídico y clínica jurídica como opciones para que se desarrollen en las universidades durante la etapa obligatoria de práctica jurídica en el marco del concepto de aprendizaje-servicio.

- Eliminar la categoría de abogado de pobres. Se estima que es un término peyorativo y discriminatorio. Podría incursionarse en el término de defensores de derechos humanos o defensores de interés público.

- Se podría trabajar con una categoría más abierta en materia de competencias, hablando no solo de personas individualmente consideradas, sino de comunidades y casos de interés público o colectivo. Debe irse más allá de la consideración socioeconómica de quienes solicitan los servicios de la clínica y eliminar la restricción en salarios mínimos para efectos de competencia, centrando la discusión en el tema de la vulnerabilidad en el acceso a los derechos individuales, de grupo o colectivos.

- Debe reconocerse, en el marco de la autonomía universitaria, la posibilidad de que las instituciones definan los objetivos misionales de este servicio que pueden orientarse a la enseñanza y pedagogía del 
derecho o a la garantía de acceso a la justicia a individuos y grupos vulnerables.

- El eje central de los consultorios jurídicos y clínicas debería ser la garantía del acceso a la justicia con un enfoque de derechos humanos y justicia social.

- Debe quedar claro que la forma de manejar los dos años de consultorio queda a discrecionalidad de las universidades en virtud de la autonomía universitaria, pero esos dos años deben ser necesariamente dedicados a labores de función social, y a generar procesos de formación profesional en prácticas y pasantías que se relacionen con el objetivo de aprendizaje-servicio.

\section{Los momentos históricos en que surgen y se desarrollan las clínicas jurídicas iberoamericanas. Historias paralelas}

Las formas de relacionamiento entre universidades y ONG en Iberoamérica posibilitan diversos modelos que inciden a su vez en la sostenibilidad de las experiencias clínicas:

a) Primacía de trabajos de universidades en alianza con ONG. Los estudiantes realizan las prácticas y tienen la asesoría docente en las ONG. Según Diego Morales, “se trata del 'modelo argentino'. Tiene gran apertura, es valioso para las organizaciones. Se garantiza el relevo generacional porque los mejores estudiantes luego ingresan a trabajar a la ONG" (Morales, 2012). La sostenibilidad de estas clínicas se garantiza por los convenios y por el permanente apoyo de las organizaciones con sus casos y requerimientos.

b) Modelo universitario de clinica, donde el liderazgo del trabajo lo asumen los programas de derecho en el nivel de pregrado o maestría y desde allí se manejan las relaciones con diversos actores sociales e institucionales para realizar su labor de impacto social. La sostenibilidad de estas clínicas se garantiza por la voluntad institucional de permanencia y trabajo con los estudiantes. Exigen la formación y permanencia de docentes calificados que asuman las labores de educación legal clínica.

c) En los últimos años han surgido también proyectos financiados para integrar alianzas interuniversitarias y crear o fortalecer clínicas jurí- 
dicas. Estos ejercicios se han realizado en Perú, en Argentina y en Colombia. La ventaja de estas propuestas radica en la posibilidad de optimizar recursos para la formación de docentes clínicos y en el intercambio que favorecen con experiencias más avanzadas y novedosas.

La siguiente figura nos muestra los periodos y etapas en el surgimiento de las clínicas en Iberoamérica.

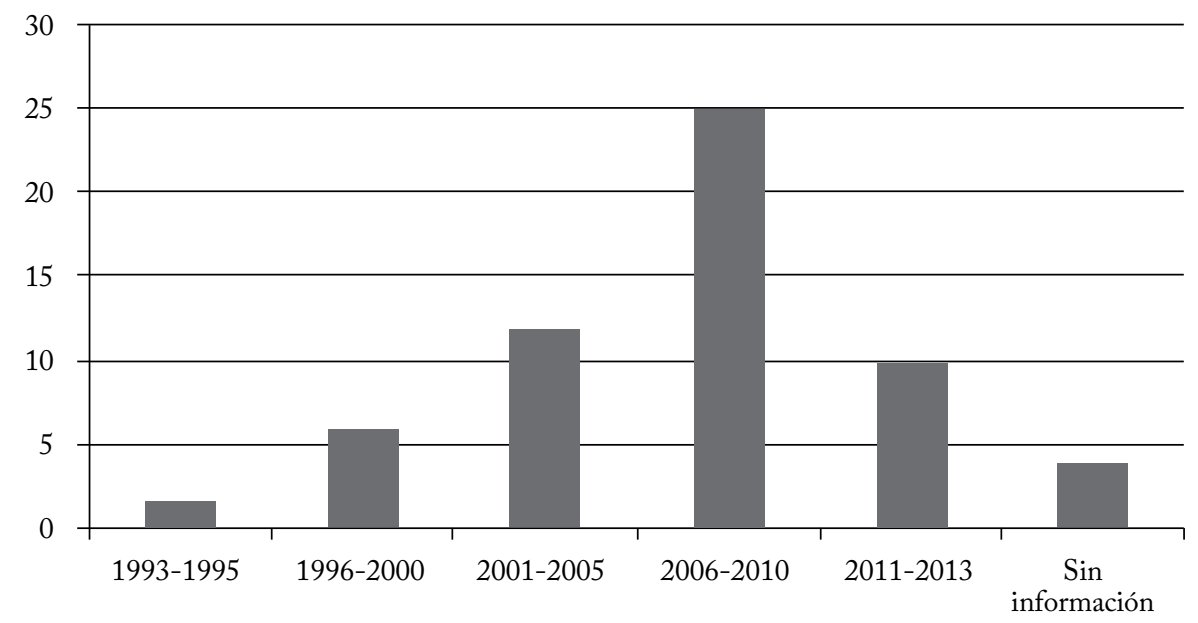

Figura 1. Surgimiento de clínicas jurídicas en Iberoamérica

Fuente: elaboración propia.

La primera generación de clínicas: los primeros intentos de formación en educación legal clínica en Latinoamérica, 1960-1980

En los trabajos de Gardner (1980), Rodríguez (2001), González (2004) y Bloch (2013) se hace la referencia expresa a la incidencia que tuvo el movimiento por el derecho y el desarrollo en los años sesenta. Estos intentos buscaron trasladar la metodología de la educación legal clínica a algunas universidades de Argentina, Colombia, Chile y Brasil, a través de recursos provenientes de la Fundación Ford y AId (Bloch, 2013, pp. 137-138). Universidades muy prestigiosas de Estados Unidos patrocinaron cursos de enseñanza clínica que tuvieron eco en algunas universidades que introdujeron el método de casos, entre las cuales se señala la Universidad de Los Andes, en Colombia. 
Se señalan también algunas experiencias de servicios sociales y jurídicos que surgen en este periodo en países como Venezuela (años sesenta). En dicho país se utiliza este término en la Universidad Central de Venezuela y luego en la Universidad Católica Andrés Bello, porque se establecieron centros jurídicos para la recepción, estudio y resolución de situaciones jurídicas reales, y, en 1985, se fundó en este país la Asociación Nacional de Clínicas y Asistencia Jurídica Voluntaria (Asocliva).

De igual forma, en el caso de Chile, la incidencia de este movimiento se dio en el mismo periodo (González Morales, 2004). Inicialmente se trabajó con apoyo de colegios de abogados con un bajo impacto, carencia de recursos y pocos docentes con conocimientos en el tema. Estos primeros intentos se acabaron con el golpe militar de Estado, pues se impuso la regresión a la cátedra magistral y a la escuela formalista del derecho (Castro-Buitrago, 2013, p. 145).

En el caso de Puerto Rico se señala que una de las pioneras en el continente fue la Universidad de Puerto Rico, a través de la clínica de asistencia legal de dicha institución, cuya existencia supera ya los 50 años y corresponde al impulso que en las universidades norteamericanas se dio hacia nuevos procesos de formación jurídica (Seijo-Ortiz, 2005).

En México las clínicas fundadoras fueron la del Instituto Tecnológico Autónomo de México (IтAм) y la del Centro de investigación y docencia económicas (CIDE), seguidas por la Iberoamericana.

Para definir cuál ha sido la clínica jurídica fundadora en Iberoamérica proponemos cuatro criterios: (i) su identificación desde los inicios como un trabajo de interés público y derechos humanos; (ii) su compromiso con el litigio estratégico; (iii) su impacto en las demás clínicas del continente y (iv) su trayectoria y sostenibilidad en el tiempo.

Según estos criterios, ubicamos la primera generación de clínicas jurídicas en el año 1993, en Argentina. Iniciamos este recorrido en el tiempo destacando que la primera clínica jurídica de Iberoamérica surgió en Argentina en 1993 con el convenio entre la Universidad de Buenos Aires (UBA) y el Centro de Estudios Legales y Sociales (cELs) e inició su funcionamiento en 1994. ${ }^{4}$ Son veinte años de trabajo ininterrumpido con grandes aprendizajes para el movimiento clínico iberoamericano.

\footnotetext{
${ }^{4} \mathrm{http}: / /$ www.cels.org.ar/servicios/?info=detalle Tpl\&ids=68\&lang=es\&ss=72
} 
La etapa inicial de cualquier clínica no es fácil, y una de las exigencias permanentes es la de adecuación del nuevo modelo. Así lo reconocen los profesores del ceLs:

\begin{abstract}
Se requería que la clínica articulara el trabajo concreto en litigio estratégico y la aplicación del derecho internacional. Para ello, era necesario lograr que todos los espacios de la clínica, incluso las clases teóricas, tuvieran un alto grado de integración entre sí y con la agenda de litigio del cels. La clínica atravesó, entonces, a dos años de su creación, su primera transformación significativa (cELs 2012,p.13).
\end{abstract}

Las transformaciones dan cuenta también de los momentos históricos que se viven y la agenda y prioridades que en derechos humanos les exigen nuevas respuestas. Una gran fortaleza de la clínica cELS-UBA es su capacidad de hacer litigio y también investigación de alto impacto, que generalmente se publican en los informes anuales de derechos humanos. Las líneas temáticas que manejan actualmente son cinco: "derechos económicos, sociales y culturales (DESC), salud mental, sistemas internacionales de protección, cárceles y violencia institucional" (Baladrón, 2013, p. 39).

Los nuevos tiempos exigen cambios; en los últimos cinco años han apoyado nuevas clínicas en Argentina, especialmente las de Jujuy y Neuquen "[...] hay nuevas clínicas con temas novedosos como salud mental, violencia contra las mujeres y tortura y cárceles entre otros; se puede tener incidencia en clínicas temáticas, pero hay una gran precariedad institucional. La crisis ha afectado en gran medida a las ong"(Morales, 2012).

De igual forma añade:

Se desdibujó el uso de clínicas para explicar simplemente herramientas o códigos procesales, que aunque se trabajan, la orientación es hacia los casos del litigio estratégico. Los temas procesales son herramientas de apoyo, no son herramientas de punta para provocar discusión. Se trabaja en diversas áreas para tratar de articular los temas de responsabilidad jurídica y la técnica procesal.

Concluye destacando que "la clínica es una de las caras más visibles del CELs" (Morales, 2012). 
En Venezuela se da para este mismo año el surgimiento de la clínica jurídica de la Universidad Andrés Bello, ${ }^{5}$ con un trabajo que tiene gran énfasis en atención de casos individuales y asesoría jurídica, pero que luego evoluciona especialmente en el tema de atención a migrantes.

En 1996 surge la Clínica de la Universidad de Palermo como un proceso de evolución desde una clínica de maestría a una clínica en el pregrado. En la maestría era una asignatura y allí se formaron muchos de los supervisores y profesores actuales de esta universidad (Nino, 2012).

En 1997 se crea una de las clínicas más emblemáticas del continente, la Clínica de Interés Público y Derechos Humanos de la Universidad Diego Portales. ${ }^{6}$ Felipe González, su fundador, cuenta cómo surge la idea de la clínica:

Había un grupo de profesores jóvenes; venían del mundo de derechos humanos y pensaron importante darle un giro al asunto. Varios habían estudiado en Estados Unidos, en particular yo había hecho un postgrado en American University; decidimos echar a andar esto [...] la creación de la clínica era un elemento importante para potenciar sin perder el horizonte teórico que ya existía.

La historia de las clínicas jurídicas en la Universidad Diego Portales se remonta a los años ochenta (dictadura), pero su impacto, solo fue medible diez años después, en los siguientes dos aspectos; por una parte en la operación del sistema judicial chileno (qué entendía el sistema judicial nacional lo que se estaba haciendo en las clínicas), y por otra parte una profunda reflexión sobre la enseñanza del Derecho, desde la academia, ya que muchas veces la docencia se basa en una jurisdicción vacía (2013).

En el año 1999 surgen dos clínicas de interés público, la Clínica de Derechos Humanos-Grupo de Acciones Públicas (GAP), en la Universidad del

\footnotetext{
${ }^{5}$ La información sobre la Clínica Jurídica de la Universidad Católica Andrés Bello en Venezuela se puede encontrar en: http://www.ucab.edu.ve/Clinica_Juridica.html

${ }^{6} \mathrm{http}: / /$ www.derechoshumanos.udp.cl/clinica/historia/
} 
Rosario, en Colombia, ${ }^{7}$ y la Clínica Jurídica de Acciones de Interés Público de la Universidad Católica del Perú. ${ }^{8}$

La Clínica Jurídica de la Universidad Católica se inicia con el liderazgo del profesor Gorki González M.y ha evolucionado hasta insertarse en el currículo de la Facultad de Derecho. Se describe como: "[...] un proyecto de la Facultad de Derecho destinado a brindar una mejor formación universitaria, buscando insertar a los alumnos en la concepción de responsabilidad social profesional a través de acciones de interés público en beneficio de grupos vulnerables que quizás no tendrían otro modo de ser defendidos". ${ }^{9}$

Por su parte, "la misión del GAP es promover la responsabilidad social universitaria mediante el uso de los mecanismos de protección de los derechos humanos y del interés público, generando a su vez espacios de asesoría jurídica para la comunidad y de investigación sobre temas públicamente relevantes". ${ }^{10}$ En esta clínica se trabaja en el ejercicio directo de acciones judiciales, mecanismos administrativos de defensa de derechos, acciones pedagógicas, incidencia en medios, trabajo pro bono, asesorías e investigación formativa, entre otras labores. Se ha priorizado la publicación de los casos emblemáticos, como una forma de divulgar el litigio estratégico y apoyar a las clínicas en formación.

Este primer momento tiene cuatro aspectos característicos: i) la educación legal clínica es liderada por un grupo de profesores al interior de las facultades de derecho o de las ONG en convenio con las universidades, que intentan romper con un modelo tradicional de formación y de asistencia jurídica; ii) La prioridad de las Clínicas es desarrollar y fortalecer el litigio estratégico; iii) El momento político en el cual surgen las clínicas (fin de las dictaduras en Argentina y Chile), evidencia la urgencia de trabajar por el fortalecimiento de la democracia y por la verdad, la justicia y la reparación para las vícti-

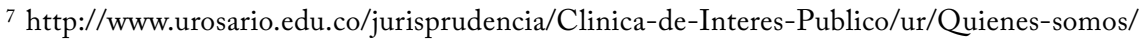
Que-es-el-Gap/

8 http://facultad.pucp.edu.pe/derecho/index.php?option=com_content\&task=view\&id=421\&Ite mid=112\#.UeOrto1M-So

${ }^{9} \mathrm{http}: / /$ facultad.pucp.edu.pe/derecho/index.php?option=com_content\&task=view\&id=419\&Ite mid=110\#.UUo0yBxhVJd

$10 \mathrm{http}: / /$ www.urosario.edu.co/jurisprudencia/Clinica-de-Interes-Publico/ur/Quienes-somos/ Mision/
} 
mas; iv) Para el fortalecimiento de las clínicas se constituye en este mismo periodo la Red Sudamericana (luego Latinoamericana) de clínicas jurídicas (Londoño, 2013).

Se destaca en el movimiento clínico de esta primera generación su liderazgo desde América Latina, la idea de constituir una red de apoyo y el impulso dado por los nuevos docentes en las universidades, además de un gran compromiso con la sociedad y con las nuevas exigencias que requería la educación jurídica.

En el caso colombiano la primera generación de clínicas se inaugura con el GAP y en este periodo se prioriza el ejercicio de litigio estratégico en defensa de derechos colectivos, a través de acciones populares (Ley 472 de 1998) y acciones de tutela. En el campo metodológico, estas clínicas plantean novedades en la forma de relacionamiento de profesores y estudiantes, en la construcción de aprendizajes derivados de la experiencia que se desarrolla en casos reales de litigio estratégico y, ante todo, este movimiento asume una posición crítica frente al formalismo imperante en la educación jurídica.

\section{La segunda generación de clínicas jurídicas en la región (2000-2010)}

La primera generación de clínicas se dedica a apoyar el surgimiento de nuevas propuestas en sus respectivos países, y luego en México, Brasil, Bolivia y Centroamérica.

La segunda generación de clínicas puede ubicarse en el decenio 20002010. Se trata de clínicas que nacen con toda la experiencia previa y los aprendizajes de un camino recorrido. Sus docentes son, en muchos casos, ex alumnos de las clínicas de primera generación y en el trabajo que realizan procuran mejorar y perfeccionar las experiencias que tuvieron.

En Chile se inicia este movimiento y se destacan el surgimiento de las clínicas de las universidades Alberto Hurtado (2001) y la Clínica Jurídica de la Universidad de Chile (2003). En 2004 nace un grupo significativo de clínicas:

En Argentina la Clinica de Migrantes, la cual constituye una verdadera novedad y muestra la evolución de la propuesta clínica. Su historia es muy particular, según lo relata su director:

En el 2004 el trabajo temático en materia de migrantes y refugiados y las fortalezas del cels hacen surgir la clínica. Hace 10 años surge 
esta clínica. En ese momento las ONG tenían una bandera: atacar la denominada Ley Videla que era totalmente violatoria de los derechos de los migrantes. Se organizó entonces un consorcio y una mesa por los derechos de las personas migrantes integrada por Caref, cels, sindicatos e investigadores. Se consideró importante apoyarse en la experiencia del cels-uba pues ya hacían litigio y tenían trabajo anterior en temas de repatriados (Asa, 2012).

Como puede observarse, esta clínica fue fruto de alianzas académicas y de ONG para trabajar un tema que inicialmente exigía cambios normativos y lobby legislativo, pero luego, al lograr la expedición de la Ley de Migraciones —Ley 25.871-, se vio la necesidad de continuar trabajando en orientación y trámite de casos y en apoyo para la expedición de una reglamentación, lo cual finalmente se produjo en el año 2010 (Reglamento Migratorio, Decreto 616/2010).

La Clínica Jurídica de la Escuela de Derecho de la Universidad Torcuato Di Tella en Argentina surge en alianza con la Acción por los Derechos Civiles (ADC) y este apoyo facilita el trabajo docente y el litigio estratégico (Gülco, 2012).

En Medellín (Colombia), surge la Clínica Jurídica de la Universidad de Medellín, pionera en el trabajo de educación legal clínica en la región y semillero de muchas de las nuevas clínicas de Antioquia. Su trabajo más destacado es en materia ambiental y en derechos humanos.

En el 2005 surge la Clínica Jurídica de la Universidad Nacional de Tucumán, que bajo el liderazgo de Mariela Puga fue una experiencia de enorme valor para toda América Latina, pero luego sufrió ataques desde la institucionalidad y la universidad a raíz del denominado caso "Rosarito", que develaba la ausencia de políticas públicas en materia de seguridad alimentaria para los niños y niñas en la provincia de Tucumán. La clínica desapareció y aunque traten de borrar su rastro, su memoria permanecerá en los nuevos ejercicios clínicos del continente.

En el mismo año, surgen las clínicas en España, con una característica interesante: en su gran mayoría, las primeras clínicas se forman en programas de máster (maestría) o en alianza de dichos programas con los de grado. La pionera fue la Clínica de Derecho Ambiental de la Universidad Rovira i Virgili, de Tarragona. En el 2006 aparecen las clínicas de la Universidad Carlos III: Clínica de Derecho Internacional de los Derechos Humanos, 
Clínica de Migrantes, Clínica de Igualdad y No Discriminación por Razón de Discapacidad y la Clínica de vin-sida. De igual forma surge la Clínica Jurídica por la Justicia Social de la Universidad de Valencia. En Colombia surge en este mismo año el Grupo de Derecho de Interés Público (G-DIP) de la Universidad de Los Andes.

También en 2005 surgen las clínicas en México, con la clínica del iт am y luego la Clínica de la Universidad Iberoamericana y la del cide. Dichas clínicas impulsaron trabajo clínico en derechos humanos, publicaciones muy reconocidas que aún se encuentran en la web, promovieron encuentros de clínicas en México y un encuentro de la Red Latinoamericana de Clínicas Jurídicas en el año 2007. Desafortunadamente las dos primeras clínicas ya no existen y aunque el cIDE continúa con trabajo clínico en pregrado, su enfoque está orientado a trabajo investigativo. El profesor Posadas describe así la situación actual: "A few but significant clinical legal education programs have been established in the last five years giving rise to an interesting, though still modest, new legal clinical wave. Bufetes jurídicos gratuitos (legal aid programs) play a role in these developments too" (Posadas, 2014).

El año 2007 trae también la formación de interesantes experiencias de educación legal clínica. En Chile nace la Clínica de Migrantes de la Universidad Diego Portales, la cual, según su directora, Helena Olea, logra "posicionarse como un referente en materia de atención clínica a inmigrantes, reconocimiento por otros actores, ONG y redes, investigación para generar los aportes documentados al Informe de Derechos Humanos en Chile y respaldo institucional" (Olea, 2013).

En España coincide con la formación de la Clínica Dret al Dret, de la Universidad de Barcelona (año 2009). Para su director y fundador:

La clínica es un proyecto institucional. Tiene que ver con el modelo de facultad que se quiere. Las clínicas son grupos de trabajo de estudiantes y profesores, donde se potencia la calidad de las prácticas, el servicio a la comunidad, la transferencia de conocimiento y la investigación. Esto las hace un proyecto de la facultad. La clínica ha de dar respuesta a necesidades actuales. No es una respuesta personal sino un modelo de facultad y de universidad (Madrid, 2013). 
Nace este año en Colombia, en la Universidad de Los Andes, la primera clínica en temas específicos de discapacidad, denominada Programa de Acción por la Igualdad y la Inclusión Social (PAIIs).

De igual forma surge en la misma universidad la clínica denominada: Justicia Global y Derechos Humanos. En esta clínica se trabajan temas de investigación y litigio estratégico en violencia, justicia y derechos humanos, economía global y derechos humanos y derecho global contra la discriminación. ${ }^{11}$

En el 2008 aparecen entre otras las siguientes clínicas: Clínica Jurídica de Acceso a la Información Pública, de la Universidad de Palermo, Argentina; Clínica Jurídica de Litigio Estructural, de la Universidad Nacional Mayor de San Marcos, Perú; el Grupo de Acciones Públicas del Icesi, en Cali, Colombia, y la Clínica de Interés Público de la Universidad Sergio Arboleda.

En México se intentó en el 2009 trasladar el modelo de alianzas onguniversidades a través de la ong Litiga, liderada por Graciela Rodríguez y Luis Miguel Cano y la Universidad Libre de México. Esta experiencia, desafortunadamente, solo duró un año. Las ong mexicanas han tenido que liderar solas el tema del litigio estratégico, como afirma Graciela Rodríguez: "el litigio de interés público se ha realizado por organizaciones de la sociedad civil [...], cada vez más las organizaciones incorporan un componente de litigio estratégico" (Rodríguez, 2013).

Los casos más sonados que en México llegan a conocimiento de la $\mathrm{Su}-$ prema Corte de Justicia de la Nación no vienen, en su mayoría, de clínicas, sino de organizaciones que se empiezan a dedicar a esto. No se constituyen como ONG de litigio estratégico; son organizaciones de derechos humanos a las que les incorporan un elemento de litigio. A veces no tienen la capacidad de llevarlo a cabo y contratan a otras organizaciones para realizarlo.

Esta segunda etapa de las clínicas, aunque prolífica, ha tenido experiencias fallidas, mayores dificultades y menor acogida por parte de las universidades para institucionalizar las nuevas propuestas, especialmente en el caso de México y Argentina. En los demás países continúa el liderazgo de los profesores, su contribución a través de planteamientos pedagógicos novedosos, como las clínicas especializadas y una participación más amplia en redes como la

${ }^{11} \mathrm{http} / / /$ derecho.uniandes.edu.co/index.php?option=com_content\&view=article\&id=53\&Itemid =260\&lang=es y http://justiciaglobal.info/ (fecha de consulta: $1^{\circ}$ de marzo de 2013). 
Global Alliance for Justice Education (GAJE) y la Red Latinoamericana de Clínicas Jurídicas).

\section{La tercera generación de clínicas (2010 hasta hoy)}

Las clínicas que incluimos en esta etapa son todavía clínicas en construcción, tienen mucho que aprender de sus antecesoras, pero también mucho que enseñar desde los debates internos que las han hecho surgir. La principal preocupación que nos planteamos es la de la sostenibilidad del trabajo de las clínicas: estos nuevos ejercicios deben nacer fuertes y con raíces claras en las universidades, para que no se conviertan en efímeros proyectos de uno o dos años, sino que tengan una trayectoria y un respaldo para la importante labor que realizan.

En el 2012 surge ClinHab, una clínica especializada en temas de vivienda, impulsada por las profesoras del área de Derecho Civil de la Universidad de Barcelona. Es un hito significativo en la historia de las clínicas por la novedad de su temática y la posibilidad de abordaje de problemas tan graves y de tan alto impacto social, como el de la burbuja inmobiliaria española (Colau, 2013).

La Clínica Jurídica en Derecho Inmobiliario y Mediación Residencial, en el marco del Proyecto Dret al Dret ("Derecho al Derecho") de la Universitat de Barcelona, ofrece, desde junio de 2012, un servicio gratuito de consultas sobre vivienda, conocido como ClinHab (www.clinicajuridicaimmobiliaria.org). Su objetivo es proporcionar respuestas a las preguntas formuladas por el público en general o canalizadas por entidades sociales y administraciones públicas, mediante el análisis de cada caso por parte de alumnos de los últimos cursos de derecho, que trabajan bajo la estrecha supervisión de expertos colaboradores y profesores de derecho privado. Desde su puesta en funcionamiento, ClinHab ha atendido más de 180 consultas, de las cuales aproximadamente el $40 \%$ han sido cuestiones hipotecarias y otro $40 \%$ arrendaticias; el restante $20 \%$ se refiere a otras cuestiones de derecho inmobiliario, como la vivienda social. Hemos llevado a cabo unas 30 reuniones semanales, donde se discuten los casos y las novedades legislativas y jurisprudenciales. Estos son algunos de los resultados de ClinHab. 
ClinHab es un servicio gratuito prestado por una Universidad pública, directamente accesible a las personas, por medio del cual se comparten los resultados de la investigación y de la docencia en un ámbito especialmente difícil para muchas personas en estos momentos, como es el de la vivienda (Viola de Mestre, 2013).

En el año 2013 se presenta una nueva etapa para las clínicas mexicanas y el profesor Posadas identifica siete clínicas:

I have identified seven Law School or University legal clinics in Mexico.Interestingly, the majority has been established very recently. Three of them were established with Usaid funds in order to work on the new adversarial criminal law system that is being gradually implemented in Mexico (American Bar Association Rule of Law Initiative (ABA ROLI) 2013]. These are the criminal procedural law clinics of $\mathrm{La}$ Salle University campus Cuernavaca, of the Autonomous University of Chihuahua Law School, and of the Escuela Libre de Derecho de Monterrey. All of them were established in 2013. Two other recent clinics have been established at UNAM. These are the Marisela Escobar Clinic of the Programa Universitario de Estudios de Género (Gender Studies University Program), ${ }^{12}$ and the Human Rights Clinic of the Programa Universitario de Derechos Humanos (Human Rights University Program). ${ }^{13}$ Both take students from UNAM Law School. ITAM has a new clinic that works in support of human traffic victims, nested within their Justice Access Center, which operates also as a bufete jurídico gratuito. ${ }^{14}$ Finally, the senior clinic in Mexico is the CIDE Law School Strategic Litigation Clinic. ${ }^{15}$

En este periodo nacen las clínicas de Derecho Penal Internacional y de Violencia Intrafamiliar y Género (vIG) en la Universidad del Rosario de

\footnotetext{
12 (Nota del texto original) http://www.pueg.unam.mx/index.php?option=com_content\&view=fro ntpage\&Itemid=92 (recuperado el 11 de octubre 2013).

13 (Nota del texto original) http://www.pudh.unam.mx (recuperado el 11 de octubre 2013).

${ }^{14}$ (Nota del texto original) http://caj.itam.mx/Paginas/index.html (recuperado el 11 de octubre 2013).

15 (Nota del texto original) www.cide.edu (recuperado el 11 de octubre 2013).
} 
Bogotá, en Colombia; la Clínica de Género y Violencia Intrafamiliar de la Universidad de Nariño, en Colombia; la Clínica de Género de la Universidad de Medellín y las nuevas clínicas jurídicas en México.

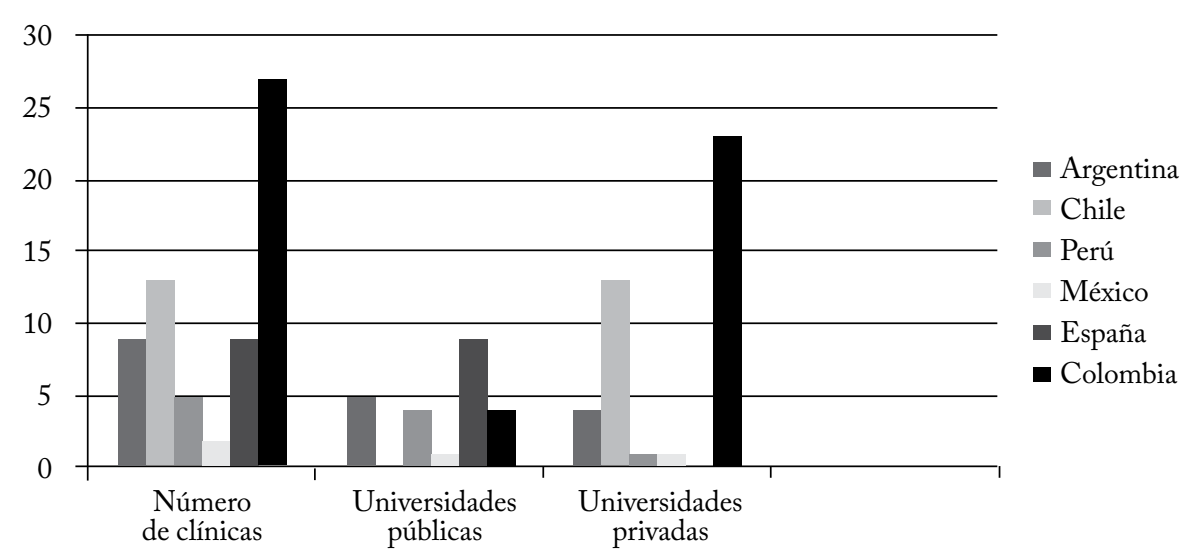

Figura 2. Clínicas jurídicas analizadas por países iberoamericanos en la investigación Fuente: elaboración propia.

En la revisión bibliográfica y directa que realizamos encontramos que a 2013, el país iberoamericano que tiene mayor número de clínicas jurídicas es Colombia, seguido por Argentina, Chile y España.

Para la selección de las clínicas se tuvieron en cuenta los siguientes criterios:

a) Participación de profesores y estudiantes en una labor que fortalece competencias de los estudiantes para su vida profesional.

b) Realización de trabajo pedagógico a partir de casos reales donde se interactúa para buscarles solución. Se consideran también como ejercicios clínicos los conceptos sobre casos reales, el lobby legislativo o ante entidades gubernamentales para la presentación de proyectos normativos en defensa de derechos humanos, la elaboración de informes sobre casos de vulneración de derechos humanos y la labor de street law.

c) Casos o ejercicios clínicos de impacto o emblemáticos finalizados. Se considera la posibilidad de que los casos tengan incidencia social, jurídica o política. 
Existe una cuarta característica que no aplicamos en esta ocasión porque es una de las mayores debilidades de las clínicas iberoamericanas: su visibilidad en medios de comunicación, redes sociales, internet y publicaciones.

Al examinar los avances en el trabajo de las Clínicas, proponemos clasificarlas en tres categorías para el análisis:

- Clinicas en formación: son propuestas clínicas muy recientes (inferiores a tres años) que se encuentran en proceso de reconocimiento académico institucional y que luchan por una sostenibilidad del proyecto. De igual forma incluimos en esta categoría a las clínicas que, a pesar de tener más tiempo, aun no reúnen con claridad los tres elementos propuestos.

- Clínicas consolidadas: son propuestas clínicas que reúnen las tres exigencias y ya tienen al menos un caso finalizado.

- Clínicas finalizadas: se trata de propuesta clínicas que no fueron sostenibles y se extinguieron por diversas razones institucionales, sociales o políticas.

Tabla 3. Muestra de clínicas examinadas en la investigación

\begin{tabular}{|l|c|c|c|c|}
\hline \multicolumn{1}{|c|}{ País } & $\begin{array}{c}\text { Número de clínicas } \\
\text { examinadas }\end{array}$ & Universidades & $\begin{array}{c}\text { Clínicas en } \\
\text { universidades } \\
\text { públicas }\end{array}$ & $\begin{array}{c}\text { Clínicas en } \\
\text { universidades } \\
\text { privadas }\end{array}$ \\
\hline Argentina & 9 & 7 & 5 & 4 \\
\hline Chile & 13 & 6 & 0 & 13 \\
\hline Perú & 5 & 5 & 4 & 1 \\
\hline España & 8 & 4 & 8 & 0 \\
\hline México & 7 & 6 & 2 & 5 \\
\hline Colombia & 27 & 21 & 4 & 23 \\
\hline Totales & 69 & 49 & 23 & 46 \\
\hline
\end{tabular}

Fuente: Elaboración propia.

En la revisión de las clínicas existentes, es preciso señalar que cuando se encontraron varias clínicas en una misma, todas fueron tenidas en cuenta. De esta forma la unidad de información de este trabajo son las clínicas iberoamericanas. El cuadro que veremos a continuación nos muestra un resumen de las cifras de clínicas examinadas y su distribución en Clínicas de Universidades Públicas o Privadas. 
La unidad de información que manejamos fueron las clínicas, pero también evidenciamos el número de universidades que las tienen:

El cuadro siguiente nos muestra las 69 clínicas que se examinaron en Argentina, Chile, México, Colombia, Perú y España. Luego haremos una profundización sobre el caso colombiano y las clínicas en este país.

Tabla 4. Muestra de clínicas jurídicas consolidadas y en formación en seis países de Iberoamérica

\begin{tabular}{|c|c|c|c|}
\hline País & Número de clínicas consolidadas & Clínicas en formación & $\begin{array}{l}\text { Clínicas que } \\
\text { desaparecieron }\end{array}$ \\
\hline Argentina & $\begin{array}{l}\text { Universidad de Buenos } \\
\text { Aires-cEls: } 1 . \\
\text { Universidad de Buenos Aires-CELs- } \\
\text { Caref: } 1 . \\
\text { Universidad de Palermo: } 2 \text {. } \\
\text { Universidad Nacional de Córdoba- } \\
\text { clip: } 1 . \\
\text { Universidad Torcuato di Tella: } 1 \text {. } \\
\text { Universidad Nacional del Litoral en } \\
\text { Santa Fe: } 1 . \\
\text { Universidad Nacional de La Plata: } \\
1 . \\
\text { Universidad de San Andrés: } 1 \text {. }\end{array}$ & $\begin{array}{l}\text { Universidad Siglo xxi- } \\
\text { Cedha: } 1 . \\
\text { Universidad Católica de } \\
\text { Córdoba-Cedha: } 1 .\end{array}$ & $\begin{array}{l}\text { Universidad de } \\
\text { Tucumán. } \\
\text { Universidad de } \\
\text { Comahue. }\end{array}$ \\
\hline Chile & $\begin{array}{l}\text { Universidad Diego Portales: } 6 . \\
\text { Universidad Católica de Temuco: } 2 . \\
\text { Universidad Central de Chile: } 2 . \\
\text { Universidad Alberto Hurtado: } 1 . \\
\text { Universidad Andrés Bello: } 1 . \\
\text { Universidad Adolfo Ibáñez: } 1 .\end{array}$ & & \\
\hline Perú & $\begin{array}{l}\text { Universidad Católica del Perú: } 1 . \\
\text { Universidad Nacional de San } \\
\text { Marcos: } 1 . \\
\text { Universidad Nacional de San } \\
\text { Agustín en Arequipa: } 1 . \\
\text { Universidad Nacional de San } \\
\text { Cristóbal de Huamanga en } \\
\text { Ayacucho: } 1 \text {. } \\
\text { Universidad Nacional del } \\
\text { Altiplano-Puno: } 1 .\end{array}$ & & \\
\hline España & $\begin{array}{l}\text { Universidad Carlos III } \\
\text { de Madrid: } 4 . \\
\text { Universidad de Valencia: } 1 . \\
\text { Universidad de Barcelona: } 2 \text {. } \\
\text { Universidad Rovira e Virgili de } \\
\text { Tarragona-Derecho Ambiental: } 1 .\end{array}$ & $\begin{array}{l}\text { Universidad Rovira e } \\
\text { Virgili de Tarragona- } \\
\text { Derechos humanos: } 1 .\end{array}$ & \\
\hline
\end{tabular}




\begin{tabular}{|c|c|c|c|}
\hline País & Número de clínicas consolidadas & Clínicas en formación & $\begin{array}{l}\text { Clínicas que } \\
\text { desaparecieron }\end{array}$ \\
\hline México & CIDE: 1. & $\begin{array}{l}\text { Universidad Autónoma de } \\
\text { México: } 2 \text {. } \\
\text { Universidad de la Salle } \\
\text { Campus Cuernavaca: } 1 . \\
\text { Escuela de Derecho Uni- } \\
\text { versidad Autónoma de } \\
\text { Chihuahua: } 1 . \\
\text { Escuela Libre de Derecho } \\
\text { de Monterrey: } 1 . \\
\text { ITAM-Clínica de Trata de } \\
\text { Personas: } 1 .\end{array}$ & $\begin{array}{l}\text { Escuela Libre de } \\
\text { Derecho. } \\
\text { Universidad } \\
\text { Iberoamericana. } \\
\text { ITAM-Clínica } \\
\text { Legal de interés } \\
\text { Público. }\end{array}$ \\
\hline Colombia & $\begin{array}{l}\text { Universidad Sergio Arboleda: } 1 . \\
\text { Universidad de Los Andes: } 3 . \\
\text { Universidad del Rosario: } 1 . \\
\text { Universidad Javeriana: } 1 . \\
\text { UPB: } 1 . \\
\text { Universidad de Antioquia: } 1 . \\
\text { Universidad de Medellín }: 1 . \\
\text { ICEsi: } 1 . \\
\text { Universidad del Norte: } 1 . \\
\text { Universidad Libre de Pereira: } 1 .\end{array}$ & $\begin{array}{l}\text { Universidad de } \\
\text { La Sabana: } 1 . \\
\text { Unaula: } 1 . \\
\text { Universidad Católica de } \\
\text { Oriente: } 1 . \\
\text { Universidad } \\
\text { del Rosario: } 3 . \\
\text { Corporación Universitaria } \\
\text { Remington: } 1 . \\
\text { Unisabaneta: } 1 . \\
\text { Luis Amigó: } 1 . \\
\text { Universidad } \\
\text { Surcolombiana: } 1 . \\
\text { Pontificia Universidad } \\
\text { Javeriana de Cali: } 1 . \\
\text { Universidad de Ibagué: } 1 . \\
\text { Universidad de Nariño:1. } \\
\text { Universidad } \\
\text { del Magdalena: } 1 . \\
\text { Corporación Universitaria } \\
\text { Autónoma del Caribe: } 1 . \\
\text { Universidad Cooperativa } \\
\text { de Colombia en Arauca: } 1 .\end{array}$ & $\begin{array}{l}\text { Universidad San } \\
\text { Buenaventura } \\
\text { (Medellín): } 1 .\end{array}$ \\
\hline
\end{tabular}

Fuente: elaboración propia. En el caso colombiano, el cuadro se basa en las encuestas que realizó el Ministerio del Interior a los decanos de las facultades de derecho de Colombia (2012).

\section{El estudio de caso de las clínicas jurídicas colombianas}

Uno de los hallazgos más interesantes en este trabajo se relaciona con la verificación de existencia de un numeroso grupo de clínicas en Colombia. En esta sección examinaremos los resultados de una investigación desarrollada por la Universidad del Rosario y la Dirección de Justicia Formal del Ministerio de Justicia (2013), que tomó como base la preocupación por la calidad del servicio en las prácticas jurídicas de las universidades colombianas y la 
necesidad de diseñar una propuesta de lineamientos de calidad para los programas de derecho.

En la encuesta del ministerio, se pretendía indagar sobre los consultorios jurídicos y las clínicas en los programas de derecho y profundizar sobre:

a) La estructura tecnológica de los procesos de atención jurídica.

b) La infraestructura de la planta física.

c) La Idoneidad del capital humano.

d) Los requisitos mínimos para la puesta en funcionamiento de un centro de atención jurídica.

e) Los tipos de servicios que prestan.

f) La diversidad de escenarios y campos de aprendizaje práctico.

La fuente de información fueron los documentos en los cuales 72 decanos de facultades de derecho del país daban respuesta a un cuestionario remitido por el Ministerio de Justicia colombiano en el año 2012. Dicha información se complementó con la consulta directa de las páginas web de las facultades y documentos de relatoría de los cuatro encuentros de la Red Colombiana de Clínicas Jurídicas.

A través del semillero de investigación y bajo la coordinación del Grupo de Derechos Humanos de la Universidad del Rosario, se realizó la sistematización y análisis de la información relacionada con la aproximación a un diagnóstico sobre las clínicas jurídicas en Colombia. Del informe final se destacan los siguientes aspectos (Londoño, 2013):

- En Colombia existen a 2013, según la información de los decanos, 28 clínicas jurídicas. Su distribución se concentra en las regiones Centro y Antioquia. En el resto del país son aún incipientes las experiencias, existen clínicas en formación y solo algunas consolidadas.

- Las clínicas en Colombia trabajan, en su gran mayoría, temáticas de interés público y derechos humanos. Han surgido también clínicas especializadas en temas como discapacidad, medio ambiente y derecho penitenciario, entre otros.

- La mayoría de las clínicas existentes tienen una relación directa o indirecta con el consultorio jurídico, ya que es en dicho espacio académico donde se ha logrado el apoyo de las facultades de derecho. 
Tabla 5. Existencia de clínicas jurídicas en Colombia a 2013

\begin{tabular}{|c|c|c|c|}
\hline Región & $\begin{array}{l}\text { Número de } \\
\text { clínicas }\end{array}$ & Universidades que tienen clínicas jurídicas & $\begin{array}{l}\text { Total de encuestas } \\
\text { respondidas por } \\
\text { región }\end{array}$ \\
\hline Centro & $\begin{array}{l}\text { Total: } 9 . \\
\text { Consolidadas: } 6 . \\
\text { En formación: } 3 \text {. }\end{array}$ & $\begin{array}{l}\text { Clinicas consolidadas: } \\
\text { Universidad Sergio Arboleda: } 1 . \\
\text { Universidad de Los Andes: } 3 . \\
\text { Universidad del Rosario: } 1 \text { GAP. } \\
\text { Pontificia Universidad Javeriana: } 1 \text {. } \\
\text { Clinicas en formación: } \\
\text { Universidad del Rosario: } 2 . \\
\text { Universidad de La Sabana: } 1 .\end{array}$ & 18 \\
\hline Antioquia & $\begin{array}{l}\text { Total: } 8 . \\
\text { Consolidadas: } 3 . \\
\text { En formación: } 5 .\end{array}$ & $\begin{array}{l}\text { Clínicas consolidadas: } \\
\text { Universidad de Antioquia: } 1 . \\
\text { Universidad de Medellín: } 1 . \\
\text { Universidad Pontificia Bolivariana: } 1 . \\
\text { Clínicas en formación: } \\
\text { Corporación Universitaria Remington: } 1 . \\
\text { Luis Amigó: } 1 . \\
\text { Unaula: } 1 . \\
\text { Universidad Católica de Oriente: } 1 . \\
\text { Unisabaneta: } 1 . \\
\text { Clínicas finalizadas } \\
\text { Universidad San Buenaventura: } 1 .\end{array}$ & 12 \\
\hline Suroccidente & Total: 5. & $\begin{array}{l}\text { Clinicas jurídicas consolidadas: } \\
\text { Icesi: } 1 \text {. } \\
\text { Clínicas jurídicas en formación: } \\
\text { Universidad de Ibagué: } 1 \text {. } \\
\text { Universidad de Nariño: } 1 \text {. } \\
\text { Universidad Surcolombiana: } 1 \text {. } \\
\text { Pontificia Universidad Javeriana: } 1 \text {. }\end{array}$ & 12 \\
\hline $\begin{array}{l}\text { Orinoquía y } \\
\text { Amazonía }\end{array}$ & Total: 1. & $\begin{array}{l}\text { Clínicas jurídicas en formación: } \\
\text { Universidad Cooperativa de Colombia en } \\
\text { Arauca. }\end{array}$ & 2 \\
\hline Costa Caribe & Total: 3. & $\begin{array}{l}\text { Clínicas jurídicas consolidadas: } \\
\text { Universidad del Norte: } 1 . \\
\text { Clínicas jurídicas en formación: } \\
\text { Corporación Universitaria Autónoma del } \\
\text { Caribe: } 1 \text {. } \\
\text { Universidad del Magdalena: } 1 \text {. }\end{array}$ & 9 \\
\hline Eje Cafetero & Total: 1. & $\begin{array}{l}\text { Clinicas jurídicas consolidadas: } \\
\text { Universidad Libre de Pereira: } 1 .\end{array}$ & 5 \\
\hline Santanderes & Total: 0. & & 14 \\
\hline Total & 27 & & 72 \\
\hline
\end{tabular}

Fuente: elaboración propia basada en las respuestas a la encuesta que realizó el Ministerio de Justicia en 2012 y complementadas por información en páginas web. 
- Aun es escaso el número de profesores que apoyan las clínicas existentes. No se han formado profesores en esta modalidad de educación legal, que es tan importante a nivel internacional.

- A pesar de que la primera experiencia de educación clínica tiene ya 14 años en Colombia, no existe un reconocimiento de esta figura en la mayoría de las facultades de derecho.

- En el análisis regional podemos observar un desarrollo desigual, pues mientras en las regiones Centro y Antioquia existen clínicas consolidadas y con gran apoyo institucional, las regiones de Costa Caribe, Eje Cafetero, Suroccidente y Orinoquía muestran avances interesantes con algunas clínicas en formación aunque son realmente pocos los resultados frente al número de facultades. Preocupa que en la región de los Santanderes no existe hasta la fecha ninguna clínica jurídica. Finalmente, es importante mencionar que en Colombia se constituyó desde 2011 la denominada Red Colombiana de Clínicas. Se han realizado cuatro encuentros de dicha Red e importantes esfuerzos en el fortalecimiento de la educación legal clínica. Es también reciente en Colombia la coordinación de acciones entre universidades y bufetes de abogados, a través del programa pro bono. Se destacan las experiencias de la Universidad del Rosario y la Universidad de Los Andes.

\section{Las clínicas de interés público y derechos humanos. Primer movimiento de clínicas jurídicas en Iberoamérica}

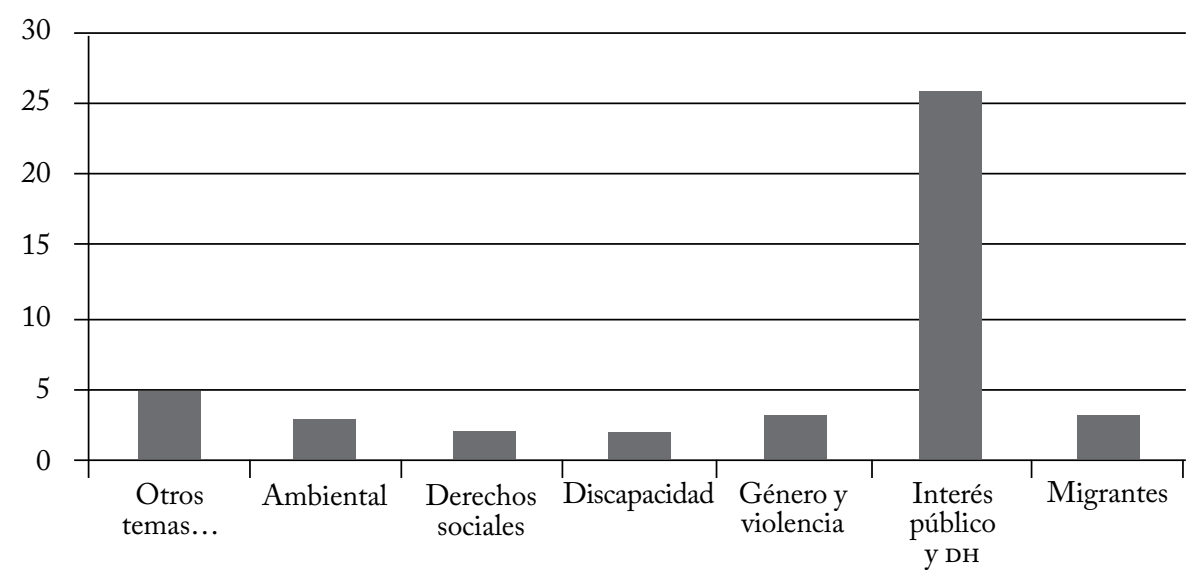

Figura 3. Temas prioritarios en la agenda de las clínicas de Iberoamérica 
Un concepto central para entender la educación legal clínica en Iberoamérica es el de derecho de interés público, eje que aglutina a la mayoría de las clínicas en lo que llamaríamos su primera fase de desarrollo (1992-2000). Los debates en todos los encuentros de clínicas y en la mayoría de los libros y revistas publicadas por la Universidad Diego Portales intentaron siempre dar una definición, buscando que el objetivo y nombre de las clínicas (clínicas de interés público) correspondieran a un campo de debate y entendimiento común para América Latina.

Para el profesor Courtis, en el denominado derecho de interés público se incluyen nuevas "estrategias y prácticas en el campo de la enseñanza y del ejercicio de la abogacía” y la reflexión sobre la "conceptualización y organización de prácticas materiales y discursivas en el ámbito jurídico”. Vale la pena señalar también que:

Los grupos que se identifican con la noción de derecho de interés público centran su interés en el desarrollo del propio derecho, poniendo énfasis en la necesidad de renovación de la enseñanza y de la práctica jurídica tradicionales. De allí que el tipo de estrategia elegida busque seleccionar casos de alto impacto público, incidir en el debate de ideas y en la formulación de propuestas de modificación normativa y curricular, sacar provecho del reconocimientos de nuevos derechos y de la consagración de instrumentos procesales novedosos, etc. [...] [incluye también] el interés público de consolidar y desarrollar el sistema de derechos y garantías y el sometimiento de los poderes estatales (y también de algunos poderes privados) a la Constitución y a la ley (Courtis, 2005, p. 168).

La gran dificultad surgió con la escuela tradicional del derecho público, donde se hacía equivalente el término interés público con el de interés estatal. El mayor debate del tema se dio en Argentina y allí, al igual que en varios países de Latinoamérica, se caracterizó esta nueva noción con varias propuestas que fueron siempre acompañadas por los nuevos docentes de universidades públicas y privadas que vieron en las clínicas una gran oportunidad de hacer real el concepto del interés público: 
- Reacción frente a las fallas en el acceso a la justicia y los graves problemas en la representación legal de ciertos sectores sociales. Se conceptualiza sobre acceso a la justicia para los grupos vulnerables, el acceso a la justicia en clave de igualdad material o sustantiva, la investigación empírica sobre necesidades jurídicas insatisfechas (Courtis, 2005, p. 164).

- A diferencia de las clínicas jurídicas norteamericanas, que se observan más centradas en el proceso pedagógico y educativo, en las clínicas latinoamericanas el enfoque apunta hacia el logro o contribución en la realización de cambios estructurales. Ven la educación legal clínica como una oportunidad de servicio a la sociedad con alto impacto.

- La crítica a la concentración de la enseñanza y del litigio en áreas tradicionales del derecho:

La instalación de la noción de derecho de interés público ha venido acompañada de un intento de rediscusión de las formas de enseñanza del derecho y de la articulación de la formación universitaria con la práctica profesional. Así se ha privilegiado la organización de cursos clínicos, la vinculación de las facultades de derecho con organizaciones de la sociedad civil y con instituciones de defensa de derechos humanos, el involucramiento de los estudiantes en la organización de actividades de debate público de temas jurídicos de interés público, su participación en la elaboración de documentos de toma de posición ante temas de trascendencia social, etc. (Courtis, 2005, p. 165).

- Diversificación temática; se propone la construcción de una nueva agenda de problemas a trabajar por las clínicas.

- El énfasis en el desarrollo del litigio sobre derechos constitucionales y derechos humanos. El concepto de interés público y el desarrollo de las clínicas en varios países latinoamericanos tiene que ver con la consolidación democrática y la existencia de nuevas cartas constitucionales (Colombia: 1991; Argentina: 1994; Perú: 1993). Coinciden con la masiva ratificación de tratados de derechos humanos y, en el caso Argentino: 
Con la incorporación de institutos procesales de garantía de derechos —como el amparo, el hábeas corpus y el hábeas data—a los nuevos textos constitucionales. En el plano institucional, se han multiplicado los esfuerzos por garantizar la independencia judicial, la del Ministerio Público y la de los órganos de contralor de la legalidad y la protección de los derechos humanos, como la Defensoría del Pueblo y la Auditoría General de la Nación (Courtis, 2005, p. 166).

- La práctica jurídica de las clínicas latinoamericanas se basa en el reclamo de derechos reconocidos por los textos constitucionales y las normas internacionales.

- La introducción de la temática de las acciones colectivas. Se ve como muy significativa la importancia que se le da en Latinoamérica a las dimensiones colectivas de la tutela de muchos derechos. Se han fortalecido debates académicos en materia sustantiva y en aspectos procesales, porque se cambian los paradigmas del derecho procesal tradicional. Se desarrolla ampliamente el amparo colectivo y en otros países las acciones populares.

Uno de los criterios elegidos por las clínicas jurídicas para seleccionar casos susceptibles de ser litigados judicialmente es el de la posibilidad de consolidar y ampliar la representación colectiva a través de miembros de la clase afectada u organizaciones de la sociedad civil que tengan como objeto la defensa de algún derecho específico [...]. Representantes de clínicas de interés público y de asociaciones vinculadas con la temática han apoyado también la introducción de modificaciones legislativas, tales como la reglamentación del amparo colectivo y de otras acciones colectivas, o la introducción de la figura del asistente oficioso o amicus curiae, cuando estos temas se han debatido en el ámbito de las respectivas comisiones parlamentarias (Courtis, 2005, p. 167).

En el caso colombiano, desde la Defensoría del Pueblo, con apoyo de las universidades y onG, se impulsó la regulación de acciones colectivas, populares y de grupo (Ley 472 de 1998). Durante estas dos décadas las acciones 
constitucionales han sido la principal herramienta de litigio estratégico en las clínicas colombianas.

\section{La práctica de las clínicas de interés público en diversos países iberoamericanos}

Las denominadas clínicas de interés público tienen dos elementos que les dan gran fortaleza: (i) la reflexión teórica sobre su objeto de trabajo y (ii) la relación directa con docentes de derecho constitucional y derecho público que deciden utilizar las acciones constitucionales como escenario para el litigio estratégico.

En Argentina se dieron varios cambios interesantes: (i) el agregado de un nuevo capítulo a la primera parte de la Constitución: se incluye una cláusula de defensa de la democracia y se consagran derechos políticos; (ii) la incorporación del bloque de constitucionalidad de los tratados de derechos humanos: jerarquía constitucional a 12 instrumentos internacionales y mecanismo de constitucionalización de otros tratados de derechos humanos.

"A la agenda sustantiva de los grupos que se identifican con la noción de derecho de interés público se ha agregado, entonces, una agenda procedimental, orientada a la discusión y mejora de los mecanismos procesales de defensa de los derechos privilegiados por su práctica" (Courtis, 2005, p. 175). Los debates más importantes se relacionan con temas de tiempos procesales prioritarios, legitimación, cuestiones de hecho y prueba, el efecto de las sentencias, amparos colectivos, requisitos de admisibilidad, eliminación de agotamiento previo de recursos administrativos como requisito para la interposición del amparo y acciones declarativas de inconstitucionalidad de carácter general (Buenos Aires).

Se destaca la consolidación institucional del tema a través de las universidades, las redes y las organizaciones.

Parte del impulso de la instalación de la noción de derecho de interés público está vinculada con instituciones universitarias. En este ámbito se ligan varias inquietudes teóricas y prácticas: la crítica a la enseñanza tradicional del derecho, un intento de renovación de la enseñanza jurídica que la reoriente hacia la práctica, la discusión sobre un espectro más amplio de perfiles posibles en el ejercicio de la profesión y la necesidad de vinculación de la universidad con la comunidad y con organizaciones de la sociedad civil [...]. 
La labor clínica fue acompañada por actividades de investigación académica sobre las herramientas del derecho de interés público y los avances en la materia (Courtis, 2005, pp. 180-182).

El caso argentino es especial: allí conviven y se relacionan las facultades de derecho y las ONG, existe un alto grado de pertenencia de los docentes a las ONG y esto facilita el litigio estratégico mediante alianzas.

\begin{abstract}
Así, y aprovechando la legitimación procesal de las organizaciones constituidas para la defensa de un derecho específico, las clínicas han servido en muchos casos como patrocinantes jurídicos de ONG en litigios de interés público — por ejemplo, en materia de derecho de los consumidores, derecho al medio ambiente, derecho a la salud, derechos de grupos discriminados, etcétera (Courtis, 2005, p. 182).
\end{abstract}

En estos 20 años, se han constituido nuevas organizaciones de la sociedad civil cuyo objeto es la defensa de causas de interés público, por ejemplo: la asociación por los derechos civiles (ADC), la Asociación Civil por la Igualdad y la Justicia (ACIJ) y Abogados y Abogadas del Noroeste Argentino en Derechos Humanos y Estudios Sociales (Andhes). Sus integrantes también son profesores en las universidades.

De la experiencia argentina se reconoce la importancia e impulso dado a buscar y consolidar nuevos actores del interés público. De igual forma el ejercicio ante el sistema interamericano de derechos humanos es sorprendente y visionario, solo posible por las alianzas de las universidades con las ONG. Finalmente destacamos cómo la agenda de interés público se ha fortalecido y repensado permanentemente.

Como retos específicos para Argentina, el profesor Courtis indica:

- "La consolidación de la perspectiva requeriría un salto cualitativo: pasar de un conjunto de experiencias piloto interesantes pero aisladas a su visualización como alternativa real a la formación jurídica y a la práctica profesional tradicionales" (Courtis., 2005, p. 186).

- "Para el afianzamiento de un espacio propio del derecho de interés público se necesitaría robustecer institucionalmente la vinculación 
de los distintos actores que participan del movimiento" (Courtis, 2005, p. 187). Propiciar mayores encuentros, debates y discusiones.

- "El trabajo en la perspectiva del derecho de interés público requiere, aún, de una mayor producción teórica que permita una definición conceptual más precisa de medios y fines, y la elaboración de materiales de enseñanza y divulgación, todavía escasos" (Courtis, 2005, p. 188). En todo caso se considera que esta labor promete mayores logros en el futuro.

\section{Características de las clínicas iberoamericanas}

En esta sección vamos a recoger los elementos comunes del trabajo en las clínicas iberoamericanas a manera de conclusión de la anterior sección y con el objeto de intentar dar respuesta a una pregunta específica: ¿qué diferencia a las clínicas iberoamericanas del modelo norteamericano?

Se encuentran tres elementos comunes y tres elementos diferenciadores: Elementos comunes:

a) Propuesta pedagógica que surge desde los profesores y se institucionaliza gradualmente. Esta es una característica necesaria para determinar la existencia de una clínica jurídica. Se debe evidenciar la participación de profesores y estudiantes en una labor que se orienta a fortalecer competencias profesionales, éticas, sociales y jurídicas de los estudiantes para su vida profesional.

b) Trabajo en casos reales. En las clínicas iberoamericanas existe trabajo pedagógico a partir de casos que surgen de muy diversas fuentes, pero que están anclados en la realidad que viven los países de la región. En el espacio de las clínicas se interactúa para buscarles solución.

c) De la revisión que se realizó se concluye que en esta categoría debemos incluir casos y ejercicios clínicos, entendiendo por tales otras formas de acercamiento y trabajo con la realidad, por ejemplo: conceptos sobre casos reales, el lobby legislativo o ante entidades gubernamentales para la presentación de proyectos normativos en defensa de derechos humanos, la elaboración de informes sobre casos de vulneración de derechos humanos y la labor de street law. 
d) Casos o ejercicios clínicos de impacto o emblemático finalizados. Se considera la posibilidad de que los casos tengan incidencia social, jurídica o política.

Elementos diferenciadores:

En esta sección miraremos dos aspectos que permean todos los anteriores y que si bien están implícitos en la educación legal clínica, en Iberoamérica muestran rasgos novedosos que hacen necesario dedicarles unas líneas:

\section{El rol de los estudiantes de las clínicas en Iberoamérica}

Poco se ha escrito sobre este tema y en muchas ocasiones se olvida el papel tan importante que cumplen los estudiantes en estos modelos.

Para intentar conocer el pensamiento de los estudiantes de las clínicas, se realizó una encuesta ${ }^{16}$ que nos permite examinar entre otros aspectos el valor que tiene la experiencia de educación legal clínica para los estudiantes, las fortalezas y debilidades de las clínicas desde su mirada y las recomendaciones más importantes.

La percepción de las clínicas es muy favorable, existiendo claridad y cumplimiento en la mayoría de sus elementos determinantes. Así mismo, existe un consenso general en relación con las actividades principalmente desarrolladas. Por último, también es posible extraer una valoración positiva del papel que cumple la clínica, entre los estudiantes que participaron o participaron en ella.

\begin{tabular}{|l|l|}
\multicolumn{2}{|c|}{ Encuesta a estudiantes que han pertenecido o pertenecen a clínicas jurídicas o clínicas de interés público } \\
\hline Marco de referencia & $\begin{array}{l}\text { Muestreo desarrollado a nivel regional (Colombia y países de Iberoamérica), partiendo } \\
\text { de la participación de estudiantes en eventos a nivel local y regional. }\end{array}$ \\
$\begin{array}{l}\text { Características de los } \\
\text { encuestados }\end{array}$ & $\begin{array}{l}\text { Estudiantes del programa de derecho que hayan participado o participen formalmente } \\
\text { en el desarrollo y funcionamiento de clínicas legales al interior de instituciones de edu- } \\
\text { cación profesional formalmente reconocidas. }\end{array}$ \\
Muestreo & $\begin{array}{l}\text { Encuesta desarrollada de modo virtual a través del sistema Survey Monkey, implemen- } \\
\text { tándose tres compiladores: link directo a formulario, invitación específica a encuestado } \\
\text { e invitación a participar a través de redes sociales (Facebook). }\end{array}$ \\
\hline Fropiedades & $\begin{array}{l}\text { Fueron resueltos 61 formularios, entre los tres compiladores activos: link (13), invitación } \\
\text { (44/85), redes (4). }\end{array}$ \\
Autores & Entre marzo 28 y mayo 28 de 2013. \\
\hline $\begin{array}{l}\text { Grupo de Investigación en Derechos Humanos - Línea de Investigación en Educación } \\
\text { Legal Clínica- de la Universidad del Rosario (Bogotá, Colombia). }\end{array}$
\end{tabular}


La clínica como experiencia pedagógica y su impacto en el futuro profesional: según la encuesta, el $65 \%$ de los estudiantes consideró que su tránsito por la clínica fue una buena experiencia, con aspectos novedosos y diferentes a las demás asignaturas. Adicionalmente, el 26,7\% consideró que su experiencia en la clínica fue determinante a la hora de decidir su futuro laboral, lo que corrobora el impacto positivo de las clínicas en los estudiantes que participan en ellas.

Actividades clínicas más valoradas por los estudiantes: los estudiantes consideran que la atención a casos de alto impacto o litigio estratégico es la principal actividad que desarrollan las clínicas (80,3\%). Destacan también las tareas de investigación (77\%) y la participación en charlas o conferencias $(75,4 \%)$. Por último, también contemplaron la atención a casos individuales, con el 62,3\%.

Elementos de la educación legal clinica: las respuestas a este ítem nos permitieron constatar el cumplimiento de las exigencias de educación legal clínica en las universidades iberoamericanas. Los estudiantes señalaron que en sus clínicas se trabajaron casos reales en los que se buscaba una solución y casos de impacto o emblemáticos (100\%). Luego destacaron la participación de estudiantes y profesores con el 96,7\% y la pertenencia a redes con el 88,5\%.

Desarrollo de competencias en la educación legal clínica: los estudiantes demostraron un gran interés por la responsabilidad social, con una valoración media de 4,56 sobre 5 . Muy de cerca, ubicaron la comprensión de problemas $(4,49)$ y la capacidad para la investigación $(4,43)$.

Con la educación legal clínica, una de las competencias que más se fortalecen es la investigación. Sobre ella, los estudiantes afirman: “[...] un aspecto fundamental para las clínicas, si pretenden tener un enfoque investigativo, es que los estudiantes al final de su paso por la clínicas tengan muy claro la metodología de la investigación desde un enfoque cuantitativo, cualitativo y mixto. En especial sobre el proceso de investigación en cada enfoque (planteamiento del problema, formulación de la hipótesis, diseño de la investigación, recolección y análisis de datos, etc.)”.

Exigencias para el trabajo en las clínicas: los estudiantes identificaron las características que consideran pertinentes para participar en las clínicas y sus principales exigencias son: (i) compromiso frente al grupo y a las labores asignadas, con una media de 4,82, (ii) el gusto o afinidad con las temáticas tratadas $(4,61)$, y (iii) la capacidad de trabajo en grupo $(4,56)$. 
Los estudiantes reconocen su papel en el impulso y renovación de la educación legal clínica y afirman que "[...] es fundamental que el estudiante perteneciente a la clínica esté entregado a la labor social, y empeño de investigar y ayudar a solucionar las problemáticas surgidas".

En la sección de recomendaciones, los estudiantes priorizan el tema de la selección de participantes, además de su responsabilidad social y compromiso.

Exigencias para los docentes clinicos: al referirse al rol de sus profesores, destacaron tres aspectos: (i) el compromiso frente al trabajo y frente a sus estudiantes, con una media de 4,89 puntos; (ii) facilidad para el trabajo en grupo y seguimiento de metodologías claras $(4,77)$ y (iii) experiencia académica $(4,53)$.

El papel de los docentes clínicos está relacionado directamente con el fortalecimiento de valores sociales y éticos frente a su profesión y reconocen que ellos son los llamados a "incentivarlos a investigar para fortalecer su conocimiento".

Al igual que en el tema de los alumnos, los estudiantes consideran que el proceso de selección de los docentes clínicos debe ser riguroso; esto asegura la calidad. "Los profesores deben tener experiencia en el área de litigios para guiar mejor la parte de litigio estratégico" y disponibilidad de tiempo para "que el estudiante tenga mayor acompañamiento profesional y educativo en todo momento".

Temáticas para la educación clínica: los estudiantes se refirieron a las áreas que consideraron como más importantes, para ser objeto de trabajo clínico. Sobresalen en su elección los temas de (i) derechos sociales, pobreza y exclusión, con una media de 4,58; (ii) temas de género y violencia contra las mujeres $(4,46)$ y (iii) el medio ambiente $(4,42)$.

Consideran necesario "[...] que la labor social se refleje en la formación de los nuevos abogados", además de "articular los trabajos en las clínicas en torno a las principales problemáticas del país” y hacer una reflexión profunda sobre el significado del "litigio de alto impacto y la forma de realizarlo".

Naturaleza de las clínicas: en este aspecto, los estudiantes prefieren la opción de prácticas voluntarias (52,5\%), seguida por la opción de asignatura electiva dentro del pregrado (23\%) y también algunos consideraron la opción de convertir la clínica en una asignatura obligatoria $(13,1 \%)$.

Recomendaciones en relación con el trabajo interinstitucional de las clinicas: los estudiantes conocen y valoran el trabajo en redes y consideran que: "una buena forma de mejorar la educación legal clínica sería creando canales in- 
terinstitucionales para dar mayor fuerza a las acciones como parte de una comunidad y de un grupo específico". De igual forma, estiman que debe fortalecerse el trabajo pro bono.

Para el trabajo de las clínicas, se consideran muy valiosos los ejercicios que permiten "Entablar conexiones permanentes con fundaciones, oNG, y algunas entidades estatales como la Defensoría del Pueblo".

Ajustes curriculares: para los estudiantes colombianos, "la clínica jurídica se podría realizar al tiempo con el consultorio jurídico, así existiría una mayor coordinación entre las prácticas".

En relación con la valoración de las clínicas, los estudiantes consideran que es necesario "que tenga valoración cuantitativa y créditos. Que se pueda hacer por más de un año". También consideran que esta experiencia debería ser abierta y electiva para todos los estudiantes de las facultades de derecho. Finalmente, los estudiantes reclaman "mayor voluntad política de las directivas de universidades, mayor interacción de las áreas, mayor difusión, mayor constancia”.

\section{Incidencia social de las clínicas}

Retomando el tema de los elementos diferenciadores de las clínicas en Iberoamérica, es preciso señalar su incidencia social, política y jurídica, como una de las mayores fortalezas.

Las clínicas PIHR se conciben a sí mismas no solo como una herramienta pedagógica para la enseñanza del derecho, sino también como agentes de cambio democrático en casos de debilidad institucional o insuficiencia de los Estados. Se caracterizan por su actuación en defensa de minorías (grupos o individuos) con desventajas sociales, políticas o culturales (Carrillo, 2011,p. 90).

Para Carrillo y Espejo existen dos características que distinguen a las clínicas latinoamericanas de sus "padres fundadores", las clínicas anglosajonas:

(i) En ellas tiene un lugar preponderante la defensa de imperativos de justicia social, incorporando a diversos actores sociales de sus democracias constitucionales; (ii) el litigio en estas clínicas ha revigorizado la adopción e implementación del derecho internacional de 
los derechos humanos, por sus estrategias creativas orientadas hacia los derechos económicos, sociales y culturales (2011, p. 91).

Una pregunta muy interesante que se ha planteado al interior de la Red Colombiana de Clínicas Jurídicas se refiere a cómo resolver la tensión entre los propósitos de formación y los de impacto social del trabajo clínico. Al respecto señala Fajardo (2012) que: "no hay riña entre el impacto y el aprendizaje. En Colombia solo se mide el impacto. Nos faltan sistemas de medición del aprendizaje".

En relación con el compromiso ético de las clínicas, la orientación de una gran mayoría de ellas en América Latina es hacia el interés público, los derechos humanos y el apoyo a comunidades en situación de vulnerabilidad. Es necesario complementar esta labor con la misión pedagógica de la universidad: la formación de los estudiantes.

Complementando este tema, Hurtado (2013), considera que las clínicas son una propuesta que acerca a la realidad. A través de este trabajo se busca repensar la realidad social, e involucrar a los estudiantes en ella. En las clínicas se combina lo teórico y lo práctico, lo ético y lo jurídico, lo individual y lo colectivo. No se trata de una práctica jurídica asistencialista, pues en la clínica se realiza acompañamiento directo, visibilización de las necesidades y búsqueda de transformaciones sociales sin sustituir al Estado.

\section{Los modelos pedagógicos y la ubicación curricular de las clínicas}

\section{¿Las clínicas jurídicas son un nuevo modelo pedagógico?}

En la educación legal clínica existen lineamientos claros de un modelo pedagógico en construcción donde se cumplen características de la nueva pedagogía (Unesco,2013), como la exigencia de ser procesos centrados en los estudiantes, la integralidad y manejo sistémico de los resultados y contenidos del aprendizaje, habilidades y competencias y la relación directa de este modelo como respuesta a necesidades sociales de acceso a la justicia para los grupos más vulnerables, además de la promoción de la participación social y el fortalecimiento de la democracia. 


\section{¿Qué concepto de modelo pedagógico tomamos como punto de partida?}

Esta es la pregunta central, porque solo en el acercamiento a las nuevas corrientes pedagógicas podemos entender la dimensión del problema que se aborda y buscar respuesta a la inquietud inicial.

Un modelo es una herramienta conceptual desarrollada para entender mejor algo, es la representación del conjunto de relaciones que describen un fenómeno. Un modelo pedagógico es una representación de las relaciones que predominan en la experiencia de enseñar y representa la teoría pedagógica predominante en este proceso, tal como lo manifiesta Flores [...], hace referencia a la interrelación entre los eventos externos de organización de la información y los procesos cognitivos internos (Murcia, 2014).

Para los expertos, un modelo pedagógico debe dar respuesta al menos a cinco exigencias claras:

"1. Las metas o propósitos de formación, que en este caso supera el concepto de adquisición de conducta, para llegar al desarrollo de competencias.

2. El concepto de desarrollo humano donde el aprendizaje puede ser concebido como un proceso genético espontáneo, natural, interior y autodirigido, o como un proceso de aprendizaje inducido desde afuera.

3. Los contenidos y su secuencia que identifica qué enseñar y depende de la naturaleza de la ciencia.

4. La relación entre los actores: profesor-estudiante que puede ser concebida como aquella que está centrada en el profesor hasta considerarla como una relación de construcción colectiva de conocimiento, donde de manera horizontal se respetan los saberes individuales. Los cambios en esta relación dependen de la forma como se consideren los roles de los actores participantes en el proceso. 
5. El parámetro técnico-pedagógico o modelo didáctico que incluye los métodos ${ }^{17}$ y técnicas de enseñanza-aprendizaje, ${ }^{18}$ los recursos o ayudas didácticas y la forma como se hace la evaluación; ¿cómo logramos que se dé un aprendizaje? La respuesta varía si la enseñanza está centrada en los contenidos o en el estudiante (Murcia 2014).

En relación con el tema de las evaluaciones, las clínicas iberoamericanas aún no han incursionado para hacer una reflexión en profundidad. Existen criterios para la evaluación, como la participación, la asistencia a las sesiones programadas, la calidad del trabajo y el cumplimiento de los términos de las acciones.

En las clínicas jurídicas norteamericanas, se ha avanzado más en el tema y, por ejemplo, en la Universidad de Minessota, se utiliza para la evaluación de los estudiantes una propuesta de seis categorías de competencias clínicas, pensando en lo que es la formación de un abogado en el área de la clínica. En esta propuesta se tienen en cuenta: (i) el conocimiento de la teoría, normatividad y jurisprudencia; (ii) razonamiento y argumentación; (iii) investigación e innovación en sus propuestas (espíritu crítico); (iv) principios éticos; (v) relaciones con usuarios y clientes, y (vi) habilidades orales y escritas. La calificación se da según el avance de cada estudiante.

La profesora Di Matteo (2012) define la evaluación educativa como "aquella que apunta a la innovación y a la mejora y no a la comprobación; recupera la subjetividad y tiene como garantía el diálogo, la posibilidad de crítica y la circulación. Es una evaluación situada”, donde los criterios deben ser explícitos (p. 78). Todos son elementos que al interior de las clínicas deben reflexionarse y explicitarse para avanzar en términos de calidad y responsabilidad del trabajo.

\section{¿La educación legal clínica es un método o un modelo?}

En la educación legal clínica los debates giran en torno a si se trata de un verdadero modelo pedagógico o si simplemente es un método o una didáctica.

\footnotetext{
17 (Nota del texto original) Método es la "herramienta con la que el objeto de estudio es trabajado por parte del aprendiz para que adquiera reconocimiento"(Secol, 2007).

${ }^{18}$ (Nota del texto original) Considerados como procesos integrales del individuo que involucran no solo el ámbito cognitivo, sino el afectivo, social, psicomotor y de valores.
} 


\begin{abstract}
Así, se ha entendido en Colombia que las clínicas son una estrategia innovadora para la enseñanza práctica del derecho (Vásquez-Santamaría, 2008). Dentro de esos aspectos innovadores se incluyen la relación práctica-teoría, compromiso social, interdisciplinariedad, litigio estratégico, interés público, población vulnerable, acciones constitucionales, entre otros. Y metodológicamente podría afirmarse que la EACD se soporta en la conjunción de las bondades de los presupuestos de los modelos autoestructuralistas, heteroestructuralistas y la andragogía (Reacd, citado en Torres Villarreal, 2014).
\end{abstract}

Si examinamos los aportes de las clínicas y su relación con la implementación de un modelo pedagógico, encontramos que los aspectos más significativos son: (i) aprendizaje activo, (ii) formación integral, (iii) aprendizaje constructivo, (iv) aprendizaje autorregulado, (v) aprendizaje significativo y (vi) aprendizaje-servicio.

La formación integral es entendida como aquella que permite y fomenta el desarrollo de las dimensiones espiritual, intelectual, cultural, psicosocial y física del ser humano. En la aplicación de este concepto a la educación legal clínica, encontramos que en estos procesos se promueve el acercamiento, análisis y comprensión de las realidades sociales, políticas, culturales, ambientales y económicas de la sociedad. De igual forma se refuerza el pluralismo, la autonomía, el respeto, la honestidad y la responsabilidad personal y profesional.

En el aprendizaje activo los estudiantes son protagonistas de sus propios procesos de aprendizaje. En la educación legal clínica se utilizan las entrevistas, simulaciones, juegos de roles, discusiones y el análisis de casos que implican reflexión profunda y aportes creativos. De igual forma se facilita el aprendizaje colaborativo a través de la interacción de los estudiantes. Con estas estrategias se potencia el aprendizaje y nuevas habilidades en los estudiantes.

El aprendizaje de la educación legal clínica es además constructivo y está enmarcado en la propuesta de aprender haciendo en un ambiente de interdisciplinariedad y crecimiento personal y grupal.

Otra característica de estos procesos es el denominado aprendizaje autorregulado, el cual exige acompañamiento y retroalimentación permanente, donde el rol del docente varía y es un supervisor y acompañante de los procesos de aprendizaje y autoevaluación que realiza el estudiante. 
Se considera también que la educación legal clínica promueve aprendizajes significativos porque los casos que se asumen implican una necesaria conexión con situaciones, experiencias y conocimientos previos y la necesidad de integrar los saberes.

Finalmente, consideramos que las clínicas responden al concepto de aprendizaje-servicio, que reúne dos propuestas: la acción comunitaria y solidaria (servicio) y los esfuerzos por aprender haciendo en un contexto de fortalecimiento del acceso a la justicia (Bloch, 2013).

Para la profesora Mascareño:

El servicio que las clínicas brindan a la comunidad y más específicamente a grupos sociales socialmente excluidos, reconociéndoles su derecho de acceso a la justicia, establece una valiosa relación entre la institución universitaria y la comunidad en la que está inserta, permitiendo que la universidad deje de considerarse como un centro formador de élites y sea reconocida como una institución progresista del bienestar social. La brecha entre derecho y realidad se va a acortar en la medida que el concepto de interés público se inserte en la esfera de la educación jurídica (Mascareño citado en Torres Villarreal, 2014).

Como elemento final de gran importancia, conviene incluir una reflexión sobre el concepto de aprendizaje-servicio, que desde los años noventa se plantea como un método por medio del cual se busca que los estudiantes o participantes aprendan, integren su currículo con actividades cívicas a través de servicios organizados en la comunidad, se involucren en la búsqueda de solución de problemas y reflexionen sobre dicha experiencia, que además deberá ser evaluada por la universidad. Algunas fundaciones le aportan elementos interesantes relacionados con el principio ético de este trabajo y lo denominan aprendizaje y servicio solidario, y se hace énfasis en un equilibrio entre el aprendizaje y el servicio.

\section{A manera de síntesis}

Se puede concluir que la educación legal clínica es un modelo en construcción a nivel internacional y que se ajusta a muchas de las nuevas exigencias de la Unesco. Se trata de una alternativa que fusiona las tres funciones misionales de la universidad: (i) extensión, con un enorme potencial social 
derivado del litigio estratégico; (ii) docencia, con muchos avances en la construcción de un modelo pedagógico innovador para el área y con grandes potencialidades para el desarrollo de investigación, y (iii) investigación, por su contribución en el fortalecimiento de competencias investigativas de los estudiantes.

De igual forma en este modelo se observan aportes en relación con procesos de formación integral, aprendizaje activo, aprendizaje constructivo, aprendizaje autorregulado, aprendizaje significativo y aprendizaje servicio.

\section{Investigación sobre el modelo pedagógico clínico realizada por las universidades de Medellín y de Chile}

La investigación presentada como avance en el encuentro de Santa Marta por las doctoras Erika Castro y Liliana Gallo (2012) tiene por objetivo analizar y comparar las líneas de intervención, criterios técnicos, programas y buenas prácticas existentes en las clínicas de Colombia, Chile y Argentina. A través de este proceso comparativo de la forma como se realiza la enseñanza clínica, se permiten contrastes y comparaciones, buenas prácticas y construcción de modelos.

En la definición de buenas prácticas se incluyen exigencias como la evidencia de mejora de procesos; la consistencia y coherencia entre planeación, objetivos y resultados; la innovación y la posibilidad de ser replicable.

En dicho trabajo se utiliza una metodología por dimensiones, las cuales son presentadas por las investigadoras:

a) Dimensión curricular. Análisis de los diferentes programas de las Facultades, la relación de su estructura curricular, perfiles de egreso. Educación desde el tema del proceso educativo.

b) Dimensión fáctica. Su objeto es analizar los aspectos prácticos de la clínica, funcionamiento, rol del docente, los estudiantes. Evaluación del aprendizaje de los estudiantes.

c) Dimensión institucional. Relación del contexto institucional con las clínicas.

d) Dimensión de contexto, que aborda los factores del contexto del país que influyen positivamente en el desarrollo de la enseñanza clínica (Castro, 2012). 
La doctora Castro considera que si bien ha existido una clara influencia de Estados Unidos en algunas clínicas, este modelo no es la referencia del trabajo de todas. En las investigaciones realizadas se observan escasas evidencias de entrenamiento de docentes clínicos, diseño de parámetros para la educación legal clínica y financiamiento. Nuestro modelo es diferente al norteamericano.

La aplicación de los instrumentos de investigación se realizó en cuatro universidades: Universidad de Medellín, Unisabaneta, upв y Universidad de Antioquia.

Algunos de los resultados iniciales fueron:

- Lineas de trabajo: se observa que no hay unificación temática.

- Apoyos institucionales: las clínicas trabajan muy solas, a pesar del reconocimiento público. Falta reconocimiento por parte de los programas académicos y las universidades.

- Currículo sobre clínicas jurídicas: no existe o se adapta y transforma.

- Construcción permanente de conocimiento real: no hay algo predefinido. Se va más allá de los conocimientos prácticos.

- El currículo oculto: las clínicas contribuyen a la convivencia, nuevas normas y prácticas sociales nuevas; permiten relaciones entre sujetos (docente, discente, comunidad educativa).

- Apoyo docente para las clinicas: se observa que hay articulación entre el trabajo del docente y los estudiantes. A veces recae en un solo docente.

- Herramienta de enseñanza: espacio aun no reconocido por las facultades.

¿Cómo puede incluirse la clínica en el currículo de las facultades de derecho? El siguiente cuadro resume algunas de las características de los modelos curriculares de clínicas universitarias existentes en América Latina: 
Tabla 7. Modelos curriculares de algunas clínicas jurídicas examinadas

\begin{tabular}{|c|c|c|c|c|}
\hline $\begin{array}{c}\text { Modelos- } \\
\text { características }\end{array}$ & $\begin{array}{l}\text { Asignatura } \\
\text { obligatoria }\end{array}$ & $\begin{array}{l}\text { Asignatura electiva } \\
\text { en los dos últimos } \\
\text { años }\end{array}$ & $\begin{array}{l}\text { Actividad } \\
\text { voluntaria }\end{array}$ & $\begin{array}{c}\text { Práctica alternativa } \\
\text { o complementaria } \\
\text { del consultorio } \\
\text { jurídico o servicio } \\
\text { social }\end{array}$ \\
\hline $\begin{array}{l}\text { Ejemplo de } \\
\text { facultades de } \\
\text { derecho que lo } \\
\text { ofrecen }\end{array}$ & $\begin{array}{l}\text { Universidad } \\
\text { Torcuato di Tella } \\
\text { (Argentina), } \\
\text { Unisabaneta } \\
\text { (Colombia). }\end{array}$ & $\begin{array}{l}\text { Universidad } \\
\text { Diego Portales, } \\
\text { Universidad } \\
\text { de Palermo } \\
\text { (Argentina). }\end{array}$ & $\begin{array}{l}\text { Universidad } \\
\text { de Medellín } \\
\text { (Colombia), } \\
\text { Universidad } \\
\text { Manuela Beltrán- } \\
\text { Proyecto Inocencia } \\
\text { (Colombia), } \\
\text { Universidad de } \\
\text { los Andes-PAIIs } \\
\text { (Colombia). }\end{array}$ & $\begin{array}{l}\text { U. Córdoba, UBA } \\
\text { (Argentina), } \\
\text { Universidad del } \\
\text { Rosario, Icesi, } \\
\text { Universidad de Los } \\
\text { Andes. Área de } \\
\text { Justicia Colectiva } \\
\text { (Colombia). } \\
\text { Universidad } \\
\text { Sergio Arboleda } \\
\text { (Colombia). }\end{array}$ \\
\hline $\begin{array}{l}\text { Duración de la } \\
\text { clínica }\end{array}$ & Un semestre. & Un semestre. & $\begin{array}{l}\text { Elegida por los } \\
\text { estudiantes. }\end{array}$ & Dos semestres. \\
\hline Ventajas & $\begin{array}{l}\text { - Mayor número } \\
\text { de estudiantes. } \\
\text { - Apoyo } \\
\text { institucional. } \\
\text { - Muchos } \\
\text { estudiantes } \\
\text { tienen } \\
\text { oportunidad de } \\
\text { participar en } \\
\text { las clínicas. }\end{array}$ & $\begin{array}{l}\text { - El estudiante } \\
\text { elige el tema } \\
\text { en el que desea } \\
\text { trabajar. } \\
\text { - Apoyo } \\
\text { institucional. } \\
\text { - Muchos } \\
\text { estudiantes } \\
\text { tienen } \\
\text { oportunidad de } \\
\text { participar en } \\
\text { las clínicas. } \\
\text { - Flexibilidad. }\end{array}$ & $\begin{array}{l}\text { - Interés y } \\
\text { dedicación. } \\
\text { - Formación } \\
\text { en valores de } \\
\text { solidaridad y } \\
\text { compromiso } \\
\text { social. } \\
\text { - Voluntariado. }\end{array}$ & $\begin{array}{l}\text { - Menor número } \\
\text { de estudiantes } \\
\text { que se eligen } \\
\text { cuidadosamente } \\
\text { para la labor a } \\
\text { desarrollar. } \\
\text { - En el caso de } \\
\text { las clínicas } \\
\text { argentinas es } \\
\text { importante el } \\
\text { apoyo de las } \\
\text { oNG. }\end{array}$ \\
\hline Desventajas & $\begin{array}{l}\text { - Gran carga } \\
\text { para un } \\
\text { docente clínico } \\
\text { sin apoyo de } \\
\text { supervisores } \\
\text { - Limitaciones } \\
\text { de tiempo } \\
\text { para el trabajo } \\
\text { clínico. } \\
\text { - Escasa } \\
\text { continuidad en } \\
\text { el seguimiento } \\
\text { de casos. }\end{array}$ & $\begin{array}{l}\text { - Gran carga } \\
\text { para un } \\
\text { docente clínico } \\
\text { sin apoyo de } \\
\text { supervisores. } \\
\text { - Limitaciones } \\
\text { de tiempo } \\
\text { para el trabajo } \\
\text { clínico. }\end{array}$ & $\begin{array}{l}\text { - Carencia de } \\
\text { valoración } \\
\text { académica para } \\
\text { tan importante } \\
\text { escenario de } \\
\text { formación. } \\
\text { - Falta de apoyo } \\
\text { institucional. }\end{array}$ & $\begin{array}{l}\text { - Escasa } \\
\text { valoración } \\
\text { académica de } \\
\text { este importante } \\
\text { escenario de } \\
\text { formación. } \\
\text { - Dificultades } \\
\text { para armonizar } \\
\text { el modelo con } \\
\text { el trabajo de } \\
\text { los consultorios } \\
\text { jurídicos } \\
\text { o servicios } \\
\text { sociales. }\end{array}$ \\
\hline
\end{tabular}

Continúa 


\begin{tabular}{|l|l|l|l|l|}
\hline $\begin{array}{c}\text { Modelos- } \\
\text { características }\end{array}$ & $\begin{array}{c}\text { Asignatura } \\
\text { obligatoria }\end{array}$ & $\begin{array}{c}\text { Asignatura electiva } \\
\text { en los dos últimos } \\
\text { años }\end{array}$ & $\begin{array}{l}\text { Actividad } \\
\text { voluntaria }\end{array}$ & $\begin{array}{l}\text { Práctica alternativa } \\
\text { o complementaria } \\
\text { del consultorio } \\
\text { jurídico o servicio } \\
\text { social }\end{array}$ \\
\hline $\begin{array}{l}\text { Integración } \\
\text { con la } \\
\text { estructura } \\
\text { curricular }\end{array}$ & $\begin{array}{l}\text { Clara y con } \\
\text { valoración } \\
\text { académica. }\end{array}$ & $\begin{array}{l}\text { Clara y con } \\
\text { valoración } \\
\text { académica. }\end{array}$ & $\begin{array}{l}\text { Sin valoración } \\
\text { académica. }\end{array}$ & $\begin{array}{l}\text { Se valora como } \\
\text { práctica pero no } \\
\text { tiene claridad en } \\
\text { materia de créditos } \\
\text { académicos. }\end{array}$ \\
\hline $\begin{array}{l}\text { Número de } \\
\text { docentes } \\
\text { clínicos }\end{array}$ & $\begin{array}{l}\text { Un profesor para } \\
\text { cada clínica. }\end{array}$ & $\begin{array}{l}\text { Un profesor para } \\
\text { cada clínica. }\end{array}$ & $\begin{array}{l}\text { Varios docentes } \\
\text { voluntarios que } \\
\text { supervisan. }\end{array}$ & $\begin{array}{l}\text { Varios docentes } \\
\text { asignados a la } \\
\text { práctica en calidad } \\
\text { de supervisores. }\end{array}$ \\
\hline $\begin{array}{l}\text { Evaluación } \\
\text { asignatura, pero }\end{array}$ & $\begin{array}{l}\text { Similar a otra } \\
\text { asignatura, pero } \\
\text { basada en los } \\
\text { trabajos. }\end{array}$ & $\begin{array}{l}\text { Sin evaluación } \\
\text { académica, pero } \\
\text { con evaluación } \\
\text { interna. }\end{array}$ & $\begin{array}{l}\text { Evaluación de } \\
\text { aprobación o no } \\
\text { del trabajo basada } \\
\text { en criterios de la } \\
\text { práctica clínica. }\end{array}$ \\
\hline $\begin{array}{l}\text { Nivel de } \\
\text { impacto } \\
\text { curricular }\end{array}$ & Alto. & Alto. & Sin impacto. & Bajo. \\
\hline $\begin{array}{l}\text { Respaldo } \\
\text { institucional }\end{array}$ & Alto. & Alto. & Variable. & Variable. \\
\hline
\end{tabular}

Fuente: elaboración propia.

El debate con las autoridades académicas —especialmente rectores y decanos- es urgente, porque los cambios requieren toma de decisiones claras, impulso y recursos para su sostenibilidad. A manera de ejemplo, podemos referenciar el intento que se realizó en Centroamérica. En el año 2001 se realizó en El Salvador la Primera Conferencia Centroamericana sobre el Uso de Clínicas y Pasantías en la Enseñanza Universitaria del Derecho, cuyo objetivo era "tratar de introducir el concepto de educación clínica" (Álvarez, 2005, p. 69). Los riesgos evidenciados en dicho ejercicio no difieren mucho de los que hoy se identifican por los docentes clínicos en Iberoamérica (Álvarez, 2005, pp. 72-73):

- La tentación de llamar clínicas a estos centros pero que no funcionen como tales: 
Mi recomendación a los decanos y otras autoridades con poder en las facultades de derecho es que aprendan el modelo, y que no se dejen llevar por la tentación de llamarlas clínicas sin comprometerse con el trabajo necesario para que verdaderamente funcionen como clínicas. Las clínicas deben aceptar el número de estudiantes que se puedan supervisar bien (Álvarez, 2005, p. 74).

- Presión de tener muchos estudiantes y pocos docentes clínicos. "Si hay demasiados estudiantes por clínica, no van a llevar los casos, o no van a recibir el apoyo que necesitan para aprender y hacer un buen trabajo" (Álvarez, 2005, p. 72).

- Carencia de recursos por parte de las universidades.

- "La otra tentación es ver la clínica como cualquier otra materia, que requiere la misma inversión de tiempo por parte del docente"; en la práctica sabemos que los docentes clínicos dedican mucho más tiempo a su trabajo, porque la supervisión implica trabajo personal altamente técnico y cuidadoso con los estudiantes (Álvarez, 2005, p. 72).

- Carencia de casos para la clínica. Es importante tener redes de referencia y alianzas con ONG.

- La contabilización de las horas en trabajo clínico y su equivalencia en créditos. En este tema coinciden los planteamientos de los docentes clínicos y los estudiantes.

- Falta de espacios de formación para docentes clínicos. "Los docentes de estas clínicas necesitan adquirir las destrezas de profesores de clínicas. Esto implica no solo las destrezas del abogado (entrevistar, planificar, asesorar, negociar y destrezas de oralidad) sino también las destrezas de cómo enseñar, incluyendo como hacer la retroalimentación".

- Trabajo común de los profesores de las diversas clínicas:

Primero, hay que buscar la manera de crear conexiones entre los profesores de las diferentes clínicas. De esta forma pueden aprender unos de otros [...]. Es importante también establecer relaciones con otros profesores de clínicas jurídicas en Centroamérica y Latinoamérica. También tienen que buscar la forma de aprender las destrezas 
necesarias para ser no solo un buen abogado, sino también un buen docente (Álvarez, 2005, p. 72).

- El reto de adaptar el modelo de clínicas a la realidad nacional y regional y el de crear capacidad interna para que pueda subsistir.

La opción que se elija en materia de fortalecimiento de competencias e institucional se encuentra ligada al modelo clínico por el cual se opta, es decir, si se trata de un modelo clínico de enseñanza aprendizaje con énfasis en investigación, o de las competencias referidas a la identificación y análisis de problemas, o de la utilización de técnicas de investigación, así como las de análisis crítico, lectura y escritura. Si el modelo opta por litigio estratégico, las competencias profesionales de observación, análisis de caso, atención de usuarios, participación en audiencias públicas, oratoria, escritura de documentos especializados, fortalezas en materia procesal, serán las definitivas. De igual forma se puede optar por un modelo clínico basado en aprendizaje-servicio y en este será necesario fortalecer competencias de relacionamiento con la comunidad y competencias pedagógicas. En cualquiera de los modelos se deben fortalecer competencias éticas y ciudadanas.

\section{Logros y dificultades de la educación legal clínica en América Latina}

Los docentes clínicos latinoamericanos tienen mucho que aportar y cada uno, en el campo de su trabajo, señala avances muy valiosos. En esta sección trataremos solo de sistematizar los aportes de las entrevistas logradas con los profesores.

\section{El posicionamiento académico, social y político de los temas de trabajo de las} clínicas

Es el primer avance común que encontramos. Veamos algunos casos.

Para la clínica de migrantes de la Universidad Diego Portales, lo más importante ha sido "lograr posicionarse como un referente en materia de atención clínica a inmigrantes y ser reconocida por los otros actores sociales del tema [...]. Es un referente para la comunidad de inmigrantes de Chile" (Olea, 2013). De igual forma el reconocimiento institucional es un avance que destacan los profesores: "lo más importante ha sido la estabilidad y el reconocimiento. Existe una ubicación, reconocimiento externo, difusión, un grupo 
de trabajo. La clínica es conocida por los estudiantes y por las organizaciones sociales que buscan sus servicios"(García Añón, 2013a).

Los resultados en materia de derechos humanos son de gran magnitud y cuando una clínica puede afirmar que gracias a su trabajo en coordinación con muchos actores, "se acabaron las expulsiones masivas de extranjeros en Argentina” o se logró "agua para 7 barrios de la localidad de Ciudad Bolívar en Bogotá - Colombia”, es necesario reconocer el gran potencial de este trabajo que en muchos países pasa desapercibido.

En relación con el posicionamiento jurídico, se destaca cómo a través del litigio en casos de violación de derechos humanos, derechos ambientales, sociales, colectivos y garantías constitucionales, se ha contribuido al fortalecimiento de una jurisprudencia latinoamericana y a la generación de precedentes en temas que jamás llegarían a los jueces o tribunales sin el ejercicio de las clínicas y las ONG.

Otra forma de actuación muy valiosa ha sido el lobby legislativo para impulsar normas que amplíen la protección de derechos humanos (como en el caso de la ley argentina de migrantes) y también la incidencia de los amicus curiae en el sistema interamericano de derechos humanos.

La incidencia o impacto público de las clínicas iberoamericanas, además del litigio en tribunales, se observa en aspectos como la producción de informes de derechos humanos, la elaboración y difusión de amicus curiae en casos de gran interés. Gracias a los medios de comunicación y las redes sociales, las clínicas logran llegar a un mayor número de personas necesitadas de protección y acompañamiento jurídico y crecen las peticiones de organizaciones de la sociedad e incluso de entidades públicas, como los ayuntamientos o alcaldías (Galiana Saura, 2013).

Incidencia legislativa en el surgimiento de nuevas normas que garanticen los derechos humanos o derechos de grupos de especial protección;

La incidencia en el futuro profesional de los estudiantes. De igual forma, reconocen los profesores la incidencia de las clínicas en el futuro profesional de los estudiantes que participan: "la clínica incide. Es la primera vez que se enfrentan ante supuestos reales. Los casos les exigen entrar en la vida práctica y asumir nuevas responsabilidades" (Galiana Saura, 2013).

Para la profesora Olea, la clínica es indudablemente "una buena experiencia según lo que las evaluaciones dicen y además les permite reencantarse con el derecho [...] en la experiencia del litigio estratégico los estudiantes 
descubren algo que les interesa mucho, parece que descubren las virtudes del trabajo profesional y del trabajo de casos y contrastan con lo que ven en teoría"(Olea, 2013).

Cambios en la docencia universitaria. En algunas universidades se ha logrado la inclusión de la clínica en la malla curricular y en ellas constituye un gran avance y permite mayor visibilidad y respeto por la educación legal clínica en las facultades de derecho, pero, independientemente de la inclusión curricular o no, se evidencian transformaciones en la docencia universitaria en muchas de las universidades que han iniciado experiencias de educación legal clínica.

Los docentes clínicos han promovido nuevas maestrías y doctorados al interior de sus universidades y generalmente están vinculados con propuestas de revistas y publicaciones que permiten continuar los debates e incorporar nuevas visiones de los problemas.

En otras clínicas, como la de la Universidad de Medellín, se considera un gran logro "la reflexión realizada sobre cómo hacer una metodología de investigación jurídica en materia ambiental, que sea novedosa y pueda ser replicada en otras universidades de la región" (Castro Buitrago, 2006).

La labor de educación legal clínica empieza a recibir reconocimientos. Por ejemplo la Clínica de la Universidad Rovira i Virgili, de Tarragona, recientemente recibió varios reconocimientos por medio de diferentes proyectos competitivos de innovación docente (2012PID-UB/031) y de divulgación de los resultados de la investigación (2012ACDC-0004) (Galiana Saura, 2013).

Impulso al trabajo en derechos humanos y surgimiento de nuevas clinicas. En el caso del cELs se destaca por su director "la existencia de un trabajo consolidado en derechos humanos y el impulso de nuevas clínicas temáticas y clínicas en las provincias de Argentina, especialmente las de Neuquen y Jujuy”.

Lentamente se avanza en la interdisciplinariedad porque los temas lo exigen. Ello es evidente en las clínicas ambientales, en las de migrantes y en las de discapacidad.

La renovación generacional. Las clínicas han permitido un relevo generacional en las universidades, muchas clínicas son verdaderas escuelas de nuevos docentes; al respecto Mariela Puga indica que: "las clínicas han sido un semillero de formación de profesores en América Latina. No se ha medido su impacto"(2012).

En la mayoría de las clínicas iberoamericanas, los mejores alumnos asumen luego roles de coordinación. Esto ha sucedido por ejemplo en el cELS, 
en la clínica cels-Caref, en la Clínica de la Universidad de Palermo, en la Universidad del Rosario, en la Universidad de Medellín, en la Universidad San Marcos, en la Universidad de Tarragona, entre muchos ejemplos que pueden mencionarse.

También se destaca que en algunas clínicas, como las de Valencia y la Universidad del Rosario, existen oNG integradas por exalumnos que continúan trabajando en derechos humanos.

La integración de docentes de diferentes áreas. Este logro se evidencia en la Universidad de Barcelona (Madrid, 2013). En esta universidad tienen una clínica constituida por docentes del área de derecho civil, pero trabajan todas las áreas. También existe esta integración de áreas en la Universidad de Valencia y los docentes apoyan como tutores los casos de su especialidad.

Estos equipos de docentes existen también en la Universidad Católica del Perú: "la clínica jurídica está organizada a partir de un equipo de profesores del Departamento de Derecho que son seleccionados en función de las especialidades que se deciden para el semestre"19.

Las alianzas para el manejo de los casos. Se observa una gran capacidad de interrelación y trabajo interinstitucional en la mayoría de las clínicas iberoamericanas. Este aprendizaje fortalece el ejercicio del litigio estratégico pero también otro tipo de actividades, como la difusión y la labor pedagógica. En algunos países las clínicas han desarrollado igualmente trabajo de capacitación a jueces, magistrados y servidores públicos.

En estas alianzas es muy fuerte el apoyo desde las ONG en su compromiso de continuar, aunque existan muchos obstáculos, por ejemplo en México: “el litigio de interés público se ha realizado por organizaciones de la sociedad civil, aunque tampoco hay mucho, cada vez más las organizaciones incorporan un componente de litigio estratégico" (Rodríguez, 2013).

Alianzas para proyectos de investigación. Un ejemplo interesante lo presentan las cuatro clínicas que hay en España, al formar parte de un proyecto de investigación en materia de migrantes.

Existe un debate interesante en relación con las alianzas norte-sur, planteado por el profesor Daniel Bonilla, ${ }^{20}$ quien reconoce importantes avances

\footnotetext{
$19 \mathrm{http} / / /$ facultad.pucp.edu.pe/derecho/index.php?option=com_content\&task=view\&id=419\&Ite mid=110\#.UUo0yBxhVJd

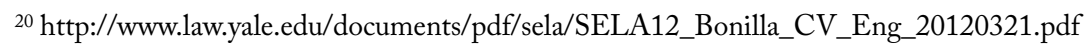


en materia de intercambios solidarios en búsqueda de solución de problemas de las comunidades más vulnerables, con servicios jurídicos de calidad y con alto impacto, sin embargo, estima que estos intercambios no deben reproducir sistemas verticales de relacionamiento centro-periferia, porque se desvirtúan los propósitos del trabajo en derechos humanos.

La constitución de la Red Latinoamericana de Clínicas Jurídicas. Para la mayoría de los profesores entrevistados, la Red Latinoamericana es uno de los mayores logros de las clínicas en la región, pero a su vez es uno de los retos a enfrentar.

El trabajo de Castro-Buitrago et ál., le da a este periodo la denominación de "segunda generación del movimiento por el derecho y el desarrollo" y se presenta la Red como uno de sus mayores logros (2013, p. 138).

Según relata González (2004, pp. 15 y ss.) la Red Sudamericana surge en el año 1997, en el marco de un proyecto piloto que coordinaba la Universidad Diego Portales. Inicialmente se circunscribió a Chile (Universidad Diego Portales, Universidad Católica de Temuco), Argentina (Universidad de Buenos Aires y Universidad de Palermo) y Perú (Pontificia Universidad Católica del Perú y Universidad de San Agustín, en Arequipa), pero luego ingresaron clínicas de México (ITAm y cide) y Colombia (Universidad del Rosario y Universidad de Los Andes).

El gran impulso de la Red fue dado por la Universidad Diego Portales en Chile y por el CELS-UBA en Argentina. Inicialmente se integran a la Red facultades de Chile, Argentina, Perú y Colombia; luego crece el grupo de países integrantes.

El tema central de esta red ha sido el derecho de interés público. "Así las clínicas jurídicas de interés público comenzaron a operar bajo la lógica del litigio estratégico, tratando de conectar las facultades de derecho con las cuestiones sociales y los nuevos desafíos dogmáticos de la teoría del derecho" (Castro Buitrago, 2006, p. 139).

Un elemento fundamental a destacar han sido los encuentros internacionales:

En este proceso de estructuración de las clínicas de interés público también han jugado un papel significativo las instancias de encuentro. Así, durante el primer lustro de funcionamiento de la Red se efectuaron anualmente dos encuentros de clínicas de interés público por 


\begin{abstract}
país, además de un Seminario y Encuentro Internacional de clínicas anual. El primer encuentro nacional en cada país estuvo dedicado en una proporción importante a discutir aspectos organizacionales y de formas de trabajo de las clínicas. Luego estos encuentros estuvieron dedicados de manera preferente a la presentación de casos por los propios alumnos, discutiéndose el interés público envuelto en ellos y las estrategias jurídicas y comunicacionales (para producir un impacto público), sin perjuicio de que, con ocasión de dichos encuentros, se hayan realizado también foros de discusión, presentaciones de especialistas y hasta lanzamientos de publicaciones de la Red (Castro Buitrago, 206, p. 140).
\end{abstract}

Se trata de oportunidades de aprendizaje, debate y aporte a casos en construcción y análisis de avances investigativos sobre los temas de la educación legal clínica y el litigio estratégico.

Se reconocen avances con los encuentros de la Red, en especial el realizado en 2005 en Chile y luego en Tucumán, Argentina. Luego la reunión de México en 2007 con participación de clínicas del continente, incluyendo algunas de Estados Unidos. En 2008, la Universidad Torcuato di Tella citó a una reunión de la Red en Argentina buscando colaboración en litigios internacionales ante la Corte Interamericana. En 2009 se realizó en Colombia la reunión de la Red y fue convocada por las Universidades de Los Andes, Sergio Arboleda y Rosario, en Bogotá, y en 2014 se convocó nuevamente en Colombia, en la Universidad del Rosario, con el objetivo de fortalecer la red a través de una declaración conjunta (ver anexo 3) y la constitución de una secretaría técnica elegida en forma democrática e integrada por el cels (Argentina), la Universidad Diego Portales (Chile), El iтам (México), la Universidad de Medellín y la Universidad del Rosario (Colombia). En dicho encuentro se reafirmaron sus objetivos y aportes:

El objetivo de esta red es fortalecer la enseñanza clínica y a través de este instrumento intervenir en la defensa del interés público y los derechos humanos mediante el litigio estratégico como herramienta. La Red ha generado cambios significativos en la docencia e investigación jurídica en América Latina y su integración garantiza la participación de docentes y estudiantes en la propuesta, desarrollo 
y evaluación de las causas de interés público que adelanta (Clínicas Jurídicas, 2013).

Las clínicas pertenecientes a esta red se han caracterizado porque: (i) su eje de trabajo lo constituyen el interés público, la justicia social y el respeto por los derechos humanos; (ii) la búsqueda de cambio social estructural a través del litigio estratégico y el activismo legal; (iii) proyectos conjuntos que relacionan a las universidades con organizaciones de la sociedad civil, y (iv) su creatividad en el desarrollo de propuestas de intervención judicial.

En el marco de la Red han surgido muchas clínicas en la región, y se promueven casos y aprendizajes conjuntos. De igual forma se realizó una labor de formación práctica de docentes y en algunos encuentros, como el de Tucumán, se trabajaron temas centrales, como el de los desafíos de la supervisión al interior de las clínicas. Otros aspectos centrales de la Red han sido el relacionamiento, la mirada regional de los problemas, los aportes de los docentes y el espacio compartido con los estudiantes de las clínicas, donde en cada encuentro se presentaban los mejores casos y se debatían estrategias, logros y dificultades.

\section{Las dificultades en la educación legal clínica iberoamericana}

Frente al reto de iniciar y fortalecer propuestas de educación legal clínica, son muchos los obstáculos que han tenido que enfrentar las clínicas iberoamericanas; los principales problemas que se evidencian de las entrevistas y las encuestas realizadas son los siguientes.

\section{Dificultades en la sostenibilidad de las clinicas}

Muchos obstáculos que impiden la sostenibilidad de las clínicas, por ejemplo, la carencia de recursos, carencia de docentes clínicos, exigencia de recibir un alto número de estudiantes, cuando este método tiene unos límites en el número de participantes por curso, además, como lo sostiene Grandez, "El tema de clínicas jurídicas exige un presupuesto, demanda más tiempo, más responsabilidades de más personas, más horas del profesor de curso" (2013).

Los docentes clínicos iberoamericanos hacen mucho énfasis en la necesidad de que se reconozcan las horas de clínica como trabajo de docencia directa. Es muy baja la dedicación en horas al trabajo clínico y en pocas universidades hay reconocimiento de dicha actividad en el plan de trabajo. Los profesores 
clínicos son externos y dada la labor que desarrollan, las universidades deberían repensar esta categoría e incluirlos en sus estatutos profesorales o en su planta en forma permanente. Además, en muchas universidades existe un abismo generacional y de pensamiento pedagógico entre los docentes clínicos y los demás profesores.

El trabajo de educación legal clínica exige espacios adecuados, salones de reunión donde se trabaje en forma horizontal y se disponga de ayudas audiovisuales. De igual forma se requiere de espacio adecuado para la atención de usuarios.

Otro de los problemas tiene que ver con el escaso reconocimiento por el trabajo clínico. Los programas de derecho deben repensar su papel en la enseñanza y en la práctica profesional. Una estrategia interesante por medio de la cual se han logrado recursos en algunas clínicas ha sido la de participar en las convocatorias de innovación docente. La Universidad de Barcelona y la de Tarragona han logrado recursos de apoyo a sus clínicas por esta vía.

No solo existen dificultades internas para iniciar procesos de educación legal clínica, sino para mantenerlos en el tiempo. Hemos visto cómo han desaparecido varias clínicas jurídicas en países como México, Argentina y Colombia, entre otras razones por "la reticencia desde las universidades a establecer clínicas de derechos humanos, por las cuestiones políticas e ideológicas que temen enfrentar" (Rodríguez, 2013).

También se señala como un problema grave la carencia de espacios de debate y formación sobre los nuevos paradigmas en la enseñanza y ejercicio del derecho. Se carece igualmente de publicaciones, sitios web y otros medios que permitan formar nuevos docentes clínicos y supervisores en las clínicas (González Morales, 2013).

Son pocas las clínicas que tienen una ubicación organizacional clara como departamento o similares. En su mayoría dependen de las decanaturas como proyectos especiales o de los consultorios jurídicos o servicios de asistencia social. Un intento muy interesante que han logrado clínicas como la de Valencia es convertir la clínica en un espacio de apoyo trasversal de las diversas áreas académicas de la facultad.

No hay tampoco recursos suficientes para la participación en redes de clínicas. Este elemento es vital, porque las redes son espacios de aprendizaje e interacción vitales. 
En países como España y Argentina, se considera un obstáculo la presión que ejercen los colegios de abogados para que no se constituyan nuevas clínicas. De igual forma existen trabas en los ayuntamientos para dar información, especialmente en el tema de licencias ambientales y urbanísticas.

Otra dificultad frecuente se relaciona con el manejo de los casos de las clínicas y su impacto en términos políticos y mediáticos. Las clínicas se acabaron, no porque no fueran buenas clínicas, sino por decisiones de las rectorías.

En varios trabajos se ha señalado como un grave problema la falta de visibilidad de las clínicas y de su propuesta pedagógica. Esta característica ha sido estudiada en trabajos como el de Puga (2012). Se concluye en ellos que esta es una de las debilidades en la gran mayoría de las clínicas iberoamericanas. En muchas ocasiones la búsqueda de las clínicas por internet es imposible, no hay resultados; en otras solo se llega a un breve párrafo genérico sin información sustancial. Las universidades no han dimensionado la importancia de una verdadera estrategia de medios y redes sociales para visibilidad las clínicas.

\section{Dificultades externas}

Para las clínicas es de gran importancia su relación con el medio y su incidencia externa. Como dificultades al respecto se señalan las siguientes:

- El trabajo realizado no se perfila en muchos casos como generador de jurisprudencia. Las clínicas tienen dificultades para lograr incidencia jurídica y judicial.

- Otro problema que se presenta es la manipulación de la información por parte de los medios de comunicación en casos de interés público. Se desvirtúa o minimiza el resultado del trabajo. En algunos casos, incluso, se ataca el proceso de formación en las clínicas y su enorme valor.

- En España y Argentina se presentan problemas con los colegios de abogados, los cuales alegan que el asesoramiento gratuito es ilegal y genera competencia desleal de las clínicas con los bufetes de abogados. Este desconocimiento de la educación legal clínica requiere de intervención urgente, especialmente desde las instancias administrativas y de autorregulación de la profesión. Igualmente las fundaciones pro bono en cada país deberían buscar cambios urgentes y trabajo de apoyo y no de ataque a las clínicas (Puga, 2012). 
- En algunos países se evidencian problemas para la inserción laboral de los estudiantes egresados a pesar de sus conocimientos en el tema de la clínica.

- La carencia de recursos financieros ha afectado especialmente a las oNG que apoyan a las universidades en educación legal clínica. Hay pocos recursos, los fondos son cada vez más reducidos e implican redefiniciones.

En el caso chileno, se plantean las siguientes críticas a la labor de las clínicas jurídicas:

Pocos de estos programas han sido capaces de alejarse de las principales características de la cultura jurídica chilena: principalmente positivista respecto a las fuentes del derecho, en la interpretación formalista de dichas fuentes, y legalista en su comprensión de la función del papel que el ordenamiento desempeña en el desarrollo de la vida colectiva [...]. De igual forma se estima que las clínicas jurídicas han permanecido al margen del proceso de transformación de la cultura y la educación jurídica chilena (Castro-Buitrago, 2013, p. 147).

En relación con Argentina, se señala que: "las facultades públicas de derecho, que tienden a tener más prestigio que las facultades de derecho privadas en Argentina, han sido especialmente reacias a implementar innovaciones curriculares, en particular respecto de los nuevos métodos pedagógicos en la enseñanza del derecho" (Castro-Buitrago, 2013, p. 140). Esta constatación se puede generalizar a América Latina. Sin embargo, en el caso de España y Perú, las universidades públicas son ahora las protagonistas.

Para finalizar se pueden señalar otros problemas en las clínicas en Iberoamérica, como los siguientes: (i) se centran en trabajo interno, doméstico o nacional; (ii) no se ha desarrollado una agenda regional de trabajo para las clínicas; (iii) falta repensar el papel de las clínicas en la enseñanza y en la práctica profesional; (iv) son escasos los esfuerzos de documentación de las experiencias pedagógicas y de litigio de las clínicas, aunque ya se empieza a tener alguna bibliografía; (v) no hay continuidad en el fortalecimiento de las redes y, finalmente, (vi) la incidencia en la reforma educativa es muy baja y a veces inexistente (Castro-Buitrago, 2013, p. 139). 


\section{Posibilidades de ejercicio del litigio estratégico desde las clínicas jurídicas en Iberoamérica}

\section{A. Evolución del concepto de litigio estratégico y algunas reflexiones sobre su relación directa con el activismo judicial}

En esta sección se presenta una aproximación al concepto de litigio estratégico que los docentes clínicos entrevistados señalaron, complementando esta visión con una revisión bibliográfica que se contrasta con la realidad en el ejercicio del trabajo clínico.

Es en Estados Unidos, en los años setenta, cuando los autores Abram Chayes, Lon Fuller y Owen Fiss desarrollan este concepto.

Chayes lo denominó litigio público en 1976. Para él lo decisivo eran las decisiones sobre derecho público. El énfasis de este litigio estaba relacionado directamente con las políticas de bienestar y los desafíos que implican para el juez. Según este autor, el rol judicial se dirige ante todo a clarificar el significado de la legislación relevante, antes que a los hechos del caso.

Fuller desarrolló el concepto de conflictos policéntricos, y Fiss, por su parte, habló de reforma pública o reforma estructural. El objetivo de este litigio era reformar instituciones donde se vulneraban derechos, como las prisiones, las escuelas o los hospitales para personas con discapacidad (Puga, 2013, p. 128).

Se proponen siete elementos del litigio estructural, a saber: (i) la intervención de múltiples actores procesales, (ii) un colectivo de afectados que no intervienen en el proceso, (iii) una causa fuente que determina la violación de derechos humanos a escala, (iv) una organización estatal, social o burocrática que funciona como el marco de la situación o la condición social que viola derechos; (v) la invocación o vindicación de valores de carácter constitucional o público con propósitos regulatorios a nivel general, o demandas de derechos económicos, sociales y culturales; (vi) pretensiones que involucran la redistri- 
bución de bienes y (vii) una sentencia que supone un conjunto de órdenes de implementación continua y prolongada (Puga, 2013, pp. 15-16).

La siguiente figura resume los elementos propuestos:

Una causa fuente que determina la violación de derechos humanos a escala.

Una organización estatal, social o burocrática que funciona como el marco de la situación a la condición social que viola derechos.
Un colectivo de afectados que no intervienen en el proceso.

La invocación de valores de carácter constitucional a pública con propósitos regulatorios a nivel general, y/o demandas de derechos económicos, sociales, culturales y/o colectivos.
La intervención de múltiples actores procesales a casos testigo.

Pretensiones que involucran la redistribución de bienes y ajustes estructurales para la protección de los derechos en disputa.
Una sentencia que supone un conjunto de órdenes de implementación continua y prolongada.

Figura 4. Elementos del litigio estratégico

Fuente: elaboración propia con base en Puga (2013, pp. 15-16).

En relación con el primer elemento se considera que es propio de los litigios estructurales basados en acciones colectivas, donde los intereses de esos actores están ligados a un interés común, colectivo o grupal (unidad de interés): "lo que define a la litis estructural es la imbricación de intereses particulares en una relación compleja, pero única" (p.18). Los casos policéntricos y no bipolares (Fuller, 1978) son los que caracterizan al litigio estructural y colectivo. Dichos casos se asocian con varias imágenes, la idea de una telaraña (red) y la idea de un puente (pretensión colectiva), donde las vigas son las pretensiones individuales. En este litigio se tiene en cuenta que el impacto del caso transciende los intereses de los actores procesales, y los intereses individuales forman parte de un sistema interconectado de relaciones múltiples (Puga, 2013, p. 21). 
Para el análisis del segundo y tercer elemento se debe tener en cuenta que el “'interés colectivo', o el 'todo' que precede a las 'partes', no es otra cosa que una imbricación de intereses (activos o pasivos) que empieza a definirse como tal a partir de la validación de la representación procesal, es decir, a partir del momento en que se reconoce la legitimación activa" (Puga, 2013, p. 25).

La decisión final en un litigio estructural debe considerar los impactos que tendrá en los que no estuvieron presentes en el caso pero que están relacionados con el mismo.

En relación con la cuarta exigencia, aunque la profesora Puga la desestima, consideramos que es importante y la complementamos incluyendo la categoría de una organización social, porque no siempre los demandados serán entidades estatales. En el análisis del litigio en casos colectivos que se ha desarrollado en Colombia en los últimos 15 años, se observa que la mayoría de estas acciones se dirigen frente a entidades estatales o particulares que cumplen función pública.

En relación con la quinta exigencia, ampliamos el marco de derechos incluyendo los económicos, sociales, culturales o colectivos, ya que en América Latina ha sido muy importante el tema de la justiciabilidad de estos derechos y se han realizado muchos logros a través del litigio estratégico.

Se trata de resaltar la importancia de la reivindicación de valores públicos en el litigio estratégico. En estos procesos es clave la llamada causalidad estructural (relación entre hechos y consecuencias) o causalidad social. Puga prefiere la denominación causalidad estructural. "los jueces suelen reconocer como causa fuente de la violación de derechos a, por ejemplo, una regla jurídica, una política institucional compuesta de múltiples prácticas, y/o a una condición o situación social" (Puga, 2013, p. 28).

Los ejes articuladores del litigio estratégico corresponden a las exigencias seis y siete de nuestra figura. Son las pretensiones las que muestran nuevos derroteros y necesidades de protección. Las pretensiones regulativas deben ser amplias y superar el simple caso individual; en muchas ocasiones exigen un trabajo interdisciplinario o de profesionales de diversas áreas del derecho. Su éxito radica en mostrarle derroteros al fallador, pasar de las tradicionales pretensiones de tipo declarativo a una propuesta clara de solución de problemáticas de derechos humanos, incluyendo las medidas a tomar, las autoridades o particulares vinculados y que harán seguimiento de la decisión, los 
recursos necesarios para la ejecución de esas órdenes y los tiempos para su cumplimiento.

El papel de los jueces es fundamental para el logro de las sentencias estructurales, la efectividad regulativa de estas decisiones no depende solamente de que se cumpla una regla particular sino de la pretensión regulativa que el juez señala, ya que los jueces en los casos de litigio estratégico "reconstruyen la litis" y la eficacia de su decisión se mide no solo por las órdenes, sino por su implementación (Puga, 2013, pp. 141 y 186).

En estas decisiones se rompen las fronteras entre el derecho público y el derecho privado, se superan paradigmas procesales como el del principio dispositivo (monopolio procesal de las partes), el de congruencia (la sentencia debe limitarse a lo probado y peticionado por las partes) y el inter aleas (restricción de los efectos de la sentencia a las partes).

La pretensión regulativa estructural busca controlar las conductas por fuera de los sujetos procesales, ir más allá. Si los actores no obedecen estarán incumpliendo la orden regulativa estructural.

En Iberoamérica podemos encontrar dos tipos de casos de litigio estructural. Los primeros son aquellos que adoptan reglas procesales colectivas y sus resultados se extienden más allá de las partes procesales. El segundo tipo de casos son los denominados casos testigo. En ellos se parte de casos individuales y se adoptan reglas individuales:

De ellos se espera, por razones tácticas, la función de disparadores de impactos regulativos-distributivos generales. Empero, también en estos casos, el éxito de su estrategia muestra bemoles importantes, sobre los que es necesario detener la atención. El agravio causado no se presenta como un hecho individual que hace inconstitucional a determinada ley, sino como una situación, una práctica o una condición que afecta o afectaría a muchos otros/as de manera similar. Si los jueces dan cuenta de ello al definir la litis, es decir, si el relato postula una situación policéntrica como base de la formulación argumental, se instaura un caso estructural (Puga, 2013, p. 201).

Desde los inicios del movimiento de clínicas de interés público, la noción de litigio estratégico ha sido medular. No se conciben las clínicas latinoamericanas sin este componente que siempre han estimado de su esencia. 
Se concluye de los análisis previos que la concepción de litigio estructural en América Latina supera las limitaciones impuestas por la doctrina norteamericana y se abre a concepciones de lo público que no son necesariamente estatales (Puga, 2013, p. 181).

La noción se asocia a la búsqueda y trabajo en casos emblemáticos. En este sentido la profesora Elena Olea manifiesta que: "son todos aquellos casos que pueden ser emblemáticos desde una práctica o una situación y por lo tanto el trabajo genera mayores repercusiones, ayudan a abrir discusiones, proponer reformas legislativas o participar en políticas públicas entre otras acciones. Para desarrollarlo se requiere de autonomía y respaldo institucional" (Olea, 2014).

En este concepto se distinguen aspectos muy valiosos:

a) Casos emblemáticos o casos testigo. Esta propuesta es muy frecuente en las clínicas iberoamericanas. Con estos casos se busca generar cambios jurisprudenciales o normativos y se intenta además hacer pedagogía y trabajo en medios para promover los derechos humanos. Son casos simbólicos, los mejores ejemplos de defensa y protección de derechos.

Se trata de casos cuidadosamente seleccionados y que "cuestionan el contenido, orientación o forma de implementación de una política estatal a la luz de estándares constitucionales o legales. Someter a la consideración de los tribunales los conflictos que están ausentes de la agenda de los poderes políticos es un modo de insertarlos en la discusión pública y otorgarles visibilidad" (Morales, 2008).

Una discusión interesante sobre este primer aspecto tiene que ver con el apoyo de los medios de comunicación para divulgar los casos y, a través de ellos, dar a conocer los resultados del litigio estratégico. Es una herramienta de enorme valor que aún se utiliza poco por las clínicas iberoamericanas. En el estudio realizado por Mariela Puga (2012) y en la labor de búsqueda de información en internet que se elaboró en nuestra investigación, se observa cómo las clínicas en general carecen de páginas de divulgación completas y que identifiquen su trabajo.

b) Las repercusiones o impactos de estos casos. Es uno de los temas más interesantes del trabajo clínico. No existe un sistema que permita medir los impactos de un caso, pero sí hay indicadores para valorarlo como caso emblemático. Podríamos mencionar inicialmente una tipología de impactos que uno podría examinar al finalizar un ejercicio de esta naturaleza: 
- Impactos jurídicos: para evidenciarlos deberíamos preguntarnos: ¿se cambió un precedente? ¿Se generó una nueva tendencia jurisprudencial? ¿Se incidió en el legislador para un cambio normativo? ¿Se logró un nueva interpretación normativa? ¿Se contribuyó a la construcción de una política pública a través del caso o la incidencia de la clínica? ¿Se promovieron derechos que carecían de garantía? Medir los avances jurídicos no implica siempre tener resultados exitosos en el litigio, así como lo señala el lema del cels: "no se trata de ganar casos, sino de efectivizar derechos" (Baladrón, 2013, p. 26). En ocasiones, el objetivo puede ser generar o abrir un debate que jamás habría llegado a los tribunales o jueces si no fuese por el trabajo de la clínica.

- Impactos socio-políticos: nos podríamos preguntar: a partir del trabajo en el caso, ¿`se fortalecieron las organizaciones sociales que lo promovían? ¿Se realizó capacitación y formación jurídica a las comunidades para empoderarlos frente a su caso? ¿Las comunidades u organizaciones han asumido directamente su lucha jurídica, política o social y ya no requieren o requieren poco de nuestro apoyo especializado? ¿Se legitimó con este caso la labor de la clínica? ¿Existe un reconocimiento social del trabajo realizado? ¿Han llegado nuevos grupos sociales o comunidades a solicitar servicios porque conocieron del trabajo de la clínica en ese caso? Este es uno de los criterios más importantes para la selección de los casos:

La elección de los casos ha estado siempre vinculada a la posibilidad de que el litigio que se emprende sea también una iniciativa del grupo social que lo demanda, porque allí radica la apuesta de que los derechos se expandan y se aseguren en la arena política democrática. De no ser así, solo contarían como pequeñas batallas ganadas en el estrecho círculo de los juristas académicos (Morales, 2008).

Como criterios para la selección de casos en las clínicas de interés público, al interior de la Red Latinoamericana se han propuesto los siguientes, donde al menos debe existir uno: 
- Que el interés público aparezca con nitidez en el caso, de manera que la Clínica respectiva no se vea en la necesidad de tomar partido entre intereses privados igualmente legítimos;

- Que se trate de casos paradigmáticos, que puedan servir de modelo para el desarrollo de otros casos y para fortalecer la jurisprudencia;

- Que sea posible detectar en el caso defectos estructurales del orden legal interno, de manera de promover, a través de la acción jurídica, cambios o sustituciones en él;

- Que sea previsible que el caso pueda producir un impacto público significativo.

- Que exista la posibilidad de usar los instrumentos internacionales de protección de los derechos humanos.

- Que exista un compromiso institucional con las defensas asumidas.

- Que el caso sea plausible, en el sentido que pueda concebirse como un caso "jurídico"y que su tramitación judicial tenga cierta viabilidad (González Morales, 2004, p. 20).

- Impactos pedagógicos: convendría mirar si: ¿los estudiantes que participaron en el caso reconocen su proceso de aprendizaje en el mismo?, ¿el grupo de estudiantes de la clínica valora el caso como un reto que se asumió desde lo académico, lo social y lo político?, ¿en el entorno universitario de la clínica se ha reconocido y difundido el caso?

c) Las condiciones institucionales para realizar litigio estratégico: la profesora Olea (2013) señala dos exigencias centrales: autonomía y respaldo institucional. Cuando una clínica opta por la realización de litigio estratégico, se necesitan canales de comunicación claros y directos con la institución a la que pertenece, espacios de debate institucional para presentar los casos que impliquen tocar intereses políticos, económicos o sociales, que sean sensibles para las universidades. De igual forma se requiere de autonomía y confianza mutua entre la coordinación de la clínica y las directivas universitarias. El entorno de una clínica es vital para el logro de sus objetivos. 
Otra tendencia en torno al concepto se ha asociado a la posibilidad de generar cambios estructurales. Al respecto, Grandez manifiesta que: "litigio estratégico es litigio estructural. No atender a casos particulares sino a estructuras. Vulneración de derechos fundamentales. Casos a un gran grupo de personas, grupos vulnerables"(2013).

En un primer momento se centraba en litigio ante tribunales, pero en muchos de los países latinoamericanos se han dado cambios que permiten trabajo directo con las instituciones administrativas, buscando ante todo la prevención o la aplicación de procedimientos administrativos en tiempos más cortos y con mayor eficacia, como en el caso de Perú.

Un debate que igualmente surge se orienta al cuestionamiento sobre el cumplimiento de las decisiones judiciales, luego de largos y desgastantes procesos litigiosos. Existe una tendencia grave al incumplimiento y esto deslegitima la opción judicial en muchas ocasiones.

Existen además nuevos espacios para el litigio estratégico, como el uso del amicus y la participación en investigaciones e informes de alto impacto social, como veremos más adelante.

Finalmente, hay una posición crítica que plantea la necesidad de una redefinición del concepto. $\mathrm{Al}$ respecto, Diego Morales afirma que:

Los cambios estructurales no se logran con acciones, se precisa del acompañamiento de las organizaciones y es necesario entender, reflexionar e investigar; el concepto está hoy basado en la incidencia y cada vez menos en el litigio judicial. Se realiza en mayor medida una búsqueda de los problemas de fondo.

El litigio estratégico implica la necesidad de que las ong y la universidades trasciendan ciertas circunstancias y trabajen en temas de verdad y justicia, en realidad se trata de promover “juicios", no solo ante los jueces sino ante diversas instituciones. "Se trata de recuperar la reflexión de los primeros tiempos”, trascender y compartir desde el ámbito de las organizaciones y desde el ámbito académico. Las clínicas implican un proyecto académico y un proyecto de investigación" (Morales, 2012).

Finalmente para el profesor González Morales, fundador de la Red Iberoamericana de Clínicas, el litigio estratégico “[...] quedó arraigado a una 
noción de lenguaje, más que a un asunto práctico; es decir no es tenido en cuenta en el trabajo realizado por la clínicas"(2013).

\section{B. ONG, universidades e instituciones estatales de derechos humanos: alianzas estratégicas}

En el tema de las alianzas estratégicas se pueden evidenciar grandes aprendizajes de las clínicas iberoamericanas. En las entrevistas y búsquedas directas de información, se encuentra la siguiente tipología de relaciones que es de enorme valor para el trabajo clínico.

\section{Relación con ONG}

Como hemos visto, existe un modelo de clínicas donde la relación con las ONG es sustancial y constitutiva. Se trata del denominado modelo argentino de clínicas. Allí, los abogados e integrantes de la ONG son docentes, los estudiantes participan de las discusiones y agendas de la ONG, se apoyan mutuamente en los casos y propuestas de trabajo clínico. Las universidades solo aportan el grupo de estudiantes para la clínica, como espacio de práctica jurídica.

En las clínicas universitarias, la relación puede ser de apoyo, asesoría, colaboración. Se observan muy claramente las alianzas en las clínicas temáticas, donde siempre se requiere de un trabajo interinstitucional. Ejemplos de estas alianzas los podemos observar a continuación:

La Clínica de Migrantes de la Universidad Diego Portales, en Chile, tiene alianzas con el instituto católico de migraciones, las organizaciones más importantes de la sociedad civil, la iglesia católica, el Instituto Católico Chileno de Migraciones (Incami), el Servicio Jesuita para las Migraciones, entre otras organizaciones. La profesora Olea destaca que: "desde hace tiempo atendemos público en las instalaciones de ellos, nos facilitan las instalaciones, nos derivan casos, nos dan apoyo con asistentes sociales y triangulamos este servicios con ellos" (Olea, 2013).

De igual forma en la clínica del cels-Caref, se destaca el aporte de las alianzas en defensa de los migrantes a través de consorcios de ong y mesas de trabajo; su gran aporte fue integrar diversos saberes y consolidar fuerzas para constituir un bloque de incidencia jurídica y social. El apoyo de los investigadores de la universidad y de las ong les permitió una participación destacada y estratégica (Asa, 2012). 
La Clínica de la Universidad Alberto Hurtado considera de gran importancia su relación con una ONG llamada Moviliza:

\begin{abstract}
Nuestros patrocinados son gente que vive en situación de calle, es decir de una muy alta vulnerabilidad y casi nulo acceso a la justicia. En este contexto, y en virtud de un acuerdo de colaboración, la Facultad de Derecho, a través de su Clínica Jurídica, presta asesoría jurídica al grupo de personas que son beneficiarios de los programas de Moviliza. ${ }^{21}$
\end{abstract}

Un aspecto importante en la relación de las clínicas con las ong hace referencia a la búsqueda y selección de casos. El profesor Hernán Gullco de la Universidad Torcuato di Tella, señala que "para la selección de casos se tiene una relación directa con la ADC, acción por los derechos civiles. Los casos de la ADC se presentan a los estudiantes. También los defensores oficiales les remiten casos" (2012).

La Universidad del Litoral señala en su página web las siguientes alianzas: Instituto Nacional contra la Discriminación, la Xenofobia y el Racismo (Inadi), Santa Fe, Asociación de Promoción y Defensa del Consumidor y del Usuario del Litoral (Aprodecon), Unión de Entidades de y para Discapacitados de la Provincia de Santa Fe y Centro de Protección a la Naturaleza. Muchas de estas alianzas tienen que ver con los casos que tramita la clínica.

La clínica jurídica de acceso a la información en la Universidad de $\mathrm{Pa}$ lermo actúa con el apoyo de Open Society Institute (osI) y conjuntamente con las asociaciones por los derechos civiles (ADC).

Las alianzas son igualmente una de las grandes fortalezas de las clínicas en España. En el caso de las clínicas del Máster en Derechos Humanos de la Universidad Carlos III de Madrid, se reconocen socios estratégicos como el Observatorio de Derechos Humanos ody y la Asociación Pro Derechos Humanos (APDH). En temas de discapacidad tiene socios como el Comité Español Representante de Personas con Discapacidad, Cermi, el Movimiento de Vida Independiente, Solidaridad Comunitaria de las Personas con Diversidad Funcional (Solcom) y, para los casos de vir/sida, tiene alianza con la Coordinación Estatal del vıн-Sida (Cesida).

\footnotetext{
${ }^{21} \mathrm{http}: / /$ derecho.uahurtado.cl/clinica-juridica/consultorio-moviliza/
} 
En la Clínica por la Justicia Social de España, se tienen convenios con organizaciones en temas de discapacidad como Cermi, y con otras organizaciones como Cesida, la Asociación de Víctimas del Metro, la Plataforma de Auditoria por la Deuda Pública, Vecinos del Cabañal, Plataforma por el Cierre de Internamiento de Extranjeros, Amnistía Internacional, Comisión Española de Ayuda al Refugiado (CEAR), la Fundación Síndrome de Down (Acindown), Open Society, Asociación de Afectados por la Hipoteca, entre otros (García Añón, 2013a).

En la Universidad de Barcelona se tienen convenios con 65 entidades, en el tema de derecho a la vivienda; llegan además multitud de consultas derivadas de plataformas. Tienen trabajo con entidades sociales, en su gran mayoría Caritas, convenios de colaboración con colegios de abogados, administraciones públicas, despachos profesionales y empresas. Los convenios deben cumplir con dos exigencias u objetivos: mejorar la formación a los estudiantes y mejorar el acceso a los derechos.

En el Perú, la Clínica de la Universidad de San Marcos se encuentra vinculada a algunas redes y ha recibido apoyo de Open Society y de la red del banco mundial en justicia y desarrollo.

Existen clínicas donde se resaltan los convenios internacionales. La Clínica de Derecho Ambiental de la Universidad de Medellín tiene convenios con la Universidad Central de Santiago de Chile; ambas clínicas realizan colaboración académica en proyectos conjuntos de investigación y fortalecimiento de la enseñanza clínica. Comprende además el intercambio de estudiantes y docentes de clínicas jurídicas.

En el 2013 finalizaron la ejecución del proyecto "Enseñanza clínica del derecho: metodologías, experiencias innovadoras y buenas prácticas. Un modelo aplicable en Chile, Argentina y en Colombia", con investigadores de tres universidades (Medellín, Central de Chile y Universidad de Córdoba).

En México se destacan las alianzas logradas por la Clínica contra la Trata de Personas, del ITAM, aspecto que le permite el acceso a los casos y su trámite conjunto. Actualmente colaboran activamente con las organizaciones Fundación Reintegra, Pozo de Vida y Camino a Casa, de corte cristiano, y con la Coalición Latinoamericana contra el Tráfico de Niñas y Mujeres (Catwlac) y el Colectivo contra la Trata de Personas Ac, de orientación feminista (Pérez, 2014). 


\section{Redes de clínicas jurídicas}

En relación con la pertenencia a redes, la mayoría de las clínicas latinoamericanas reconocen su pertenencia a la Red Latinoamericana de Clínicas y a GAJE. Las clínicas colombianas pertenecen a la Red Colombiana de Clínicas Jurídicas, formada en el 2009 en Bogotá.

En el caso de la Red Iberoamericana de Clínicas de Interés Público, Diego Morales considera que: "este valor se daba por los espacios de reflexión jurídica de los alumnos y los profesores. Luego nos quedamos más en el relato y la información y se perdió la profundidad del análisis. Sería importante retomar nuevamente el encuentro de la Red como espacio de reflexión profunda" (2012).

Para Pablo Asa: "lo valioso de las redes es profundizar en las experiencias, compartir por ejemplo formas de trabajo, formas de evaluarlo etc. Se propone hacer algo parecido. Pensar estrategias más articuladas, cosas más compartidas" (2012).

Mariela Puga (2012) indica que "la red de clínicas ha sido parte de la vida de la mayoría de las clínicas latinoamericanas. Los momentos más destacados fueron los encuentros de Chile y Tucumán”. Como grandes aportes destacan: (i) conocimiento de las experiencias de otras clínicas; (ii) formación de profesores y estudiantes; (iii) permear el discurso público hacia los derechos humanos; (iv) mirada compleja y sistémica en los casos y (v) incidencia en los estudiantes.

Actualmente considera que la Red tiene problemas porque faltó discusión sobre pedagogía clínica, de igual forma faltó definir una agenda prioritaria y mirar propuestas frente a las limitaciones normativas en muchos países latinoamericanos. A manera de ejemplo hace referencia a los temas de legitimación por activa en el caso de la provincia de Córdoba, donde el Defensor del Pueblo no puede litigar. Otro tema que debería profundizarse a nivel latinoamericano es el de los amparos colectivos.

Como propuestas, la profesora Mariela señala la necesidad de darle continuidad a la agenda de Tucumán; buscar apoyo para becas de doctorado en temas de interés público y apoyo a los profesores en su proceso de formación.

Otros aportes en relación con el trabajo en redes reconocen que: "la Red debe capacitar a los capacitadores. Hacer mesas cerradas sobre problemas concretos en el litigio. Lograr consensos, coaliciones" (Picolotti, 2012). El profesor Gullco considera importante realizar reuniones temáticas de la Red 
y el profesor Nino de la Universidad de Palermo, indica que en la Red Latinoamericana de Clínicas falta "quién tome la posta"(Nino, 2012).

Las clínicas temáticas como PAIIs tienen mayores opciones de pertenencia a Redes, como la Red Iberoamericana de Expertos en la Convención de Naciones Unidas sobre los Derechos de las Personas con Discapacidad, la Red Latinoamericana de Organizaciones No Gubernamentales de Personas con Discapacidad y sus Familias (Riadis) e Ida Institute.

Todos estos aportes empiezan a ser revisados por la nueva Secretaría Técnica de la Red Latinoamericana de Clínicas Jurídicas y serán un insumo valioso para generar cambios y nuevas propuestas. En la declaración firmada en Bogotá en junio de 2014 se da un nuevo impulso a esta Red y se renuevan sus principios de acción en defensa del interés público y los derechos humanos (ver anexo 2).

\section{Relación con instituciones estatales o gubernamentales nacionales e internacionales}

Como experiencias significativas, se resaltan las siguientes: la clínica ClinHab tiene un protocolo de colaboración con la Agencia de Vivienda Catalana. Basados en dicho acuerdo lograron la financiación de campañas de divulgación, publicaciones y asesoría a usuarios de vivienda. De igual forma la Clínica Ambiental de la Universidad de Tarragona tiene convenio con la Diputación de Tarragona; apoyan a dicha entidad en la preparación de una ordenanza tipo en materia ambiental. Los integrantes de esta clínica consideran de gran importancia su incidencia en cambios normativos.

En Colombia se desarrolla en la actualidad un proyecto denominado Alianza para el Fortalecimiento de la Enseñanza de los Derechos Humanos, con el apoyo de la Agencia de los Estados Unidos para el Desarrollo Internacional (Usaid, por su sigla en inglés) y Higher Education For Development (HED). Participan tres universidades norteamericanas: Universidad de Minnesota, Universidad de La Florida y American University. Cada una de estas universidades apoya a su vez a una alianza regional en tres zonas de Colombia: Costa Caribe, Antioquia y Valle del Cauca. En el caso de la alianza en Antioquia:

El objeto general del programa es apoyar las iniciativas nacionales y locales para mejorar el respeto y la protección de los derechos 
humanos en Colombia, en alianza con la Universidad de Medellín, Universidad Pontificia Bolivariana, Universidad Católica de Oriente y Universidad de Antioquia.

Entre los objetivos específicos de este programa de alianzas se encuentran: fortalecer la capacidad institucional de las facultades de derecho en Colombia para capacitar a futuras abogadas y abogados en derechos humanos a través de programas de estudios nuevos o mejorados; mejorar la capacidad de gestión de las facultades de derecho para atender las necesidades de las poblaciones vulnerables a través de la creación de nuevas líneas en la clínica jurídica y redes regionales de derechos humanos; proveer a las futuras y futuros profesionales del derecho con un mejor entendimiento de los estándares nacionales e internacionales de derechos humanos y las capacidades necesarias para apoyar la práctica y la reforma de derechos humanos en Colombia.

La Clínica Jurídica de Interés Público de la Universidad de Medellín a través de la alianza fortalece el estudio y trámite de casos de interés público, abre nuevas líneas de intervención y fortalece las competencias de sus estudiantes, docentes y usuarios en la práctica de los derechos humanos. ${ }^{22}$

Las pasantías en instituciones gubernamentales nacionales e internacionales Otra forma de construir relaciones en las clínicas son las pasantías. A manera de ejemplo observamos cómo una de las clínicas del máster en Derechos $\mathrm{Hu}$ manos de la Universidad Carlos III de Madrid realiza pasantías en la Oficina de Derechos Humanos del Ministerio de Asuntos y Cooperación de España. Existe también la posibilidad de realizar pasantías en la Subdirección General de Naciones Unidas y Asuntos Globales en España.

En la Universidad de San Marcos (Perú), destacan sus alianzas con entidades estatales como la Defensoría del Pueblo, con la que trabaja casos referidos a la situación carcelaria; con la Municipalidad de Lima, en temas de información y educación ciudadana, y en litigio estratégico, con la Coordinadora Nacional de Derechos Humanos.

\footnotetext{
${ }^{22}$ http://www.udem.edu.co/index.php/clinica-juridica-de-interes-publico/clinica-juridica-internacionalizacion
} 
La Clínica gap de la Universidad del Rosario en Colombia también ha desarrollado alianzas fuertes con la Defensoría del Pueblo; inicialmente apoyó la recepción de casos colectivos en la Defensoría, y luego firmó un convenio de colaboración que ha permitido el apoyo en casos y el fortalecimiento de la investigación conjunta.

¿Cómo funcionan las alianzas? Los docentes de las clínicas consideran que las alianzas se logran por el trabajo en temas de interés común, pues los trabajos conjuntos son los que unen a las clínicas o instituciones. Uno de los aspectos clave de las alianzas se relaciona con el acceso y la posibilidad de compartir información. Generalmente los socios se buscan para temas concretos en los que tienen fortalezas. La Clínica de la Universidad San Marcos tiene un buen número de convenios de cooperación conjunta.

\section{Trabajo inter-clínicas}

El otro tipo de relación, que implica trabajo inter-clínicas, es esporádico y generalmente se da para la construcción conjunta de casos o amicus curiae.

Para lograr el trabajo de apoyo en casos concretos de orden interno o ante el Sistema Interamericano de Derechos Humanos se requiere de conocimiento y confianza entre las clínicas y organizaciones participantes. Como casos exitosos que muestran este ejercicio podrían referenciarse los amicus curiae en el caso Fujimori, ${ }^{23}$ liderados por la Clínica de la Universidad Católica del Perú, y los amicus en el caso de Richard Vélez, liderados por la Clínica de Derechos Humanos de Washington University. ${ }^{24}$

\section{Alianzas con organizaciones pro bono}

"El trabajo pro bono consiste en la prestación de los servicios legales por parte de abogados a personas que no pueden acceder a esos servicios, bien sea por su condición económica o de especial protección constitucional o legal, de conformidad con la situación propia de cada país” (Torres Villarreal, 2010, p. 102). Son aún escasas las alianzas de esta naturaleza en América Latina.

\footnotetext{
${ }^{23} \mathrm{http} / /$ www.urosario.edu.co/jurisprudencia/Clinica-de-Interes-Publico/documentos/AmicusCuriae-Alberto-Fujimori.pdf

http://www.pj.gob.pe/wps/wcm/connect/a33fa7804e3b3c7482268aa826aedadc/13.+Doctrina+ Nacional+-+Ra\%C3\%BAl+Pariona+Arana.pdf?MOD=AJPEREs\&CACHEID=a33fa7804e3b3c7482268a a826aedadc

${ }^{24} \mathrm{http}: / /$ www.corteidh.or.cr/docs/casos/articulos/seriec_248_esp.pdf
} 
En Nueva York se firma la Declaración pro bono para las Américas en el año 2005 impulsada por el Cyrus R. Vance Center, con el apoyo de universidades y bufetes de abogados, y se constituyen fundaciones pro bono para impulsar la pedagogía en el tema y el apoyo al litigio estratégico en derechos humanos e interés público.

Las posibilidades de estas alianzas se centran en trabajo concreto para la organización conjunta de actividades académicas en derechos humanos, desarrollo de publicaciones y proyectos de investigación, conformación de equipos de litigio estratégico para promover y hacer seguimiento judicial a casos e incidencia en los procesos de formación de los estudiantes de derecho a través de prácticas pro bono en las firmas de abogados.

En Colombia, el ejercicio más exitoso se ha logrado entre la Universidad del Rosario, la Fundación Probono Colombia y la Universidad de La Sabana. Este caso será descrito en la siguiente sección.

\section{Litigio estratégico internacional}

Cuando se examina el tema en América Latina, es preciso reconocer que el mayor avance en la región ha sido de tipo político y consiste en darles valor normativo interno en el orden constitucional a los instrumentos internacionales de derechos humanos, en especial a los del Sistema Interamericano.

De igual forma es innegable la alta incidencia de las decisiones de la Corte Interamericana en los fallos de las cortes, tribunales y jueces latinoamericanos. Colombia, Argentina y, en forma más reciente, México plantean un sistema jurídico integrado, y tesis como la del bloque de constitucionalidad o el control de convencionalidad fortalecen esta posibilidad.

En el litigio estratégico de la región, se estudia en forma detallada la jurisprudencia de la Corte Interamericana de Derechos Humanos, los casos que permiten el cumplimiento por parte de los Estados de sus obligaciones de protección, respeto y garantía de los derechos humanos, y la posibilidad de avanzar hacia la estructuración de estas obligaciones frente a los derechos económicos, sociales y culturales. De igual forma se promueve la evolución desde un concepto de igualdad formal hacia una igualdad sustancial o material, donde un tema como la "discriminación estructural" toma cada vez mayor fuerza y demanda "al Estado un papel activo para generar equilibrios sociales y exige la protección especial de ciertos grupos que padecen procesos históricos o estructurales de discriminación"(Abramovich, 2011, p. 217). 
Desde los años noventa, algunas clínicas jurídicas latinoamericanas han optado por el litigio internacional con apoyo de ONG que las acompañaron en dicho camino. Los logros han sido importantes y, como lo afirma Abramovich, "el sidH, tanto la Comisión como la Corte, se consolida gradualmente como un escenario de activismo de la sociedad civil, que ha desplegado estrategias innovadoras para aprovechar en el ámbito nacional la repercusión internacional de los casos y situaciones denunciadas" (2011, p. 215). Se reconocen los grandes aportes realizados por el cels y la Clínica de Acciones de Interés Público de la Universidad Diego Portales.

La evolución del litigio ante el Sistema Interamericano es sorprendente y muestra la importancia del trabajo inicial ante las instancias internas, así como nuevos problemas de derechos humanos que abren jurisprudencia en estas instancias:

En lo que se refiere al trabajo en el ámbito americano, el Sistema Interamericano de Derechos Humanos ha venido cobrando mayor relevancia en los últimos años, y la presentación de denuncias ante la Comisión Interamericana de Derechos Humanos se ha diversificado significativamente, pasándose de una concentración casi completa de las denuncias en violaciones masivas y sistemáticas (lo que ocurría hasta avanzada la década de los ochenta) a un nuevo contexto en el cual a esas materias se agregan otras tales como problemas de discriminación, de libertades públicas, de cuestiones estructurales de los sistemas penales, etc.

En el pasado, en un contexto de violaciones masivas y sistemáticas bajo regímenes dictatoriales, con poderes judiciales carentes de imparcialidad y eficacia para confrontar dichas violaciones, el conflicto se daba derechamente entre los órganos internacionales y el estado respectivo, y, por no tratarse de regímenes democráticos, mal podía plantearse siquiera como problema el hecho de que aquellos que aspiraban a fortalecer la participación ciudadana recurrieran a dichas instancias internacionales. Tanto es así que, en esas circunstancias, la práctica usual de la Comisión Interamericana consistía en admitir a tramitación las denuncias sin hacer exigible la regla del previo agotamiento de los recursos internos (recursos que incluyen los de carácter judicial) (González Morales, 2004, p. 36). 
El litigio ante el sistema interamericano se fortaleció igualmente por los aportes académicos de docentes universitarios que a su vez eran integrantes de ONG y trabajaban en casos ante la Comisión y la Corte. Se han llevado algunos casos directamente o en alianza ante el Sistema. ${ }^{25}$ Son muchas las investigaciones realizadas sobre el $\operatorname{siDH}^{26}$ derivadas de este ejercicio, pero el principal ha sido el de amicus curiae. ${ }^{27}$ Se encuentran también referenciadas acciones muy novedosas ante el Panel de Inspección del Banco Mundial. ${ }^{28}$

\section{Las agendas de las clínicas y los temas prioritarios de derechos humanos en Iberoamérica}

En esta sección se presentarán los temas más importantes de las clínicas iberoamericanas, con una reflexión inicial que da cuenta de las características de este litigio y una ilustración particular con casos reales de litigio estratégico impulsado desde las universidades o sus alianzas.

Es preciso anotar que en los espacios de trabajo de las clínicas jurídicas no se ha construido una agenda común, ni se han establecido sistemas de seguimiento de los casos en determinadas áreas. La construcción ha respetado las particularidades de la región y los problemas y necesidades más graves, traducidos con un enfoque de derechos humanos en prioridades en la defensa, promoción y protección de los derechos. En este primer eje podemos encontrar los llamados derechos emergentes, el trabajo jurídico para que se reconozcan y respeten nuevos derechos o derechos que nunca antes habían aparecido en las agendas judiciales.

Se observa igualmente que en las agendas individuales de las clínicas es muy fuerte el eje que denominamos de defensa de población vulnerable. Los grupos poblacionales que se buscan proteger o acompañar mediante las acciones de las clínicas son: la población en condición de discapacidad, las

\footnotetext{
${ }^{25}$ Caso Atala vs. Chile, en: http://www.corteidh.or.cr/docs/casos/articulos/seriec_239_esp.pdf

${ }^{26} \mathrm{http} / /$ www.surjournal.org/esp/conteudos/getArtigo12.php?artigo=12,artigo_02.htm

${ }^{27}$ www.corteidh.or.cr/docs/opiniones/seriea_19_esp.doc; http://www.acnur.org/biblioteca/pdf/2351. pdf?view=1; http://www.clinicasjuridicas.org/integridad-personal.htm

${ }^{28} \mathrm{http}: / /$ www.cels.org.ar/common/documentos/la_lucha.pdf;

http://www.aida-americas.org/sites/default/files/InFormereP5Cyacyreta_0.pdf;

http://www.ciel.org/Publications/citizensguidespanish.pdf
} 
mujeres, las víctimas de trata de personas, la población carcelaria y los indígenas, entre otros.

Son escasos los trabajos de las clínicas frente a poblaciones como la población LGBTI, los afrocolombianos o las personas mayores.

Los indicadores que podrían construirse frente a este tema tendrían que considerar, en primer lugar, la existencia de clínicas especializadas frente al tema, en segundo lugar, la existencia de casos relacionados con el tema en las clínicas generales y, en tercer lugar, la existencia de alianzas para apoyar estas temáticas específicas.

Con estos elementos iniciamos nuestro recorrido haciendo énfasis en los casos, en las estrategias y en los resultados obtenidos. Tomamos casos exitosos para esta muestra, pero esto no significa que el litigio estratégico no se nutra igualmente de las derrotas y las dificultades. Sobre este último aspecto, quedaría pendiente una reflexión profunda de las clínicas y las ong de la región.

\section{Prioridades en derechos civiles y políticos. Debate y casos}

\section{Tema 1: derechos civiles}

Cuando se examinan los orígenes del litigio estratégico, se observa cómo son los derechos civiles y políticos el primer campo de desarrollo en Estados Unidos. En el trabajo de Puga (2013), queda claro que es en los temas de discriminación donde surge el litigio estratégico. ${ }^{29}$ La relación del litigio estratégico con problemas reales y frente a los cuales existe una sensibilidad social o al menos un debate público importante facilita los resultados, siempre y cuando se le sume un tercer ingrediente: el activismo judicial.

Haremos una breve referencia a continuación al litigio estratégico en materia de libertad de expresión, organización y sindicalización, mirando las clínicas que los trabajan y algunos ejemplos del litigio latinoamericano en la materia. Según la investigación de campo, las universidades que trabajan en el tema son la Diego Portales, la Universidad de Palermo, la Universidad de Córdoba, la Clínica de Litigio de Interés Público (cLIP) y la Universidad Torcuato di Tella.

Se destaca en la búsqueda de casos el referido a los derechos básicos del personal penitenciario en Córdoba, Argentina, promovido por la Clínica de

\footnotetext{
${ }^{29}$ Ver Plessy vs. Ferguson y Brown vs. Board of Education of Topeka.
} 
Interés Público de la Universidad de Córdoba en el año 2008. ${ }^{30}$ En Argentina los empleados del Estado que cumplen funciones de seguridad civil, especialmente en las cárceles y la policía, tienen prohibición de ejercer su libertad de expresión y el derecho a realizar reclamos laborales colectivos, entre otras manifestaciones de esta libertad. Frente a dicha situación, la clínica apoya un amparo colectivo promovido por una empleada del Servicio Penitenciario de la provincia y lograron en primer lugar el reconocimiento de legitimación activa para actuar en representación de todos los empleados del servicio. Según informa la clínica, "la demandante había sido pasada a retiro por repartir panfletos que reproducían el artículo 14 bis de la cN, y los cuales fueron considerados 'subversivos".

La sentencia, dictada por el juez Novak el 18 de febrero de 2008, garantiza los derechos del personal penitenciario en Córdoba. "En un fallo sin precedentes, se cuestiona las violaciones a los 'derechos básicos' a expresarse, organizarse y sindicalizarse que sufren los miembros del personal penitenciario de la provincia de Córdoba, las que, sugestivamente, subsisten en épocas de democracia a lo largo y ancho de todo el país, y en las distintas fuerzas de seguridad del Estado". El juez declara la inconstitucionalidad de la prohibición de actividades tendientes a la agremiación u organización colectiva de los trabajadores del servicio penitenciario (Ley Provincial 8231, artículo 10, inciso 19) y de las sanciones correlativas (decretos 25/76, articulo 9o, inciso 10 y 13 , y artículo 10, inciso 34) y les reconoce el derecho a afiliarse a sindicatos y a desplegar actos y conductas tendientes a su sindicalización ante el Ministerio de Trabajo de la Nación en las condiciones emergentes de la Constitución Nacional sin que puedan existir sanciones derivadas de esta garantía.

Otro caso importante y directamente referido al tema que nos ocupa es el de los derechos de los periodistas en Venezuela, promovido por la Clínica de la Universidad Torcuato di Tella en el año 2009, al intervenir con un amicus ante la Corte Interamericana de Derechos Humanos en el caso 12.441. Según se relata en el informe, la clínica sostuvo que "la conducta persecutoria llevada a cabo por Venezuela contra ciertos periodistas violaba el derecho a la libre expresión. En el 2009 la Corte Interamericana dicta sentencia haciendo lugar a la demanda”. ${ }^{31}$

\footnotetext{
${ }^{30}$ Tomado de: http://clinicajuridicaudem.blogspot.com/

${ }^{31}$ Tomado de:http://www.utdt.edu/ver_contenido.php?id_contenido=5709\&id_item_menu=11852
} 
De igual forma, en el año 2012, las clínicas George Washington (Estados Unidos), GAP- Universidad del Rosario (Colombia) y la Clínica de Justicia Social de la Universidad de Valencia (España) presentan amicus ante la Corte Interamericana de Derechos Humanos en defensa de los derechos de los periodistas en Colombia, específicamente en el caso Richard Vélez vs. Colombia. ${ }^{32}$

Este caso evidencia las enormes dificultades que tiene en Colombia el ejercicio del periodismo, especialmente cuando se trata de cubrir temas referidos al conflicto armado interno. A continuación presentamos una síntesis basada en el trabajo de Torres:

El periodista Luis Gonzalo Vélez Restrepo ('Richard’Vélez), sufrió una agresión por parte de miembros de la fuerza pública colombiana, cuando en ejercicio de sus labores, cubría unas manifestaciones contra la fumigación de cultivos de coca en el departamento de Caquetá. Posteriormente, recibió amenazas en contra suya y de su familia por las denuncias que había presentado con ocasión del ataque del que fue víctima. Los constantes hostigamientos obligaron a la familia Vélez a exiliarse en los Estados Unidos (Torres, 2013, p. 7).

La Clínica Jurídica de Derechos Humanos de la Universidad George Washington representó al periodista ante el Sistema Interamericano de Derechos Humanos e invitó a otras clínicas (Universidad de Valencia y Universidad del Rosario) a participar a través de amicus curiae.

El Grupo, siguiendo los lineamientos propuestos en la demanda [...] presentó un amicus curiae que lleva por título "La libertad de expresión como garantía de los derechos humanos: el derecho a la familia y los derechos de los niños". En este escrito, se hace un recuento de los estándares internacionales en materia de libertad de expresión y se utiliza el concepto de "función instrumental de la libertad de expresión" desarrollado por la cidH, según el cual, el desconocimiento de la libertad de expresión conduce a la violación de otros derechos

\footnotetext{
${ }^{32}$ Sentencia de la Corte Interamericana de Derechos Humanos. Disponible en: http://www.corteidh. or.cr/docs/casos/articulos/seriec_248_esp.pdf
} 
humanos, tales como el derecho a la familia y los derechos de los niños en el caso del señor Vélez y sus familiares.

En este sentido, el caso Richard Vélez vs. Colombia significó la lucha por dos intereses sociales y esenciales para la democracia como lo son: la garantía de la libertad de expresión y el apoyo a organizaciones que promueven y garantizan los derechos humanos a través de herramientas jurídicas como el amicus, logrando la aplicación del derecho en un caso que encerraba una necesidad real de una persona en particular y que terminó en la consecución de un fallo internacional no solo favorable para él en particular, sino también para la libertad de expresión en la región a partir de la creación de un precedente judicial (Torres, 2013, p. 9).

\section{Tema 2: derechos políticos}

En Argentina se planteó por la Clínica del CELS-UbA el caso del derecho al voto para los presos sin condena desde el año 1988. Este logro se obtuvo gracias a una acción de amparo que se describe a continuación:

E1 29 de diciembre de 2003, a través de la Ley 25.858, se incorporó al Código Nacional Electoral de la Argentina el derecho al sufragio de las personas privadas de su libertad sin condena firme. La norma ordenaba a la Cámara Nacional Electoral confeccionar un Registro de Electores Privados de Libertad y habilitar mesas de votación en cada establecimiento de detención.

Establecía, además, que si la persona se encontrase detenida en un distrito electoral diferente, sus votos se adjudican al distrito en el que esté empadronado. El decreto que implementaba esta ley y señalaba cómo se llevaría a cabo se publicó el 28 de septiembre de 2006 en el Boletín Oficial.

Esta incorporación fue consecuencia de una acción de amparo presentada por el cels en octubre de 1998 en la justicia federal con competencia electoral, cuyo objetivo era garantizar a las personas privadas de su libertad sin condena firme la posibilidad de participar, a través del sufragio, en las elecciones nacionales que se realizarían en 1999. La acción procuró cuestionar, además, la degradación y el menoscabo de los derechos que se verifica intramuros. 
Entre 1998 y 2003, cuando finalmente se sancionó la ley que incorporaba el derecho al sufragio de los privados de libertad al Código Penal, la acción llevada adelante por el cels recorrió varias instancias judiciales hasta la decisión de la Corte Suprema de Justicia de la Nación de instar a los poderes legislativo y ejecutivo a que dispusieran las medidas necesarias para que los presos pudieran efectivamente votar, cuando llegara el momento, en sus lugares de detención.

La intervención del cels en este caso, sin embargo, no finalizó con la decisión de la Corte Suprema y la reforma legislativa; por el contrario, requirió un trabajo de seguimiento para garantizar y verificar su eficacia (Baladrón, 2013, p. 23).

\section{Tema 3: acceso a la información}

En el tema de acceso a la información han trabajado las clínicas del ITAM, la Universidad de Palermo (Argentina), ${ }^{33}$ la Universidad Alberto Hurtado (Chile) ${ }^{34}$ y la Pontificia Universidad Católica del Perú, ${ }^{35}$ entre otras. Su labor se enfoca en las denominadas leyes de trasparencia y acceso a la información, frente a las cuales han desarrollado lobby jurídico de enorme importancia. Además han coordinado casos referidos a temas como libertad de prensa, libertad de expresión, acceso a la información, corrupción, entre otros.

Un interesante caso de litigio estratégico para garantizar el acceso a la información como herramienta de litigio estratégico fue propuesto por la Clínica del itam-México en el año 2002:

Una de las herramientas que la clínica promueve para litigar estratégicamente es el acceso a la información.

El derecho a la información se ha convertido en uno de los ámbitos centrales de la discusión en torno en la relación del Estado con la sociedad civil. Uno de los objetivos del derecho a la información es contribuir a la democratización y vigencia del Estado de Derecho

\footnotetext{
${ }^{33} \mathrm{http}: / /$ www.adc.org.ar/592_clinica-juridica-de-derecho-de-acceso-a-la-informacion/

${ }^{34} \mathrm{http}: / /$ derecho.uahurtado.cl/clinica-juridica/consultorio-acceso-a-la-informacion/

${ }^{35} \mathrm{http}: / /$ facultad.pucp.edu.pe/derecho/alumnos/servicios-en-el-campus/clinica-juridica/informacion-publica/
} 
[...]. Esta clínica, está convencida de que el acceso a la información, como derecho humano, es un principio básico para la democracia. Según todo lo anterior, la clínica, comprometida con la promoción de los derechos humanos, intenta hacer efectivo el derecho de acceso a la información. Una de las formas de hacerlo, es mediante su ejercicio a través de lo establecido en la Ley Federal de Transparencia y Acceso a la Información Pública Gubernamental (LFTAIPG), aprobada en el 2002 como resultado de la participación de grupos de la sociedad que llevaron una iniciativa propia del Congreso (Meraz, 2007, pp. 127-128).

\section{Tema 4: lucha contra la discriminación}

La Clínica de la Universidad Torcuato di Tella, en compañía de la ADC, demandó en el año 2004 una norma que prohibía ingresar en docencia a los extranjeros.

En mayo del 2004 la ADC, con la colaboración de la clínica jurídica, promovió una acción de inconstitucionalidad ante el Tribunal Superior de la Ciudad de Buenos Aires en el que se solicitaba se declarara la invalidez de una disposición del Estatuto Docente local que vedaba a los extranjeros el acceso a la mayoría de los puestos docentes en la educación pública de la ciudad. Sin bien la mayoría del tribunal rechazó la demanda con fecha 31.3.2005, poco tiempo después, la legislatura eliminó del Estatuto Docente la citada restricción en perjuicio de los extranjeros. ${ }^{36}$

En el año 2006, la misma clínica presentó una acción de inconstitucionalidad frente a la prohibición existente en Buenos Aires para que los extranjeros pudieran ser escribanos.

"En dicha demanda, se solicitó la declaración de inconstitucionalidad de varios artículos de la Ley 404, que regula la profesión de escribano en la ciudad de Buenos Aires, por ser contraria a los derechos constitucionales a no ser discriminado por la nacionalidad y a tener una tutela judicial efectiva. Por mayoría, el Tribunal rechazó la demanda”. Se procedió entonces a presen-

${ }^{36}$ Tomado de: http://www.utdt.edu/ver_contenido.php?id_contenido=5709\&id_item_menu=1185 
tar "una denuncia ante la Comisión Interamericana de Derechos Humanos contra el Estado argentino en la que se sostuvo que la prohibición de que los extranjeros accedieran, en el ámbito de la ciudad de Buenos Aires, a la profesión de escribano era una discriminación violatoria de la Convención Americana sobre Derechos Humanos". ${ }^{37}$

El caso Pandolfic vs. Universidad Nacional del Comahue fue una acción de amparo en el año 2009. La Clínica de la Universidad Torcuato di Tella (Argentina) intervino a través de un amicus:

El caso se refiere a un profesor universitario que no fue contratado porque tenía más de 40 años [...], se presenta escrito de amicus curiae ante $1^{\mathrm{a}}$ y $2^{\mathrm{a}}$ instancias de la Justicia Federal, en donde se sostuvo, en apoyo de la posición del actor, que el rechazo de designación de aquel como profesor consulto de la Facultad de Derecho de esa universidad era una discriminación prohibida por la Constitución Nacional. Con fecha 30.09.2009, el juez federal de Neuquén dictó sentencia haciendo lugar a la acción de amparo y declarando la nulidad de la decisión de la universidad demandada. Ese pronunciamiento fue confirmado por la Cámara Federal de Apelaciones de General Roca el día 11.03.2010.38

Un caso muy difundido en los medios de comunicación colombianos fue el de la acción de tutela interpuesta en el año 2008 por el Observatorio de Discriminación Racial de la Universidad de Los Andes contra tres discotecas de Bogotá y contra la Alcaldía Mayor y el Presidente de la República. La demanda buscaba tutelar los derechos a la igualdad y dignidad humana de seis afrodescendientes a quienes les fue impedido el acceso a las discotecas por el color de su piel. ${ }^{39}$

\section{Tema 5: prisión preventiva y violación de derechos}

En la Universidad de San Marcos, la clínica ha asumido desde el año 2012 el estudio de la prisión preventiva en los casos de delitos de hurto por montos

\footnotetext{
${ }^{37}$ Tomado de:http://www.utdt.edu/ver_contenido.php?id_contenido=5709\&id_item_menu=11852

${ }^{38}$ Tomado de: http://www.utdt.edu/ver_contenido.php?id_contenido=5709\&id_item_menu=11852

${ }^{39}$ Ver: http://www.elespectador.com/impreso/bogota/articuloimpreso-ruta-de-esclavitud
} 
muy pequeños. Están defendiendo a una persona que se encuentra en prisión preventiva por robarse un sol.

Luis Zabaleta, estudiante de la Facultad de Derecho y miembro de la Clínica Jurídica de la Universidad de San Marcos, relata así el caso:

El año pasado un grupo de alumnos nos avocamos a investigar; se trataba de un chico de 20 años que fue detenido y llevado al penal donde llevan a los delincuentes más peligrosos del país. La razón de su detención, fue que amenazó a unos menores y la única prueba existente eran las declaraciones de los menores. El juez procedió a ordenar la detención.

Como parte de la investigación se ha profundizado en el tema de la medida de detención preventiva en los casos que no lo amerita [sic], la clasificación por parte de los jueces y de los que administran los centros penitenciarios en el Perú, clasifican a las personas y determinan que lo lleven [sic] a cárceles con un nivel de inseguridad muy alto para su vida, donde están personas ya condenadas, delincuentes. El tema de la clasificación de los internos [es] por qué una persona con un prontuario apenas abierto está con los condenados. Lo más grave de este caso es que esa medida tan dura se toma por solamente haber robado un sol. Y a su vez otra rama más del caso es ver la posibilidad de que a raíz de ese error judicial pueda exigirse al Estado una reparación (citado en Grandez, 2013).

La Clínica de la Universidad de Córdoba en Argentina ha abordado desde el año 2012 el caso de las detenciones ilegales por "merodeo" en dicha Provincia.

En la provincia de Córdoba existe una ley provincial sobre certificación de antecedentes (solo los relevantes). Basada en dicha ley la Policía incrementó en forma significativa las detenciones ilegales por contravenciones. El "merodeo" es considerado como una contravención, basta la sospecha y la negativa a identificarse de una persona y la detienen.

Según informó la Clínica de la Universidad de Córdoba, van 73.000 casos de detenciones. La clínica trabaja el tema. Su aporte ha sido un estudio riguroso y una visión sistemática y de derechos humanos frente a tan grave problema. 
La clínica GDIP de la Universidad de los Andes, en Colombia, realizó una intervención y apoyo en un caso de acción de tutela sobre condiciones indignas de reclusión en el año 2012.

El pasado 31 de enero, la jueza 56 del Circuito Penal de Bogotá expidió una sentencia de tutela con efectos inter communis en la que declaró la persistencia del estado de cosas inconstitucional en las cárceles colombianas —declarado en 1998 por la Corte Constitucional—y además amparó los derechos fundamentales del tutelante y los demás internos de la Cárcel Modelo de Bogotá. Dentro de las órdenes que impartió la jueza se destacan: (i); [sic] que el director de la Cárcel Modelo se abstenga de recibir más internos en el establecimiento por un periodo de tres (3) meses (ii); [sic] que el Inpec y la Unidad de Servicios Penitenciarios gestionen el traslado de todas las personas condenadas recluidas en la Cárcel Modelo a las penitenciarías del país, teniendo en cuenta que en la Modelo solo deben estar personas sindicadas (iii); [sic] que la Fiscalía General inicie las investigaciones penales pertinentes ante la posible existencia de fosas comunes con cadáveres al interior de la Cárcel Modelo (iv); [sic] y que la Secretaría Distrital de Salud haga visitas periódicas al establecimiento de reclusión para comprobar que existen allá las condiciones mínimas para recluir seres humanos. Durante el curso del proceso, el juzgado solicitó al Grupo de Derecho de Interés Público y la Relatoría de Prisiones de la Universidad de Los Andes un concepto sobre el caso, el cual fue determinante para expedir las órdenes mencionadas. ${ }^{40}$

\section{Tema 6: objeción de conciencia frente a la prestación del servicio militar obligatorio en Colombia}

En este tema han trabajado el GDip de la Universidad de Los Andes en Colombia y la Defensoría del Pueblo. ${ }^{41}$ En el año 2009 la clínica utilizó la acción

\footnotetext{
${ }^{40}$ Tomado de: http://gdip.uniandes.edu.co/index.php?modo=interna\&seccion=litigios Visita: Noviembre 9 de 2014

${ }^{41}$ Ver: http://www.corteconstitucional.gov.co/relatoria/2014/T-314-14.HTM
} 
pública de inconstitucionalidad contra la Ley 48 de 1993, para garantizar el derecho a la objeción de conciencia al servicio militar obligatorio.

La estrategia de litigio consistió en la elaboración de una acción pública de inconstitucionalidad en contra del artículo 27 de la Ley 48 de 1993, ya que en su redacción el legislador omitió incluir a los objetores de conciencia dentro de las exenciones en todo tiempo de cumplir la obligación de prestar el servicio militar obligatorio. En octubre de 2009, la Corte Constitucional reconoció la objeción de conciencia al servicio militar obligatorio como un derecho fundamental y exhortó al Congreso para que expidiera una ley en la que se defina las condiciones en las que puede hacerse efectivo el derecho. Este proyecto se realizó en alianza con el Observatorio de Justicia Constitucional de la Universidad de Los Andes, la ong internacional Civis y la Acción Colectiva de Objetores y Objetoras de Conciencia (Acooc). ${ }^{42}$

\section{Tema 7: memoria, justicia transicional, atención a víctimas del conflicto}

Se destacan en esta novedosa propuesta de litigio estratégico los trabajos de la Universidad de Valencia y de la Universidad del Rosario.

Para la Clínica de la Universidad de Valencia es muy importante el tema de la memoria y la justicia transicional. Actualmente realiza un estudio para buscar la anulación del proceso donde se condenó a muerte al poeta español Miguel Hernández.

En Colombia se ha iniciado desde el año 2012 un trabajo clínico en la Universidad del Rosario para contribuir desde la práctica en el Observatorio de Restitución y Regulación de Derechos de Propiedad Agraria.

Aunque se trata de una clínica reciente, su objeto de estudio es de gran importancia frente al momento que vive Colombia.

[.... la clínica del observatorio se enfoca exclusivamente en temas relativos a derechos de propiedad agraria. Nuestras estrategias están encaminadas a llevar algunos casos que son seleccionados por el equipo y que por su importancia pueden lograr incidir en la trans-

${ }^{42}$ Ver: http://gdip.uniandes.edu.co/index.php?modo=resultados\&id=3 
formación o solución de problemas sociales en materia de tierras. Para este fin, contamos con la presencia de estudiantes de derecho que están finalizando sus estudios y con un equipo de abogados con experiencia en litigio de derechos humanos. Nuestro trabajo se enfoca en tres clases de procesos. El primero, aquellos relacionados con la Ley 160 de 1994 como el de titulación de baldíos, divisiones, etc. El segundo relativo a la Ley 1448 de 2011 sobre restitución de tierras. Finalmente, todas aquellas acciones constitucionales que tengan la virtualidad de incidir en los derechos de propiedad agraria. Por ejemplo, acciones de inconstitucionalidad, intervenciones ciudadanas, acciones populares, acciones de grupo, acciones de cumplimiento, etc. ${ }^{43}$

\section{Propuestas novedosas en derechos económicos, sociales y culturales} El litigio estratégico en esta materia es el que ha caracterizado el trabajo de las ONG y las clínicas en América Latina. Las propuestas desarrolladas son muy novedosas y en algunos casos inéditas en la jurisprudencia a nivel mundial.

\section{Tema 1: derecho a la salud}

Uno de los casos más documentados y divulgados es el propuesto desde la clínica CELS-UBA en el año 1996 para buscar la producción y suministro de la vacuna contra la fiebre hemorrágica. En la literatura se le conoce como el "caso Viceconte".

La fiebre hemorrágica argentina, también llamada mal de los rastrojos, es una enfermedad endémica y epidémica característica de la pampa húmeda, que afecta principalmente a las personas que viven $o$ trabajan en el campo, aunque se extiende también a las zonas urbanas. La medida sanitaria más adecuada para combatir esta enfermedad es la producción y suministro de la vacuna Candid 1, cuya efectividad está en el orden del 95\% y ha sido avalada por la Organización Mundial de la Salud (oms). Se trata de una vacuna cuya producción no resulta rentable para los laboratorios, ya que es necesaria solo en determinadas zonas de la Argentina.

\footnotetext{
${ }^{43}$ Tomado de: http://www.observatoriodetierras.org/clinica-juridica/
} 
Entre 1991 y 1995 se aplicaron 140.000 dosis de la vacuna a los pobladores de la zona endémica con más alto riesgo de enfermarse, que habían sido adquiridas en Estados Unidos. Pero a partir de 1996, las 60.000 dosis restantes de aquella compra no eran suficientes para emprender campañas de vacunación masiva ya que solo en la provincia de Buenos Aires se necesitaban alrededor de 3.500.000 dosis. Varios diarios alertaron sobre esta situación y el cels inició una investigación, en la que se comprobó la falta de vacunas y se confirmó su eficacia como medida sanitaria para prevenir la enfermedad. La decisión fue preparar una acción de amparo fundada en el derecho a la salud que fue presentada ante la justicia federal por Mariela Viceconte, vecina de la localidad bonaerense de Azul y alumna de la Clínica Jurídica uba/cels.

E1 Estado había evaluado que la única medida sanitaria idónea para enfrentar la epidemia era la fabricación local de la vacuna y había dispuesto las partidas presupuestarias necesarias para su producción. Sin embargo, no estaba cumpliendo con ello. El amparo se articuló, entonces, en torno al compromiso asumido por el Estado y se fundamentó en el derecho internacional de los derechos humanos y en la legislación local que imponen obligaciones concretas vinculadas con el resguardo del derecho a la salud pública y el consecuente control de las enfermedades epidémicas. Además, un elemento interesante de este caso fue el modo en que se identificó un derecho de incidencia colectiva, el derecho a la salud pública, para habilitar el planteo colectivo de la acción.

Durante 10 años el caso pasó por varias instancias hasta que la justicia obligó al Ministerio de Salud de la Nación a cumplir con la producción y campaña de vacunación. Finalmente, en la última audiencia celebrada en septiembre de 2006, se anunció que la vacuna ya contaba con la debida autorización y registro por parte de la Autoridad Nacional de Medicamentos, Alimentos y Tecnología Médica (Anmat) para ser aplicada en adultos y que había numerosas dosis disponibles fabricadas en la Argentina para comenzar con la campaña de vacunación.

$\mathrm{El}$ caso Viceconte constituye un precedente fundamental en la jurisprudencia de los tribunales argentinos, tanto por el contenido y la 
fundamentación de la decisión sobre el planteo de fondo como por la legitimación activa para la exigibilidad de los derechos sociales. Además, muestra la importancia del rol de la justicia en la asignación y ejecución de las partidas presupuestarias. Las sentencias que ordenan al Estado la adopción de acciones positivas en materia de política social contienen la necesidad de este control judicial sobre la gestión de los fondos (Baladrón, 2013,pp. 17-18).

La Clínica de Derechos Humanos de la Universidad Diego Portales, en el año 1999, lideró un caso donde se buscaba el acceso a tratamientos médicos para personas viviendo con VIH-sida. El proceso duró casi tres años (1999-2002) y allí se logró que los medicamentos y tratamientos estuviesen en la lista que cubren planes de salud. Fue muy útil en este caso el papel de los medios de comunicación.

\section{Tema 2: derecho a la alimentación para los niños y las niñas}

El caso Rosarito es un ejemplo de litigio estratégico con caso testigo de gran impacto social y jurídico. Según los informes de la provincia, en Tucumán, Argentina, se presentaron 23 muertes de niños por desnutrición, por tal razón, la Clínica de la Universidad de Tucumán empezó a hablar de la desnutrición como un tema de interés público y tomó como caso emblemático por vía de amparo el de una niña llamada Rosarito, que se encontraba en grave situación de desnutrición.

En el caso se declaró como responsable el Estado por ser el garante de los derechos fundamentales como el derecho a la salud y a la vida, los cuales estaban siendo vulnerados por los casos de desnutrición.

A partir de este proceso fue que por primera vez un caso de desnutrición llegó a los tribunales de la provincia de Tucumán y de Argentina. ${ }^{44}$

\footnotetext{
${ }^{44}$ Tomado de: http://iidh-webserver.iidh.ed.cr/multic/UserFiles/Biblioteca/IIDH/2_2010/XXVICurso_Interdisciplinario_en_Derechos_discursos_y_ponencias/3.\%20G.Alfaro\%20-\%20Ponencia.pdf; http://www.derecho.unt.edu.ar/clinicajuridica/casos.htm
} 


\section{Tema 3: derecho a la vivienda}

Más que un caso, se trata de una acción jurídica integral que desarrolla la clínica ClinHab de la Universidad de Barcelona, desde el año 2011, donde se atienden casos relacionados con el derecho a la vivienda.

$\mathrm{El}$ procedimiento de trabajo en los casos se inicia con el relato, luego viene una explicación a los usuarios sobre todas las opciones jurídicas y se les asesora. Si en la entrevista se encuentra que existe riesgo de exclusión, se les acompaña a los servicios especiales para que presenten apoyo en la emergencia.

No podemos olvidar que, en España, la dura situación de crisis económica ha llevo a las personas a tomar decisiones como el suicidio.

Los usuarios de esta clínica son españoles pero también inmigrantes (caso hermanos de Malí y disputa de una vivienda en España; caso de pareja rusa, etc.). El tema más frecuente tiene que ver con las hipotecas. Se realizan también estudios normativos para realizar propuestas en la materia.

\section{La defensa de los derechos colectivos a través de las clínicas}

\section{Tema 1: derecho al ambiente sano}

Uno de los casos más destacados de alianzas inter-clínicas y con organizaciones pro bono en Colombia es el caso denominado "E1 Islote".

En el año 2010 se inició este caso, el cual se consideró como una oportunidad de trabajo conjunto entre las clínicas de la Universidad del Rosario y firmas de abogados (área pro bono), por conducto de la Fundación Probono de Colombia.

En el caso se busca la protección y garantía de los derechos colectivos de una comunidad integrada por un grupo numeroso de familias afrocolombianas que residen en Santa Cruz, un pequeño Islote (Colombia) que carece de todos los servicios públicos y donde la presencia de gran cantidad de niños exige acciones urgentes en temas como educación, salud, vivienda y calidad de vida. En el marco de la propuesta:

Se diseñaron y planearon una serie de estrategias de litigio para asumir el caso, incluyendo acciones de diferente tipo, así:

- Acciones políticas: se resalta el acercamiento con la Personería Distrital de Cartagena, lo que permitió el desarrollo de estrategias 
sociales, especialmente para la realización de un taller pedagógico en la comunidad.

- Acciones sociales y pedagógicas: en mayo de 2011, se realizó un taller sobre derechos humanos, derechos colectivos y servicios públicos básicos con la comunidad; en este espacio se expusieron, por parte de la comunidad, las necesidades y expectativas en lo referente a las temáticas analizadas. Así mismo, se planteó a la comunidad la estrategia jurídica planeada para asumir el caso, la cual fue avalada por la comunidad.

- Acciones jurídicas: el trabajo conjunto de los "aliados", sumado al interés de la comunidad, permitió que se iniciara la construcción de la demanda para un proceso de acción popular y el recaudo del material probatorio.

[...] se trabajó en la elaboración de la acción popular que propende por la defensa de los derechos colectivos i) a la prevención y atención de riesgos técnicamente previsibles, ii) a la salubridad pública y a la disponibilidad y acceso a una infraestructura que garantice la salubridad pública, iii) a la prestación efectiva de los servicios públicos domiciliarios y iv) al acceso a los servicios públicos y a que su prestación sea eficiente y oportuna. Esta acción legal fue suscrita por los miembros de la comunidad, representados por los abogados de la clínica (Torres, 2013).

El caso fue admitido por un juez administrativo y se ordenaron las medidas cautelares solicitadas (suministro de agua, suministro de energía y apoyo en temas de salud).

El caso aún no ha finalizado pero ya ha permitido avances significativos en la garantía de los derechos de esta comunidad.

En otro ejercicio de gran interés en materia ambiental, la Clínica de la Universidad de Medellín presentó una acción popular en el caso del relleno sanitario de La Pradera. Se basaba en el mal manejo ambiental y se buscaba la prevención de desastres previsibles técnicamente, la garantía del derecho al ambiente sano, entre otros derechos. ${ }^{45}$

${ }^{45}$ Ver en páginas web: http://books.google.com.co/books?id=SNKnsBe3X34C\&pg=PA18\&lpg= $\mathrm{PA} 18 \& d q=$ relleno+sanitario + parque + ambiental + la + pradera\&source $=b 1 \& o t s=f 4 \mathrm{~L} 1 \mathrm{M} 2 \mathrm{Tekh} \& s i g=\mathrm{It} 0$ 
La misma clínica resalta también un trabajo de incidencia política a través del lobby que realizaron ante el Consejo de Medellín (Colombia) para prohibir las estaciones de servicio que se construían en las zonas residenciales. Se mencionan a continuación algunos apartes de la Intervención de la clínica:

Desde la academia advertimos con preocupación, la ineficacia de la política pública ambiental municipal en el cumplimiento de los deberes impuestos por la Constitución en cabeza de las autoridades públicas $[\ldots]$.

En este sentido, es notoria la falta de aplicación y control del cumplimiento de los lineamientos de política consignados en el Acuerdo municipal 21 de 2007, frente al manejo de los residuos peligrosos de la ciudad de Medellín, de conformidad con las funciones otorgadas por el artículo 65 de la Ley 99 de 1993.

De acuerdo con el Plan de Gestión Integral de Residuos Sólidos, para el año 2005, en el área metropolitana del Valle de Aburrá se generaban alrededor de 779.55 toneladas mensuales de residuos peligrosos, de las cuales solo el 17,40\% eran tratadas adecuadamente. El resto de los residuos eran y siguen siendo dispuestos en el relleno sanitario de la pradera, el cual no cuenta con la autorización legal y los elementos técnicos para la disposición y tratamiento de estos residuos. [...].

Así mismo, cabe citar la improvisación y la falta de atención que las autoridades administrativas y ambientales han dado al actual proyecto de "relleno de seguridad para el manejo de disposición final de residuos peligrosos y especiales", el cual se pretende ejecutar en el corregimiento de Altavista. En este proyecto, a pesar del concepto favorable de la Oficina de Planeación Municipal, se transgreden las normas ambientales y de ordenamiento territorial sobre protección

bT-KS_e398fsweKYiMzr06lg\&hl=es\&sa=X\&ei=mzkIUf79LYS89gSy44AY\&ved=0CHAQ6AEwc @\#v=onepage\&q=RELLENO\%20sANITARIO\%20PARQUE\%20AMBIENTAL\%20LA\%20PRADERA\&f=false;

http://www.corantioquia.gov.co/docs/PGirs/IVASESORIAMUNICIPIOS/ANEXo\%201\%20-\%20\%20 AMva325-in-pap.pdf;

http://www.elcolombiano.com/BancoConocimiento/E/en_la_pradera_no_va_mas_la_separacion_en_la_planta/en_la_pradera_no_va_mas_la_separacion_en_la_planta.asp 
de zonas de especial interés ecológico, teniendo en cuenta que se trata de una zona de gran riqueza hidrográfica y orográfica.

No obstante, advertimos la importante oportunidad que representan los principios de gestión pública consignados en el Plan de Desarrollo Municipal 2008-2011, para dar cumplimiento a los deberes de protección e integridad del ambiente impuestos al Estado por la Constitución.

La preocupante situación de los residuos peligrosos en el municipio exige la inclusión en el Plan de Desarrollo Municipal, "Línea 4 hábitat y medio ambiente para la gente", la reflexión sobre el estado de la gestión de los mencionados residuos, como quiera que los objetivos de la política ambiental municipal se orientan a prevenir, mitigar y/o remediar los impactos sobre los recursos naturales, a fin de garantizar calidad del medio ambiente y la calidad de vida de los ciudadanos. Así mismo, el Plan es la oportunidad para establecer y viabilizar las estrategias establecidas en el PGIRS para Identificar y promover alternativas de manejo en el marco de la gestión integral de residuos sólidos peligrosos, con énfasis en programas de separación en la fuente, presentación, almacenamiento, recolección, transporte, aprovechamiento, tratamiento y disposición final adecuada.

En las estrategias que adopte el plan se deben articular todas las acciones públicas, privadas y de los usuarios del servicio público, a fin de aumentar su impacto en la minimización de la generación de residuos, en el reciclaje y aprovechamiento y en la protección del patrimonio ambiental. De igual manera, se deben establecer programas de educación y concientización ambiental para fortalecer los valores sociales acordes con el desarrollo humano sostenible, para la construcción de un nuevo ciudadano, mediante programas de desarrollo cultural, educación y capacitación ambiental y apoyo a la participación ciudadana como forma fundamental de pedagogía. ${ }^{46}$

${ }^{46}$ Tomado de http://clinicajuridicaudem.blogspot.com/ 


\section{Tema 2: derechos de los consumidores y usuarios de servicios públicos}

Un caso realmente innovador por su impacto y por la época en que fue interpuesto por la Clínica Jurídica de la Universidad de Palermo es el denominado “caso Moneditas”, en el que se hace una defensa de derechos colectivos de los usuarios de servicios públicos a la protección de sus intereses económicos y a la información sobre las condiciones del servicio de telefonía pública:

En 1997 la tarifa de la telefonía pública (en Argentina) era de 22 centavos, los teléfonos públicos tenían un sistema llamado "mejor vuelto", en virtud del cual se le restituye a la persona el mejor vuelto posible de acuerdo con las monedas que el usuario había introducido. De igual forma los teléfonos no aceptaban monedas de un centavo, por lo cual era imposible para los usuarios pagar exactamente lo que iban a consumir.

Por lo anterior la licenciataria Telecom baja su tarifa a $\$ 0,20$, por lo cual obtenía una ganancia ilegitima por cada llamada que se realiza$\mathrm{ba}$, siendo calculada por la autoridad de control ( $\mathrm{CNC}$ ) en una suma cercana a los diez millones de pesos.

La clínica jurídica de la universidad de Palermo en cooperación con la asociación de defensa de consumidores y usuarios Adecua, inicia la acción judicial de amparo colectivo, para la adecuación del sistema de operación de los teléfono públicos y de esta manera lograr que los usuarios paguen el precio debido por sus comunicaciones.

Por lo anterior la empresa reprogramó sus teléfonos para cobrar $\$ 0,20$, pero no informó dicho cambio a los usuarios. Esto fue verificado por el tribunal interviniente quien obligo a la empresa a informar debidamente a los usuarios la nueva situación tarifaria, por tal razón debía modificar los instructivos de uso de los teléfonos para informar el valor correcto de las llamadas y difundirlo mediante avisos en diarios, radios y televisión. ${ }^{47}$

En la Clínica de Derechos Humanos de la Universidad del Rosario se apoyó en el año 2010 una gran acción popular cuyo tema era el acceso a agua potable para doce barrios de Ciudad Bolívar, en Bogotá (Colombia).

\footnotetext{
${ }^{47}$ Visibilidad en página web: http://www.palermo.edu/derecho/clinicas_juridicas/caso_moneditas.html
} 
El caso de Ciudad Bolívar posee características particulares que lo catalogan como un asunto de interés público no solo por el número de personas involucradas, sino porque pone de presente una situación que infortunadamente vive gran parte de la población colombiana: la falta de acceso a los servicios públicos domiciliarios, en particular al servicio de agua y alcantarillado.

[...].

La problemática que enfrenta la comunidad de Ciudad Bolívar, conformada principalmente por los habitantes de los barrios Tierra Colorada, Brisas del Volador, Tabor Alta Loma, Recuerdo Sur parte Alta, Alpes, Bella Flor, Verbenal, La Torre, El Edén, Paraíso, Volador Parte Alta y El Recuerdo, se enmarca de manera general en la precaria prestación del servicio de agua y alcantarillado por parte de la Empresa de Acueducto y Alcantarillado de Bogotá (en adelante EAAB) la falta de recolección de las basuras, y el cobro de facturas que no guardan relación con el consumo real.

Lo anterior, sumado a la acción negligente de las autoridades distritales frente a la situación que desde hace más de 11 años padecen los habitantes de Ciudad Bolívar en la ciudad de Bogotá, ha generado que hasta la actualidad quienes viven allí no cuenten con un servicio de agua y alcantarillado que satisfaga las condiciones mínimas de continuidad, eficiencia y oportunidad.

[...]. A pesar de que los vecinos del sector han solicitado durante años al Distrito y a la EAAB la instalación de un servicio de acueducto y alcantarillado digno, sus reclamos no han sido atendidos. La única acción encaminada a solucionar, de manera parcial el problema, fue la construcción de un tanque de abastecimiento hace más de una década en el barrio Alpes y otro en Brisas del Volador. Infortunadamente, al poco tiempo de su instalación aparecieron grietas en la base del primer tanque que generaron filtraciones de agua y terminaron por averiar el artefacto. Fue evidente entonces, que los tanques no reunían las condiciones técnicas para abastecer al gran número de personas que habitan el lugar; de hecho, el agua no llegaba a las casas por más de una o dos horas al día.

E131 de junio de 2010 el señor Dagoberto Bohórquez presentó una acción popular contra la EAAB, Aseo Capital S.A., la Superintenden- 
cia de Servicios Públicos Domiciliarios, la Gobernación de Cundinamarca, la Corporación Autónoma Regional y la Alcaldía Mayor de Bogotá. Esta acción, junto con la coadyuvancia presentada por el GAP, buscaba la pronta instalación de una infraestructura adecuada que permitiera la prestación del servicio de agua y alcantarillado de forma continua, así como un sistema de aseo y recolección de las basuras eficaz.

La sentencia de primera instancia (2010) decidió "no acceder a las pretensiones de la acción popular". Según lo sostenido por este despacho, los barrios de Ciudad Bolívar, al ser ilegales, no cuentan con la infraestructura necesaria para que se preste un servicio eficiente y oportuno. De forma que, sugirió el juez, deben acogerse a las posibilidades que les ofrezca la empresa, es decir, a los carrotanques que ocasionalmente iban a vender agua en algunos sectores.

E1 Tribunal Contencioso Administrativo de Cundinamarca revoca la sentencia de primera instancia "debido a que esta no se pronunció sobre la totalidad de los barrios afectados de la demanda por la vulneración de los derechos colectivos; en efecto, si bien en otra sentencia se garantizaron los derechos colectivos de barrios aledaños a la zona, no se puede desconocer el derecho de los barrios que aún no están dentro del ámbito de protección judicial.

Bajo las anteriores consideraciones y para tomar una decisión de fondo, el Tribunal analiza la vulneración de los derechos colectivos invocados en la demanda sobre la presunta responsabilidad de las entidades demandadas y concluye que "los barrios objeto de la acción popular presentan una inadecuada prestación de los servicios públicos puesto que no existe infraestructura de alcantarillado, y los habitantes de estos barrios han optado por construirlo ellos mismos con sus propios medios"; y por otro lado, el Tribunal concluye que "la recolección de basuras y escombros de las viviendas se realiza sobre las vías principales mas no puerta a puerta, debido a que las características topográficas de los predios impiden el acceso de los vehículos de recolección".

Conforme a lo anterior, el Tribunal determina que el Distrito Capital es responsable por omisión constitucional porque ha reconocido la legalidad de la mayoría de los barrios que son objeto de la Acción 
Popular y no ha prestado el servició público de manera efectiva; ordena que la Gobernación de Cundinamarca deberá apoyar al Distrito Capital y a la Empresa de Acueducto y Alcantarillado de Bogotá (ЕАAB) para que se le preste eficiente y oportunamente el servicio público de acueducto y alcantarillado a dos barrios legalizados; y resuelve que la Corporación Autónoma de Cundinamarca (CAR) deberá emitir concesiones, permisos, autorizaciones y las licencias ambientales necesarias para la ejecución de obras que permitan la prestación futura del servicio público.

[...].

De este modo, el GAP concentró todo el litigio estructural en un trabajo por la comunidad, con la comunidad y para la comunidad, a través de diferentes estrategias de litigio que permitieron una sentencia (cuyo impacto social y jurídico es muy importante) en segunda instancia favorable a los intereses de la comunidad de Ciudad Bolívar (Fager, 2013).

\section{Derechos de grupos de especial protección en derechos humanos}

\section{Tema 1: derechos de las mujeres}

Son realmente recientes los ejercicios de clínicas jurídicas en esta materia. En el texto de Coral (2010) se muestran los temas centrales de este litigio y su relación con problemáticas de violencia basada en género y violencia doméstica o intrafamiliar.

En Estados Unidos son muy numerosos los trabajos que sistematizan las experiencias de las Clínicas en esta materia (Shalleck, 2003), pero en Iberoamérica es aún un campo poco explorado.

En Colombia existen a partir de 2013 tres clínicas derivadas de un proyecto de investigación desarrollado con onU-Mujer y liderado por la Universidad del Rosario con el apoyo de las universidades de Nariño, Pontificia Universidad Javeriana de Cali y el Tecnológico Comfenalco en Cartagena. Se trata de clínicas en formación que buscan plantear casos de litigio estratégico en la materia y acompañar a las mujeres en la ruta de atención que se señala para la garantía de sus derechos. 


\section{Tema 2: derechos de las personas con discapacidad}

En varios países de la región y, de manera muy especial, en Colombia, se ha desarrollado una amplia jurisprudencia para la garantía de los derechos de las personas con discapacidad. Trabajos como el de Correa dan cuenta de temáticas que aún no han sido exploradas por el litigio estratégico, sino a través de casos individuales, pero que permiten examinar las líneas jurisprudenciales planteadas por la Corte Constitucional (Correa-Montoya, 2009).

De igual forma se han elaborado estudios profundos sobre el litigio estratégico que se ha realizado en Latinoamérica en materia de discapacidad (Bariff, 2013), en los que al realizar un diagnóstico del tema se observan factores en toda la región, como la situación de invisibilidad, la exclusión estructural, la carencia de oportunidades, la escasa formación jurídica de esta población, su situación de vulnerabilidad, las fuertes tendencias al asistencialismo, entre otros (Correa, 2013, pp. 29-30).

Se destacan casos liderados por las clínicas en temas como (i) internación coactiva o forzada de personas con discapacidad cognitiva como restricción a la libertad, planteado en Argentina con múltiples casos exitosos en Buenos Aires propuestos por la Defensoría General de la Nación con apoyo de las universidades; (ii) acción de inconstitucionalidad frente al concepto de incapacidad como causal de revocación de cargos de elección popular en México; (iii) el caso Ximenes Lopes vs. Brasil, en el que se condena al Estado de Brasil por la Corte Interamericana ante la internación y malos tratos sufridos por una persona con discapacidad mental y su posterior muerte (julio 4 de 2006) (Bariffi, 2013).

La Clínica de Discapacidad de la Universidad Carlos III relata la recepción y manejo del caso de un joven musulmán que sufrió un accidente, perdió la memoria y lo habían internado en un centro para personas mayores. Se presentaba un escaso contacto con familiares o amigos, nadie tenía la tutela y ante su situación médica se buscó una prórroga de la situación de internamiento.

De igual forma, la Clínica de Valencia proyectó para varias organizaciones en temas de discapacidad un dictamen en el cual se aborda la grave problemática de supresión de la gratuidad en las medicinas y prótesis para las personas con discapacidad. Se considera que existe un problema de desigualdad frente a las demás comunidades y se analiza el principio de igualdad y el principio de discriminación indirecta. 
Existen grandes retos en la materia, en especial, lograr la difusión amplia, la pedagogía y el cumplimiento de instrumentos internacionales recientes, como la Convención sobre los Derechos de las Personas con Discapacidad de Naciones Unidas (2007), cuyo objeto es "Promover, proteger y asegurar el goce pleno y en condiciones de igualdad de todos los derechos humanos y libertades fundamentales por todas las personas con discapacidad, y promover el respeto de su dignidad inherente" (artículo $1^{\circ}$ ).

\section{Tema 3: derechos de los migrantes, refugiados y desplazados}

\section{Casos de migrantes}

Los derechos de migrantes empiezan a ser uno de los temas más abordados por las clínicas especializadas en países como España, Argentina, Chile, Venezuela, entre otros. En este ejercicio se ha utilizado el derecho interno y el derecho internacional, generando aprendizajes de enorme valor en el litigio y a nivel académico.

Un primer ejemplo de casos relacionados con la figura del amicus curiae se relaciona con el tema del uso de la fuerza legítima frente a migrantes en la frontera entre Haití y República Dominicana (masacre de Guayabín).

Se trata de un amicus curiae que fue redactado conjuntamente por la Clínica del Sistema Interamericano de Derechos Humanos de la Universidad Carlos III de Madrid, Boston University School of Laws y Loyola Faculty of Law, en el año 2012.48

De igual forma en esta clínica se construyó un memorando sobre el caso de trabajadores indocumentados en Estados Unidos. En la argumentación hay dos ejes: (i) el tema de igualdad y (ii) la no discriminación. Se desarrolla el derecho a la seguridad social, su progresividad y la utilización del Protocolo de San Salvador en el tema. Se presentan recomendaciones para los tratados de libre comercio, señalando la importancia de acoger los principios de la OIT y la protección de trabajadores migrantes. Se considera que el desconocimiento de la seguridad social promueve la migración ilegal en lugar de controlarla. No hay criterios de racionalidad ni proporcionalidad.

Recomendaciones: instar a Estados Unidos a revisar sus políticas internas y revisar la jurisprudencia que está vulnerando derechos humanos. Por otro la-

\footnotetext{
${ }^{48}$ Tomado de: http://www.cidh.org/demandas/12.688Esp.pdf
} 
do están la exigencia a los empleadores de permitir que los trabajadores puedan reclamar ante las instancias e instar para revisión de su normatividad interna.

En Chile existe una clínica dedicada a este tema en la Universidad Diego Portales. La clínica surge como un curso electivo sobre migración y refugio en la Facultad de Derecho de la Universidad Diego Portales: "un área que hemos manejado son los reclamos de nacionalidad de hijos de extranjeros transeúntes. Se trata de niños que nacen en Chile y les niegan la nacionalidad por la situación irregular de sus padres". Lo interesante de esta interpretación de la Constitución que ha logrado la Corte Suprema es el efecto práctico, ya que "si el niño se regulariza uno puede después regularizar a los padres”(Olea, 2013).

Uno de los casos más representativos de la Clínica de Migrantes del CELs-Caref-uba fue el relacionado con una acción de amparo en defensa de Daniela Reyes Aguilera, que como relata el profesor Efron, era una menor de edad de origen boliviano con parálisis cerebral. En el recurso "solicitaron una pensión por discapacidad para garantizarle condiciones mínimas de subsistencia”. Esta pensión le fue negada en el año 2003 por la Comisión Nacional de Pensiones Asistenciales, señalando que para lograr la pensión se exige a los extranjeros un mínimo de veinte años de residencia legal en Argentina. La Clínica de Derechos de Inmigrantes y Refugiados cels-Caref-uba denunció la inconstitucionalidad de ese requisito en marzo de 2003 y solicitó que se le otorgara la pensión.

El caso llegó a la Corte Suprema de Justicia de la Nación y en septiembre de 2007 esta condenó al Estado argentino a otorgarle una pensión por invalidez a Reyes Aguilera. En su fallo, la Corte sostuvo que frente a situaciones de extrema necesidad que ponen en juego la subsistencia de las personas "el Estado está obligado a adoptar medidas positivas que aseguren condiciones mínimas de una vida digna” y que "esta obligación rige con independencia del origen nacional de las personas" (Efrón, 2014, p. 2).

\section{Casos de desplazamiento forzado}

La Clínica Jurídica sobre Derecho y Territorio de la Pontificia Universidad Javeriana realiza asesoría directa a población desplazada colombiana en la recuperación de tierras en el denominado caso "Las Pavas". Interpuso una coadyuvancia dentro de una acción de tutela. En dicho escrito afirma: 
Los campesinos de la "Hacienda Las Pavas" a favor de quienes se interpuso la acción de tutela que es objeto de revisión, han sido víctimas de la violación de sus derechos fundamentales debido a su desplazamiento forzado, así como a las acciones y omisiones de las autoridades públicas que constituyen fallas en la atención adecuada de la población desplazada y que han favorecido el despojo. Esta desprotección de sus derechos humanos claramente implica el incumplimiento del Estado colombiano de sus obligaciones internacionales. Así, la honorable Corte Constitucional debe pronunciarse para garantizar la efectividad de los derechos de esta comunidad. ${ }^{49}$

\section{Tema 4: derechos de las personas mayores}

Entre los casos que se han conocido al interior del Grupo de Acciones Públicas, donde por medio del litigio estratégico se ha logrado incidir en políticas públicas, la sociedad civil e incluso la legislación, está el denominado "Ciudadanía de Oro", un ejercicio jurídico que permitió, a partir del diseño de una serie de acciones de interés público, la consecución efectiva de los elementos que aportan para una solución a la problemática de un colectivo de especial protección constitucional como lo es la población de adultos mayores:

El ciudadano Efraín Belalcázar Carvajal, persona mayor, acudió a las instalaciones del GAP con el fin de consultar por qué no se le estaba dando cumplimiento a la Ley 1091 de 2006 que le daba derecho a contar con una tarjeta especial de identidad que lo identificaba como un "Ciudadano de Oro".

La Ley 1091 del año 2006, establece que la Registraduría Nacional del Estado Civil debe entregarles a los ciudadanos mayores de 62 años, una credencial especial que los identifique como "Colombianos de Oro”; sin embargo, luego de una revisión preliminar de la legislación relacionada con el caso, el GAP encontró que no solo la Ley 1091, aludida por el señor Belalcázar no tiene cumplimiento, sino la mayoría de las disposiciones legislativas relacionadas con los adultos mayores está ausente de aplicación en temas como [...] i) beneficios para garantizar los derechos a la educación, a la recreación, a la salud

\footnotetext{
${ }^{49} \mathrm{https} / /$ retornoalaspavas.wordpress.com/documentos-juridicos/corte-constitucional/
} 
y propiciar un mejoramiento en las condiciones generales de vida de los adultos mayores, ii) la protección a las personas de la tercera edad de los niveles I y II de Sisbén, buscando brindarles una atención integral;iii) garantizar la atención y prestación de servicios integrales con calidad al adulto mayor en las instituciones de hospedaje, cuidado, bienestar y asistencia social, entre otras, son ejemplo de ello. [...] La estrategia jurídica, [...] se vio concretada en una acción popular presentada por el GAP en el año 2010, que buscaba el reconocimiento de los derechos colectivos de las personas de la tercera edad. Sin embargo, esta acción no hubiese podido elaborarse si de manera concurrente no se hubiera llevado a cabo una estrategia pedagógica, que por medio de talleres y capacitaciones dirigidos al colectivo afectado, buscó ponerlo al tanto de sus derechos y de las acciones que estos podrían ejercer; esta estrategia permitió que varios grupos de adultos mayores presentaran un total de cuatro coadyuvancias a la acción jurídica instaurada por el GAP. De igual forma, se aprovecharon estos espacios pedagógicos para realizar una estrategia social, representada en actividades culturales alternadas con espacios de aprendizaje, empoderando a la población a partir de la concientización de su condición y de la importancia de ellos para la consolidación de un Estado, pues sobre la base del reconocimiento a la "experiencia de los años", el mismo legislador ha expedido las normas alusivas a esta población.

Ante la implementación de estas estrategias, se logró obtener como resultado un fallo de fecha 8 de marzo de 2013, donde se conminó al Ministerio de Salud a expedir la reglamentación necesaria para que la Registraduría Nacional inicie la expedición de la credencial de "Colombiano de Oro" e instó a las superintendencias Financiera y de Salud, a insistir en el tratamiento especial y prioritario de las personas de la tercera edad (Torres, 2013, p. 10).

\section{Tema 5: derechos de la población LGBTI}

En Colombia el litigio estratégico en defensa de la población LGBTi lo han liderado las organizaciones sociales del sector, entre ellas Colombia Diversa. Se han constituido alianzas importantes con diversas clínicas jurídicas del 
país, buscando que se promuevan acciones o se les apoye en casos específicos, utilizando la herramienta del amicus curiae.

Como caso emblemático se presenta el logrado con la Sentencia C-075 de 2007 de la Corte Constitucional, donde la clínica GDIP de la Universidad de Los Andes, con apoyo de varias organizaciones y universidades, presentó una acción de inconstitucionalidad ante la Corte Constitucional.

En este caso se lograron alianzas muy importantes y apoyo de diversas clínicas jurídicas de Colombia y el exterior. ${ }^{50}$ Se logró hacer una publicación muy valiosa donde se recogen las estrategias de litigio en el caso y el texto de la sentencia (Bonilla, 2008).

A manera de ejemplo presentaremos un resumen de la intervención del Icesi:

La Clínica de la Universidad Icesi presentó el 23 de junio de 2008, ante la Corte Constitucional, un amicus curiae apoyando la acción de inconstitucionalidad D-7290. En la intervención se solicitaba la ampliación de los derechos de las parejas heterosexuales a parejas homosexuales alegando que la visión tradicional de familia no es el único fundamento para brindar protección jurídica a una práctica de vida en común. De hecho, la jurisprudencia internacional muestra ejemplos claros de redefiniciones más garantistas de la "familia" que deberían incorporarse a la jurisprudencia nacional.

Adicionalmente, en la intervención se incoaba el derecho civil fundamental al libre desarrollo de la personalidad el cual integra aspectos como la libertad de toda persona de optar sin coacción alguna por un determinado estado civil, y entre otras opciones de decidir entre contraer matrimonio, vivir en unión libre o permanecer en soltería. ${ }^{51}$

Otro caso emblemático es el de Atala Riffo y niñas vs. Chile. Este caso se inicia en el 2004 con una petición ante la Comisión Interamericana presentada por la señora Karen Atala Riffo relacionado con el proceso de custodia o tuición que interpuso el padre de las niñas M., V.y R. contra ella por estimar que su orientación sexual y situación de convivencia con una pareja del mismo sexo generarían un daño para las niñas, caso que fue fallado por la Corte

\footnotetext{
${ }^{50}$ Ver en páginas web:http://www.icesi.edu.co/grupo_acciones_publicas_icesi/campos_de_accion.php

${ }^{51} \mathrm{http}: / /$ www.icesi.edu.co/grupo_acciones_publicas_icesi/campos_de_accion.php
} 
Suprema de dicho país. La señora Atala fue representada por abogados de la Asociación Libertades Públicas, la Clínica de Acciones de Interés Público de la Universidad Diego Portales y la Fundación Ideas. En el año 2010, la Comisión somete el caso a la jurisdicción de la Corte Interamericana.

En la Sentencia la Corte declaró a Chile responsable internacionalmente por haber vulnerado: i) el derecho a la igualdad y la no discriminación consagrado en el artículo 24 (igualdad ante la ley), en relación con el artículo 1.1 (obligación de respeto y garantía) de la Convención Americana, en perjuicio de Karen Atala Riffo; ii) el derecho a la igualdad y la no discriminación consagrado en el artículo 24 (igualdad ante la ley), en relación con los artículos 19 (derechos del niño) y 1.1 (obligación de respeto y garantía) de la Convención Americana, en perjuicio de las niñas M., V. y R.; iii) el derecho a la vida privada consagrado en el artículo 11.2 (protección a la honra y a la dignidad), en relación con el artículo 1.1 (obligación de respeto y garantía) de la Convención Americana, en perjuicio de Karen Atala Riffo; iv) los artículos 11.2 (protección a la honra y a la dignidad) y 17.1 (protección a la familia), en relación con el artículo 1.1 (obligación de respeto y garantía) de la Convención Americana en perjuicio de Karen Atala Riffo y de las niñas M., V. y R.; v) el derecho a ser oído consagrado en el artículo 8.1 (garantías judiciales), en relación con los artículos 19 (derechos del niño) y 1.1 (obligación de respeto y garantía) de la Convención Americana en perjuicio de las niñas M., V. y R., y vi) la garantía de imparcialidad consagrada en el artículo 8.1 (garantías judiciales), en relación con el artículo 1.1 (obligación de respeto y garantía) de la Convención Americana, respecto a la investigación disciplinaria, en perjuicio de Karen Atala Riffo. Por otra parte, la Corte declaró que el Estado no violó la garantía judicial de imparcialidad consagrada en el artículo 8.1 (garantías judiciales) de la Convención Americana, en relación con las decisiones de la Corte Suprema de Justicia y el Juzgado de Menores de Villarrica ${ }^{52}$ (Caso Atala Riffo y niñas vs. Chile, 2012).

52 Vid: http://joomla.corteidh.or.cr:8080/joomla/index.php?option=com_content\&view=article\& catid $=40$ :resumen\&id $=1612$ 
Llama la atención en este caso la enorme cantidad de amicus curiae recibidos por la Corte Interamericana, muchos de ellos provenientes de profesores universitarios, organizaciones sociales, centros de investigación y algunas clínicas.

\section{Tema 6: derechos de pueblos indígenas, afroamericanos y comunidades tribales} Un caso interesante fue el que trabajó la Clínica de Derechos Humanos de la Universidad de Palermo, en relación con los derechos de las comunidades aborígenes al respeto de su identidad cultural, buscando acceso efectivo a la educación bilingüe para los niños de una comunidad mapuche de la provincia del Neuquén.

Varias normas constitucionales, concretas reglamentarias de la provincia del Neuquen, garantizan el acceso a educación bilingüe para las comunidades aborígenes.

Las anteriores normas no eran cumplidas efectivamente, por tal razón en cooperación abogados de la provincia del Neuquen, la clínica presenta un reclamo administrativo al consejo de educación provincial para que se hiciera efectiva la designación de un maestro bilingüe. Por falta de respuesta, se promovió una acción de amparo para exigir la designación de un maestro para la comunidad afectada. El tribunal de Junín de Los Andes consideró procedente la demanda y condenó al estado provincial a producir el nombramiento de un maestro bilingüe para la comunidad. El estado consintió la sentencia e implementó el nombramiento efecto del maestro. ${ }^{53}$

En la Clínica de la Universidad de San Marcos, en Perú, tuvieron acercamiento a la Clínica de la Universidad de Toronto, en Canadá, dirigida por el profesor Shin Imaí. Trabajaron conjuntamente en el caso de la explotación minera de Cajamarca.

En Cajamarca (Perú), se otorgó una concesión minera con varias irregularidades y se vulneraban los derechos de muchas personas, en especial de

${ }^{53}$ Visibilidad en páginas web: http://www.palermo.edu/derecho/clinicas_juridicas/educacion_bilingue.html; tomado de: http://www.palermo.edu/derecho/clinicas_juridicas/educacion_bilingue.html;

http://www.probono.org.ar/downloads/158_download.pdf 
los indígenas. Ambas clínicas elaboraron un informe señalando la situación, las consecuencias y la viabilidad de emprender un amparo a nivel nacional.

El GAPI ha venido realizando labores de litigio estratégico para instar a la sala especializada de productos naturales, la inclusión de la hoja de la coca en el vademécum de plantas medicinales. Para ello, se conformó un grupo interdisciplinario integrado por profesores y estudiantes de las carreras de Medicina, Antropología y del Grupo de Acciones Públicas — GAPI- de la Universidad Icesi, quienes trabajan para que el patrimonio cultural de las comunidades indígenas sea conservado. Lo anterior, teniendo en cuenta el valor medicinal y cultural que tiene la hoja de coca. Es importante resaltar que la hoja de coca es una planta que engloba la sabiduría ancestral que puede ser utilizada como antiinflamatorio, anestésico local y analgésico. Por ello, el objetivo de esta acción consiste en garantizar el acceso de todos los colombianos a la hoja de coca, en las mismas condiciones en las que otros productos de origen natural son reconocidos. ${ }^{54}$

En acciones de tutela se ha buscado, en el caso colombiano, la defensa de los territorios de comunidades indígenas y afrocolombianas.

En noviembre de 2007 el Grupo de Derecho de Interés Público (GDIP), bajo la dirección de Daniel Bonilla, y el Centro de Estudios de Derecho,Justicia y Sociedad (Dejusticia) presentaron conjuntamente una acción de tutela que solicitaba la protección de los derechos a la identidad cultural, la integridad, la autonomía y la existencia de la comunidad negra de las Islas del Rosario. La acción pretendía que el Incoder tramitara y diera respuesta de fondo a la solicitud de titulación colectiva presentada por el Consejo Comunitario de $\mathrm{Co}^{-}$ munidades Negras de la Unidad Comunera de Gobierno Rural de Isla del Rosario - Caserío Orika. La tutela fue negada en primera y segunda instancia. La Corte Constitucional seleccionó el caso y el pasado 21 de enero publicó la Sentencia T-680 de 2012, en virtud de la cual amparó los derechos fundamentales de petición, debido

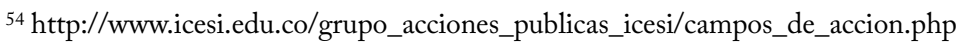


proceso administrativo y a la propiedad colectiva de las tierras del Consejo Comunitario de Orika. En la sentencia se ordena al Incoder resolver la solicitud de titulación colectiva y se dictamina que hasta que dicha solicitud no se resuelva, se suspende la celebración de nuevos contratos de usufructo y arrendamiento con poseedores privados sobre los terrenos de las islas, así como la prórroga o adición de los que ya han sido celebrados. La Corte también previene al Incoder para que, si en el futuro expide decisiones que afecten a la comunidad negra del archipiélago, lo haga garantizando el derecho de esta a la consulta previa. .5

\section{Tema 7: derechos de las víctimas de trata de personas}

Una de las más graves formas de violación de derechos humanos en el siglo XXI es la trata de personas, tráfico que moviliza enormes cantidades de dinero en el mundo y que revive ciertas formas de esclavitud a nivel mundial. Se trata del tercer negocio ilícito en cifras del mundo, después del tráfico de drogas y el de armas.

En el iтам (México), desde el año 2013, funciona la Clínica Contra la Trata de Personas. Se trata de un proyecto conjunto en el cual participan también el Bufete Jurídico en Contra de la Trata de Personas de la Universidad de Michigan (нтс) y el Instituto Nexus. Esta clínica trabaja la defensa y acompañamiento jurídico a víctimas de este flagelo; de igual forma realiza incidencia en las instituciones del Estado y, en tercer lugar, diseña estrategias de difusión para sensibilizar y concientizar sobre la problemática.

Según expone el profesor Pérez:

La meta de este proyecto es desarrollar una clínica de interés público en contra de la trata de personas en México para las víctimas de este delito, que servirá como modelo para aumentar el apoyo y la defensa legal que reciben los afectados y para brindarles los servicios legales de abogados independientes. Tales servicios podrán incluir acompañamiento en procedimientos judiciales, reunificación de familias y acceso a asistencia migratoria (Pérez, 2014, p. 3).

\footnotetext{
$55 \mathrm{http} / /$ gdip.uniandes.edu.co/index.php?modo=resultados\&id=4
} 


\section{Tema 8: derechos de las personas en establecimientos de reclusión}

Es innegable la crisis humanitaria que viven los centros de reclusión en América Latina. Frente a esta situación algunas clínicas han iniciado labores de denuncia, propuestas de políticas públicas que garanticen los derechos humanos y acciones judiciales.

Se destaca la labor que en este campo realizó la clínica GDip (Universidad de Los Andes) en el año 2013, a través de (i) talleres de pedagogía en derechos en las principales cárceles de Colombia; (ii) el borrador de proyecto de ley para un nuevo Código Carcelario y Penitenciario, que desafortunadamente no fue acogido por el Ministerio de Justicia para presentarlo al Congreso; (iii) la acción de tutela en defensa de los presos en la Cárcel Modelo de Colombia y (iv) la evidencia de no superación del estado de cosas inconstitucional en materia carcelaria en el país, entre otras grandes intervenciones estratégicas en defensa de esta población. ${ }^{56}$

\section{Aprendizajes del litigio estratégico}

- Se toma como punto de partida la necesidad de evolucionar en la noción de litigio estratégico hacia la de litigio estratégico colectivo y progresista, dos adjetivos que diferencian claramente la intervenciones y exigen impactos que trasciendan el debate individual,y que en sus objetivos se propongan incidir en elevar el nivel de garantía y protección de los derechos, avanzar en su interpretación e incluso generar transformaciones en políticas públicas para fortalecer los derechos humanos.

- Se observan valiosas experiencias y resultados exitosos del litigio estratégico de las clínicas. Una metodología generalizada es la de buscar casos emblemáticos y lograr, a través de ellos, la reflexión, el debate y los avances jurídicos que se planean.

- Las acciones que más se utilizan son las de amparo (tutela), inconstitucionalidad, acceso a información o derecho de petición y, en el caso colombiano, las acciones populares.

- Se evidencian estrategias exitosas, como las que buscan fortalecer el trabajo pro bono, la alianza de clínicas y ONG, los amicus curiae y la

\footnotetext{
${ }^{56}$ Ver: http://gdip.uniandes.edu.co/index.php?modo=resultados\&id=1
} 
elaboración y publicación de informes sobre casos de vulneración de derechos humanos. De igual forma existen experiencias interesantes de pedagogía en derechos humanos y litigio estratégico, como la que promovió Litiga en México en el año 2010, cuando:

Realizaron unos talleres itinerantes de litigio estratégico en la república, financiados por la Suprema Corte en un proyecto para formar capacidades de litigio. Seleccionaron cuatro lugares de México y allí se reunieron con abogados en talleres de tres o cuatro días. Las personas presentaban casos de derechos humanos o interés público de sus localidades. En el taller se examinaban casos, estrategias y se decidía en conjunto llevar un caso a la práctica real. El compromiso del staff de litiga era apoyarles y asesorarles (Rodríguez, 2013).

- El trabajo conjunto empieza a perfilarse, aunque falta mucho apoyo para que las clínicas planteen casos comunes y las redes apoyen este tipo de esfuerzos.

- Un trabajo prioritario para ampliar las posibilidades de litigio estratégico debería orientarse a la ampliación de la legitimación en las acciones de interés público.

- El litigio estratégico es un escenario de gran valor para la formación integral de los estudiantes de derecho, y contribuye igualmente a aportarles competencias y herramientas para conocer y buscar transformar la realidad social.

- En el caso de las estrategias que vinculan trabajo pro bono, se requiere "una mayor conciencia por parte de los abogados de la importancia de su función social, superando las visiones clásicas del ejercicio profesional y adentrándose en el conocimiento de causas que logren aportar al capital social de un país" (Torres, 2013, p. 16).

- Se precisan muchos espacios de intercambio y formación en temas de litigio estratégico especializado. Hay temas en los que aún es escaso el trabajo por parte de las clínicas, como los casos de violencia de género y derechos de las mujeres, la trata de personas, la defensa de las personas mayores y de la comunidad LGBTI. 


\section{Conclusiones}

\section{Aportes para la agenda pendiente de la educación legal clínica y el litigio estratégico en Iberoamérica}

\section{Propuesta pedagógica}

Como hemos visto en este trabajo, la educación legal clínica puede ser una respuesta que complemente otras alternativas en la búsqueda de reformas a la educación jurídica en Iberoamérica.

Las clínicas tienen esa característica de nova et vetera tan importante en una propuesta de modelo pedagógico que, siendo innovador, hunde sus raíces en problemas que se han evidenciado en las facultades de derecho desde el siglo xix. Tienen además la característica esencial, acorde con los planeamientos de Bolonia, de ser una propuesta centrada en los estudiantes como eje constructor de cambios en la docencia, la investigación y la extensión universitaria. Reúne además elementos de fuentes teóricas muy valiosas, como el realismo jurídico y la teoría crítica, entre otras.

Conviene que a través de las redes de clínicas se busquen consensos sobre los principios pedagógicos y criterios que puedan identificar con claridad cuándo se está desarrollando verdadero trabajo clínico. Para la discusión proponemos los siguientes: (i) trabajo con un doble objetivo misional: intereses académicos e impacto social para solucionar problemas reales; (ii) responsabilidad de los estudiantes (son los líderes del proceso); (iii) cambio en el rol del profesor, pues asume el papel de supervisor, y (iv) trabajo en casos reales.

Se considera también importante que las clínicas tengan una norma interna de creación, un reglamento de acceso público y un rubro presupuestal.

Aún se evidencian muchas dificultades para la implementación de la educación legal clínica, entre ellas la tradición formalista de los sistemas jurídicos en la región y la falta de claridad sobre los presupuestos de funcionamiento de las clínicas. Se observa además que son escasos los escenarios de formación y sistematización de experiencias y, además, se carece de análisis regionales. 
Falta una revisión más profunda sobre la perspectiva pedagógica del trabajo de las clínicas. En América Latina, se debe avanzar en la consideración de que, más que un método, es un modelo en construcción. Algunas tareas adicionales pendientes se relacionan con la investigación y reflexión sobre los sistemas de evaluación en la educación legal clínica y con estrategias para lograr un enfoque multidisciplinario en el manejo de casos y en la investigación sobre educación jurídica.

La gran inquietud por el reconocimiento de las clínicas se orienta a que sean una práctica con valor académico, que los docentes sean de planta o de tiempo completo, que se valore en créditos la actividad de las clínicas y que se promueva institucionalmente su creación. Las clínicas deben relacionarse con las fortalezas académicas de las facultades y con su reconocimiento social y relaciones externas, ya que el litigio estratégico o el trabajo street law no puede hacerse sin alianzas.

Según el examen realizado a las clínicas iberoamericanas, se considera necesario fortalecer una inserción más clara de ellas en las facultades de derecho: hace falta una mayor visibilidad e inclusión curricular explícita. Se reconoce que existe una directa relación entre el fortalecimiento de la educación legal clínica y mayores y mejores estándares de calidad en la docencia jurídica; en los procesos de acreditación esta es una característica de gran importancia.

El rol de los docentes en este cambio es igualmente transformador e implica rupturas con paradigmas de docencia jurídica internalizados en las facultades durante varios siglos.

En la formación de docentes clínicos debe tenerse en cuenta que se requiere que existan profesionales interesados en desarrollar transformaciones en torno a la enseñanza del derecho y que sus esfuerzos generen el impacto suficiente. Se requiere en los docentes competencias específicas, experiencia en el área de trabajo de la clínica, habilidades didácticas — como el diseño de casos simulados (role playing) —, propuestas de atención de clientes, fortalezas en supervisión y revisión de escritos jurídicos, entre otras. Deben igualmente tener capacidad para generar procesos de autoaprendizaje y de aprendizaje activo y significativo con incidencia en la resolución de problemas relacionados con su entorno.

En relación con la estructura y funcionamiento de las clínicas, conviene revisar el compromiso institucional con esta figura y fortalecer los recursos físicos, el número de docentes supervisores, sus espacios de trabajo, el uso de 
nuevas tecnologías para apoyar el trabajo, y la divulgación en medios de comunicación, en internet y al interior de las universidades sobre el trabajo de las clínicas y su impacto social y académico.

Tal vez la mayor complejidad del modelo está en su insumo central: los casos reales, el acercamiento del estudiante a su entorno, el aprendizaje para asumir problemas y buscar soluciones integrando conocimientos y saberes de su profesión. Tiene además un don maravilloso y es que atrae poderosamente a los estudiantes, pues el nuevo rol que asumen los dignifica; pasan de ser simples depositarios de saberes ajenos a constructores de su propio conocimiento, con un acompañamiento especializado y personal de los docentes supervisores de la clínica.

Es igualmente necesario reconocer que el antecesor más importante de la educación legal clínica han sido los denominados servicios legales gratuitos, bufetes o consultorios jurídicos, que han existido desde los años sesenta en la mayoría de los países iberoamericanos, salvo en el caso de España.

La propuesta es asumir las clínicas como una evolución de los servicios ya existentes y permitir que continúe la atención para el acceso a la justicia individual que se viene prestando de forma eficiente en la región, pero que se complemente con las clínicas como servicios de acceso colectivo o individual en casos de interés público, derechos humanos y otras áreas del derecho.

Esta visión de complementariedad y no de oposición entre modelos permitiría el fortalecimiento de las prácticas jurídicas, la formación de los estudiantes en responsabilidad social universitaria y el acceso a la justicia gratuita y de calidad para quienes lo requieran.

En el rediseño curricular, conviene igualmente que esta evolución sea explícita y que se asignen créditos a las prácticas en consultorio jurídico o en clínicas jurídicas. Los impactos de estos cambios en la educación jurídica serán visibles en el fortalecimiento de competencias específicas en materia de investigación, ejercicio directo del derecho y aprendizaje de valores éticos y ciudadanos. De igual forma, la repercusión social y la visibilidad de estos servicios de extensión por parte de las universidades permitirán más altos estándares en los resultados de extensión, aprendizaje-servicio y responsabilidad social universitaria, y esto se reflejará en los procesos de acreditación.

Se considera que un concepto medular del trabajo clínico en Iberoamérica ha sido el litigio estratégico, y que los cambios estructurales se dan a largo 
plazo y requieren del acompañamiento de las organizaciones y las universidades a través de la acción y la investigación.

Surge como un elemento de consenso la importancia del trabajo en redes y comunidades de práctica en el que se profundicen experiencias, formas de trabajo y sistemas de evaluación. Otras recomendaciones importantes apuntan a fortalecer el intercambio de docentes, apoyar ejercicios de supervisión, realizar propuestas de trabajo en grupos o inter-clínicas para casos complejos, hacer reuniones temáticas, fortalecer los sitios web en los que esté la información de apoyo a las clínicas, videoconferencia con los estudiantes de otras clínicas y, en general, la promoción de estrategias de enlace y relacionamiento.

El enfoque temático se impone en el diseño de las nuevas clínicas y en la selección de los casos. Esta evolución que parte de las fortalezas de las universidades y las organizaciones permite la sostenibilidad de las clínicas y garantiza procesos de aprendizaje e investigación con resultados claros que se pueden sistematizar. De igual forma facilita la construcción y permanencia de las redes y las alianzas con ONG, organizaciones pro bono y otras clínicas o instituciones nacionales o internacionales en torno a objetivos comunes.

La definición de las temáticas a abordar por las clínicas implica trabajo previo de investigación, examen de la situación de derechos humanos y de los problemas más significativos a los cuales se trata de dar una respuesta desde las universidades, con un carácter realista e innovador.

Es igualmente importante conocer y multiplicar en Iberoamérica las experiencias que se tienen en clínicas de maestría. Son ejemplos importantes los trabajos de las universidades de Palermo (en Argentina), Carlos III, Valencia, Barcelona y Tarragona (en España). Los estudiantes de posgrado pueden aportar valiosos conocimientos y un tratamiento profundo y cualificado a la labor de litigio estratégico en todas sus modalidades. 


\section{Anexo 1 El diseño de una clínica jurídica}

Autora: María Marques Banqué. Directora de la Clínica Jurídica Ambiental. Centro de Estudios de Derecho Ambiental de Tarragona (Cedat). Universitat Rovira y Virgili.

Material adaptado de Shrag, P. G. (1996). “Constructing a Clinic”. En 3 Clinical Law Revierw, 175.

\section{I. Área de actuación de la clínica}

a. ¿A qué ámbito del Derecho hace referencia la propuesta?

b. ¿Es imaginable la colaboración puntual o permanente con otras áreas jurídicas y/o con otras disciplinas? ¿Cuáles?

\section{Objetivos de la clínica}

a. ¿Cuáles son los objetivos formativos?

b. ¿Cuáles son los objetivos sociales?

c. ¿La propuesta es una experiencia de aprendizaje?

\section{El equipo docente}

a. ¿Cuántos miembros debe tener la clínica como mínimo?

b. ¿Qué perfil tienen que tener los miembros de la clínica?

c. ¿La Clínica debería contar con colaboradores externos puntuales o permanentes? ¿Cuáles y por qué?

d. ¿Cuáles son los mecanismos de coordinación y funcionamiento del equipo docente?

e. ¿Qué tipo de reconocimiento académico tienen los profesores que participan en la clínica?

\section{Los casos o proyectos}

a. ¿Se trata de una clínica especializada dentro de la propia disciplina? 
b. ¿Qué tipo de servicio ofrece la clínica?

c. ¿Cuál es el procedimiento interno para escoger los casos o proyectos en los que trabajará la clínica?

d. ¿Cuáles son los criterios de selección? ¿Se garantiza la vinculación del caso con los contenidos curriculares?

e. ¿Cuáles son los procedimientos y criterios para asignar los casos a los estudiantes?

f. ¿Los estudiantes participan en la selección y asignación de los casos o proyectos de la clínica?

g. ¿En cuántos casos se prevé trabajar durante un curso académico?

h. ¿Cuál es la duración óptima del caso o proyecto? ¿Pueden aceptarse casos que requieran más de un curso académico?

i. ¿En función de la naturaleza y la duración del caso? ¿Cómo se gestionan los periodos no lectivos?

j. ¿Se prevé hacer publicidad de los casos cerrados y/o en curso de la clínica? ¿Con qué limitaciones?

k. ¿Cuándo el encargo se materializa en un informe o producto? ¿Cuál es el régimen de propiedad intelectual y/o industrial aplicable?

\section{Los clientes}

a. ¿Quién puede ser cliente de la clínica? (instituciones, colectivos, particulares...)?

b. ¿La clínica tiene previsto trabajar por/con organizaciones no gubernamentales?

c. ¿Cómo se llega al potencial cliente? ¿Existen estrategias de difusión de la clínica?

d. ¿Es necesario firmar algún tipo de convenio o acuerdo con el cliente? En caso afirmativo, ¿qué aspectos es necesario contemplar?

e. ¿Se prevé hacer publicidad de los clientes de la clínica? ¿Con qué limitaciones?

\section{Los estudiantes}

a. ¿A qué estudiantes se orienta la clínica?

b. ¿Cómo se integra la clínica en el plan de estudios? ¿Qué tipo de reconocimiento académico tienen los estudiantes que participan en la clínica? 
c. ¿Es requisito haber adquirido determinantes conocimientos antes de poder participar en la clínica?

d. ¿Es requisito haber demostrado el dominio de determinadas competencias antes de poder participar en la clínica?

e. Si la clínica no constituye una materia obligatoria de la titulación, ¿hay un proceso formalizado de solicitud y selección de estudiantes participantes? ¿En qué momento hay que hacerlo?

f. Si la clínica no constituye una materia obligatoria de la titulación, ¿qué número de estudiantes deberían participar en la clínica?

g. ¿Es necesario que el estudiante firme algún tipo de acuerdo o compromiso? En caso afirmativo, ¿qué aspectos es necesario contemplar?

\section{Dinámica de trabajo}

a. ¿Cuál es el cronograma de la clínica?

b. ¿Los estudiantes trabajan en equipo o individualmente?

c. En caso de trabajo en equipo:

i. ¿Cuál es el procedimiento y criterios para formar los equipos de trabajo? ¿Los estudiantes pueden escoger con quién trabajar?

ii. ¿Cuántos estudiantes tienen que trabajar en un equipo?

iii. ¿Cuántos tutores tiene cada equipo? ¿Cómo se asignan?

iv. ¿Cuál es el rol de los tutores?

v. ¿Cuál es la periodicidad de los encuentros con los tutores?

vi. ¿Qué grado de autonomía tienen los estudiantes?

vii. ¿Qué mecanismos o herramientas de trabajo colaborativo está previsto utilizar?

d. ¿Se programa una entrevista inicial del equipo o el estudiante con el cliente? ¿Cuál es la finalidad? ¿Dónde se realiza?

e. ¿Cuál es la relación con el cliente durante el desarrollo del caso o proyecto? ¿Los estudiantes tienen libertad para contactar con él al margen del tutor?

f. ¿La clínica celebra sesiones plenarias (todos los estudiantes, todos los tutores) con cierta periodicidad? ¿Con qué finalidad?

g. ¿Se organizan seminarios o sesiones formativas relacionadas con el contenido de los casos? ¿Quién las imparte? ¿Son obligatorias para los estudiantes? 
h. En el caso de que los objetivos formativos incluyan competencias transversales, ¿la clínica cuenta con un programa de competencias? ¿En qué consiste exactamente?

i. Si en el marco del programa de competencias se organizan sesiones formativas o de trabajo, ¿quién las imparte? ¿Son obligatorias para los estudiantes?

j. Si el encargo se materializa en un informe o producto, ¿cuándo, cómo y dónde se hace la entrega del resultado final al cliente?

\section{Evaluación de los aprendizajes}

a. ¿Cuál es el sistema de evaluación de la clínica?

b. ¿Todos los objetivos formativos de la clínica se traducen en resultados de aprendizaje evaluables?

c. ¿Cuál es la estrategia o instrumento evaluativo a utilizar para cada uno de los resultados de aprendizaje? En concreto, ¿cómo se evalúan las competencias transversales?

d. ¿Quiénes son los agentes de la evaluación? ¿Participa el cliente o el propio estudiante?

e. ¿Se ha previsto algún tipo de evaluación inicial o diagnóstica? ¿Con qué finalidad?

f. En caso de evaluación formativa, ¿¿cuáles son los mecanismos de retroalimentación más adecuados?

\section{Recursos e infraestructura. Financiación}

a. ¿Qué tipo de recursos materiales e infraestructuras son imprescindibles para el buen funcionamiento de la clínica?

b. En concreto ¿es necesario un espacio propio? En caso afirmativo, ¿con qué finalidad?

c. ¿La clínica necesita personal administrativo? ¿qué funciones tendría?

d. ¿Cómo se financia una clínica?

e. ¿El cliente tiene que pagar alguna cantidad por el servicio prestado? ¿Hay algún tipo de baremo o criterios para decidir si debe hacerlo y, en su caso, calcular el importe?

f. En el caso de que el cliente tenga que pagar alguna cantidad, ¿a qué se destinan estos ingresos? 
g. ¿La clínica puede acogerse a convocatorias públicas para obtener financiación?

h. ¿Se prevé la posibilidad de donaciones a la clínica?

i. ¿Cómo se articula institucionalmente la gestión económica de la clínica?

\section{Código ético}

a. ¿Está previsto que la clínica cuente con un código ético propio? En caso afirmativo ¿qué aspectos debería contemplar?

b. ¿La clínica trabaja con datos confidenciales de los clientes?

c. ¿Qué tipo de difusión del código ético se prevé dar a los estudiantes?

d. ¿Es necesario que los estudiantes firmen algún tipo de compromiso con relación al código ético?

e. ¿Cuáles deben ser las consecuencias internas de la vulneración del código ético, sin perjuicio en su caso de las legalmente establecidas?

\section{Relaciones institucionales}

a. ¿Cuál es la relación de la clínica con la propia universidad? ¿Se encuentra vinculada a alguna facultad, instituto o centro de investigación? ¿Forma parte de alguna línea estratégica de la universidad?

b. ¿Con qué instituciones u organizaciones externas a la universidad hay que contar en el diseño de la clínica para evitar posibles conflictos?

c. ¿Con qué instituciones u organizaciones externas a la universidad sería óptimo contar en el desarrollo de la clínica con el fin de optimizar los resultados?

d. ¿Con qué unidades, centros, departamentos e iniciativas de la propia universidad sería óptimo contar en el desarrollo de la clínica con el fin de optimizar los resultados?

e. ¿Existen clínicas similares en otras universidades? ¿Conviene relacionarse con ellas?

\section{Seguimiento y evaluación de la calidad}

a. ¿Se prevén mecanismos de seguimiento del cumplimiento de los objetivos formativos y sociales de la clínica? ¿Cuáles? 
b. ¿La clínica tiene que elaborar una memoria anual? ¿Quién tiene que ser el responsable?

c. ¿Cómo hay que organizar y archivar la documentación relevante de la clínica? ¿Quién tiene que ser el responsable?

d. Se prevé que los procesos internos estén suficientemente protocolizados? ¿Quién tiene que ser responsable?

e. ¿Está previsto que el diseño de estrategias de mejora sean resultado de un proceso colectivo de reflexión por parte de todos los miembros de la clínica? ¿Cómo se articularía exactamente?

f. ¿Se prevé pasar encuestas adaptadas a la naturaleza de la clínica a los estudiantes?

g. ¿Se prevén estrategias para recoger sugerencias de mejora, ya sea por parte de los estudiantes o de los clientes? 


\section{Anexo 2 \\ Declaración de la Red Latinoamericana de Clínicas Jurídicas}

Bogotá, junio 13 de 2014

RECONOCIENDO que el acceso a la justicia en todas sus modalidades, el acceso a medios para el desarrollo de las capacidades humanas y el interés público, son esenciales para las sociedades democráticas;

CONSIDERANDO que las necesidades legales y de desarrollo básicas de individuos y comunidades, en situación de vulnerabilidad social, marginados, o de especial protección, con frecuencia son desatendidas;

RESALTANDO que las Universidades, las organizaciones privadas y las no gubernamentales abajo firmantes, han realizado esfuerzos para crear una conciencia social y de responsabilidad de la profesión en los y las estudiantes y profesionales del Derecho;

EVIDENCIANDO que la educación legal clínica es un modelo de educación abierto que se posiciona como un mecanismo de enseñanza del derecho pluralista, práctico, y con un alto contenido de responsabilidad social de la profesión del abogado, que se encuentra encaminado a buscar mejores resultados en la defensa de los derechos humanos y la justicia social;

destacando que de conformidad con la Declaración Pro Bono para las Américas, "la profesión legal está posicionada de manera única en materia de acceso a la justicia y tiene la responsabilidad, los medios y la oportunidad de promover un sistema legal justo y equitativo, así como el respeto por los derechos humanos y constitucionales en colaboración con el Estado, el poder judicial y las organizaciones no gubernamentales"; 
RECONOCIENDO que a partir del trabajo conjunto y las alianzas estratégicas entre Universidades, entidades privadas y no gubernamentales, se pueden encontrar en la educación legal clínica y en el trabajo Pro Bono medios para lograr un mejor acceso a la justicia social y protección del interés público;

CONSTATANDO que las clínicas jurídicas se han constituido como espacios de pedagogía extensión e investigación, que promueven la defensa del interés público y la protección de los derechos humanos, a través del litigio estratégico y de alto impacto;

EVIDENCIANDO que las clínicas jurídicas se han multiplicado por los diferentes países y continentes, llevando consigo una nueva forma de enseñanza del derecho, y promoviendo nuevos retos para los estudiantes y profesionales;

CONSIDERANDO que Latinoamérica continua una zona donde confluyen un amplio catálogo de necesidades en materia de protección de los derechos y desarrollo social y económico, y que esto ha llevado a un vertiginoso crecimiento de la labor que realizan las clínicas jurídicas;

EVIDENCIANDO los resultados exitosos, que se han obtenido, fruto del trabajo conjunto, a partir de redes y alianzas estratégicas en materia de educación legal clínica;

evidenciando el interés de las universidades Españolas y Portuguesas, aquí firmantes, en la educación jurídica clínica han decidido sumarse a la declaración;

NOsoTros, los abajo firmantes, declaramos solemnemente nuestro compromiso con la educación legal clínica y manifestamos:

PRIMERO: que ante el crecimiento del movimiento de clínicas de interés público tanto en América Latina como en España y Portugal, y atendiendo a los lazos académicos que se tienen entre las dos regiones, resulta a todas luces importante fortalecer a la Red Latinoamericana de Clínicas con la incorporación de las participantes en este encuentro. En el futuro podrán vincularse nuevas universidades y organizaciones interesadas en suscribir esta declaración. 
SEGUNDO: que realizaremos los esfuerzos necesarios, desde el rol que ocupamos en las organizaciones y universidades, para fortalecer, consolidar y posicionar la educación legal clínica en Iberoamérica. Estas acciones se orientarán de manera especial a la participación e incidencia en los procesos de reforma a la educación jurídica y en la defensa permanente de los mecanismos de protección de los derechos humanos.

TERCERO: que promoveremos el fortalecimiento de las redes existentes y las alianzas entre clínicas, ONG y entidades privadas como el instrumento más idóneo para avanzar en la protección y garantía de los derechos humanos, el acceso a la justicia, el interés público y la justicia social.

CUARTO: que mantendremos y desarrollaremos nuevos espacios de reunión y plataformas de comunicación para apoyar y divulgar las iniciativas, investigaciones y publicaciones sobre educación legal clínica, litigio estratégico, defensa del interés público y los derechos humanos.

QUINTO: que seguiremos reconociendo que los estudiantes son el eje central y articulador de estos procesos de formación en el Derecho y la justicia social, y que las clínicas jurídicas hacen parte de su formación integral.

SEXTO: que manifestamos la necesidad de crear un comité ejecutivo que fortalezca los principios de esta declaración.

Esta Declaración se firma en la ciudad de Bogotá, D.C. (Colombia), a los trece (13) días del mes de junio de 2014, en el marco de la Reunión de la Red Iberoamericana de Clínicas Interés Público:

\section{Clínicas y organizaciones firmantes de la declaración de la Red Latinoamericana de Clínicas de Interés Público}

Centro de Estudios Sociales y Legales (CEls) - Argentina.

Grupo de Acciones Públicas de la Universidad del Rosario - GAP - Colombia. Clínica de Género de la Universidad de Nariño - Colombia.

Clínica de Interés Público Universidad Autónoma Latinoamericana - Colombia.

Clínica de Migraciones de la Universidad Diego Portales - Chile. 
Clínica Jurídica de Interés Público de la Universidad Católica de Ecuador sede Ambato - Ecuador.

Clínica Jurídica de Interés Público de la Universidad de Medellín - Colombia. Clínica Jurídica de Interés Público de la Universidad Pontificia Bolivariana - Colombia.

Clínica Jurídica de Interés Público Guiis de la Universidad Surcolombiana - Colombia.

Clínica Jurídica de Interés Público contra la Trata de Personas de la ITAM - México.

Clínica Jurídica de la Universidad de La Sabana - Colombia.

Clínica Jurídica de la Universidad de Magdalena - Colombia.

Clínica Jurídica de la Universidad Sergio Arboleda (sede Santa Marta) - Colombia.

Clínica Jurídica de Violencia Intrafamiliary de Género de la Universidad del Rosario - Colombia.

Clínica Jurídica del Observatorio de Restitución de Tierras de la Universidad del Rosario - Colombia.

Clínica Jurídica en Acciones Públicas en Materia de Discapacidad de la Universidad Libre (seccional Pereira) - Colombia.

Clínica Jurídica en Derecho y Territorio de la Universidad Javeriana - Colombia.

Clínica Socio Jurídica de Interés Público de la Universidad de Caldas - Colombia.

Grupo de Acciones Públicas de la Universidad Icesi (GAPI) - Colombia.

Grupo de Litigio de Interés Público de la Universidad del Norte - GLIP - Colombia.

\section{Clínicas e iniciativas aliadas presentes en la reunión}

Clínica Jurídica de Desarrollo Comunitario y Económico de University of Michigan Law School - Estados Unidos.

ClinHab Universidad de Barcelona - España.

Clínica Jurídica Internacional de DDHн de la Universidad de Valencia.

Global Alliance for Justice Education - GAJE.

Open Society. 


\section{Anexo 3 \\ Algunas herramientas prácticas para el funcionamiento de las clínicas jurídicas, aportes desde el GAP: reglamento y ficha de viabilidad para los casos}

\section{Reglamento interno del Grupo de Acciones Públicas \\ Autor: Grupo de Acciones Públicas. Universidad del Rosario.}

Artículo 1. Definición. El Grupo de Acciones Públicas - GAP, es una clínica jurídica de interés público y de trabajo pro bono de la Facultad de Jurisprudencia de la Universidad del Rosario. Este grupo está conformado por un conjunto de estudiantes y profesionales que prestan un servicio gratuito a la comunidad en defensa de derechos humanos. En este trabajo jurídico y social los estudiantes aprenden la aplicación de sus conocimientos teóricos, así como nuevos conocimientos de origen práctico desde su experiencia, utilizando herramientas de investigación formativa.

Artículo 2. Estructura funcional. E1 Grupo de Acciones Públicas GaP consta de dos salas integradas de la siguiente manera: Sala Plena, por todos los miembros del GaP; y Sala de Dirección, por la Directora del GaP, y tres supervisores.

\section{TÍTULO I}

Plenaria y comisiones

CAPÍTULO I

La Plenaria

Artículo 3. Definición. Se entiende por la plenaria la reunión en la cual tienen asiento todos los miembros del GAP, los supervisores y los estudiantes en práctica pro bono. 
Artículo 4. Objetivo. Sus objetivos son adelantar discusiones en temas jurídicos, formar en temas de educación legal clínica, fortalecer las competencias y habilidades para el ejercicio de la profesión y el litigio estratégico, retroalimentar el trabajo jurídico y revisar los casos que son de conocimiento de la clínica.

Artículo 5. Escenario de formación en Derecho. Dado que la clínica es un espacio previsto para entrelazar los conocimientos teóricos con el escenario práctico, se prevé la realización de conferencias y talleres orientados a cumplir los fines de la clínica jurídica, donde los estudiantes puedan palpar la realidad y desarrollar actividades que probablemente vayan a necesitar al interior de sus casos. De la misma manera, se tiene previsto para este espacio la discusión de temas de especial relevancia que resultan de interés para la formación en educación legal clínica y en la defensa del interés público.

Artículo 6. Horario. La reunión en pleno tendrá lugar los días miércoles de 9:00 am a 11:00 am, en el salón del GAP.

Artículo 7. Formalidades. A la plenaria deberán asistir puntualmente todos los miembros del GAP y se levantará un acta de la reunión por parte del estudiante asignado, la cual deberá subirse al aula Moodle, a más tardar dos días después de la reunión.

Parágrafo. La asistencia a plenaria tiene carácter obligatorio para los estudiantes miembros activos del grupo y los practicantes pro bono. Las excusas para justificar la inasistencia a la plenaria se tramitarán ante la Dirección Administrativa del Consultorio Jurídico, con copia al Monitor del GaP. En las plenarias que hayan sido asignadas para tal fin, los estudiantes deberán rendir un informe sobre el desarrollo de los casos que tienen a su cargo y las tareas pendientes.

\section{CAPÍtULO II}

Las comisiones

Artículo 8. Estructura. Las comisiones están integradas por un número plural de estudiantes, miembros activos del GAP y practicantes pro bono, coordinados por un supervisor, los cuales serán responsables por los casos jurídicos que se 
trabajen al interior de cada comisión, por las funciones que desarrollen y por las actividades que se le asignen.

$\mathrm{Al}$ interior de las comisiones se deberá adelantar una labor de control pormenorizado y minucioso de los casos asignados a los estudiantes que pertenezcan a cada una y que se encuentren, tanto en jurisdicción, como en investigación.

Para cada caso existirán por lo menos dos (2) ponentes, los cuales serán responsables directos del mismo.

Artículo 9. Reuniones. Las reuniones de las comisiones se realizarán en horario diferente al de la reunión general y su duración será mínimo de una hora. El día, hora y lugar será acordado por los supervisores de común acuerdo con los estudiantes.

Parágrafo 1. A las reuniones de las comisiones deberán asistir todos los miembros de esta.

Parágrafo 2. La asistencia a las reuniones de las comisiones tiene carácter obligatorio para los estudiantes. Las excusas para justificar la inasistencia a las reuniones de comisión se tramitarán ante la Dirección del GAP.

Artículo 10. Funciones. Son funciones generales de las comisiones, además de las específicas relacionadas más adelante:

1. Verificar las tareas de los respectivos casos.

2. Revisar de memoriales tales como derechos de petición, consultas, etc.

3. Hacer seguimiento a las estrategias diseñadas para cada caso.

4. Hacer análisis jurídico del caso.

5. Hacer seguimiento al contacto con los usuarios y la comunidad afectada en cada caso.

6. Hacer la actualización de los casos en el aula virtual de Moodle.

7. Rendir informes de sus actividades en plenaria.

Artículo 11. Comisión de Investigación. Su objeto es analizar la jurisprudencia y la normatividad nacional e internacional acerca de temas de interés público que permitan establecer posibles estrategias de litigio. Así mismo, desarro- 
llará procesos de investigación formativa en interrelación con el Semillero de Investigación y el Grupo de Investigación en DDHH.

Artículo 12. Comisión Pedagógica (COPE). Se encarga de realizar actividades pedagógicas con la comunidad, apoyar jornadas de orientación a grupos de especial protección constitucional, respecto de temas de derechos humanos e interés público. Así mismo, desarrolla material didáctico de apoyo.

Artículo 13. Comisión de Medios y Relaciones. Se encarga de difundir la labor del grupo y los resultados que este obtiene, así como de manejar las relaciones del Grupo con autoridades del Estado (altas cortes, Congreso de la República, etc.).Igualmente, se encarga de los temas relacionados con eventos nacionales e internacionales, trabajo Pro Bono, pasantías, amicus curiae y fortalecimiento de la relaciones con otras clínicas nacionales e internacionales, entre ellas la Red Latinoamericana de Clínicas de Interés Público.

\section{TÍTULO II}

Equipo supervisor

Artículo 14. Estructura. El equipo supervisor está integrado por:

1. E1 Director.

2. El Coordinador designado por el Consultorio Jurídico.

3. Dos profesores o jóvenes investigadores del Grupo de Investigación en Derechos Humanos de la Facultad de Jurisprudencia. Según las necesidades de la clínica, el equipo supervisor podrá acudir a otros profesores o profesionales de la Facultad de Jurisprudencia o de otras unidades académicas y áreas de la Universidad.

Artículo 15. Funciones. El equipo supervisor tiene las siguientes funciones:

1. Manejo del archivo físico.

2. Manejo de notas.

3. Realización de Informes (orales, escritos).

4. Trámite de excusas. 
5. Dirección de las comisiones de medios y relaciones, investigación y pedagógico.

6. Puente de comunicación con el Consultorio Jurídico y el Grupo de Derechos humanos.

7. Dirección de las reuniones generales.

8. Control y seguimiento de los casos.

9. Manejo administrativo (tareas, actas).

10. Labores de enlace con el Grupo de Investigación en DDHH y el Semillero de Investigación.

11. Labores de enlace con las directivas de la Facultad de Jurisprudencia y de la universidad.

12. Revisión final de las actuaciones procesales.

13. Actualización del aula virtual.

14. Fijar los criterios de viabilidad.

15. Dirección encargada y/o compartida de la educación legal clínica.

\section{TÍTULO III}

Selección de los miembros del GAP

Artículo 16. Selección. Los miembros del GAP serán seleccionados semestralmente mediante concurso público que se fijará en las carteleras del Consultorio Jurídico, del Grupo de Investigación en Derechos Humanos y de la Facultad de Jurisprudencia de la Universidad del Rosario y a través de medios electrónicos institucionales.

Las reglas en dicho concurso serán las siguientes:

1. Podrán participar estudiantes de Jurisprudencia que vayan a iniciar Consultorio Jurídico I y Consultorio Jurídico II.

2. Los aspirantes deberán acreditar un buen desempeño académico, en el área de derecho público, tener conocimientos sobre derechos humanos, sus mecanismos de protección y acciones públicas y tener interés en el trabajo con comunidades.

3. La evaluación en la entrevista de selección para el ingreso al grupo incluirá los siguientes elementos: desempeño en la misma, sensibilidad social, análisis de casos y conocimientos básicos de la regulación de las acciones constitucionales. 
4. El comité de selección estará conformado por los miembros del equipo supervisor y uno o dos estudiantes delegados por cada comisión.

5. Los resultados serán públicos y se darán a conocer por los mismos medios a través de los cuales se difundió la convocatoria.

Artículo 17. Número de miembros del gap. De conformidad con las necesidades de atención de casos en materia de derecho público, la dirección del Grupo, definirá cada semestre, antes de la convocatoria, el número de miembros para el GAP.

\section{TÍTULO IV}

Práctica jurídica pro bono

Artículo 18. Generalidades de la práctica: La Práctica Jurídica I es un requisito de grado que hace parte del plan de estudios de la Facultad de Jurisprudencia de la Universidad del Rosario, cuyo propósito es la aplicación práctica de los conocimientos teóricos y destrezas que previamente ha adquirido el estudiante, acercándose a la realidad social y laboral del país.

El Plan Curricular de la Facultad de Jurisprudencia determina que la Práctica Jurídica I es un requisito que:

1. Hace parte del Consultorio Jurídico.

2. Tiene el carácter de práctica social.

3. Tiene una duración mínima de 144 horas.

4. No tiene el carácter de remunerado (Ley 583 del 2000).

Parágrafo. Para acreditar las horas de la práctica jurídica se debe diligenciar un formato de cumplimiento de horas y al finalizar el GAP envía un informe sobre el cumplimiento de las obligaciones del practicante y la nota que se le asigna.

Artículo 19. Objetivo de la práctica. Asegurar que el estudiante tenga una primera experiencia profesional al desarrollar funciones exclusivamente de tipo sociojurídico.

Artículo 20. Obligaciones del practicante. En un marco ético y de responsabilidad social universitaria el estudiante asignado se obliga a: 
1. Respetar y cumplir con los reglamentos y normas de la Universidad del Rosario, la Facultad de Jurisprudencia, el Consultorio Jurídico y el GAP, especialmente las relacionadas con la práctica a desarrollar.

2. Realizar la práctica con diligencia y profesionalismo para lograr el mayor rendimiento y los mejores aportes a su formación.

3. Cumplir las labores en las áreas definidas por el gAP en el desarrollo de la práctica.

4. Manejar correctamente la información y documentación del GAP. Así mismo, guardar, sin excepción, reserva debida de los asuntos que conozca en razón de sus actividades y que por su naturaleza no deban divulgarse.

5. Estar afiliado al Sistema de Seguridad Social en Salud o medicina prepagada u otro sistema que garantice cubrir los riesgos a los que pueda estar expuesto en caso de enfermedad o accidente.

6. Realizar las acciones que resulten necesarias para el adecuado cumplimiento de los objetivos propuestos en el GAP.

7. Apoyar las distintas actividades y casos que se desarrollan en el GAP y en cada una de sus tres comisiones.

8. Apoyar la revisión de información sobre aspectos conceptuales, documentación, marco legal y reglamentario, jurisprudencia nacional e internacional y experiencias relevantes en relación con los casos que se estudian y desarrollan por el GAP.

9. Hacer seguimiento procesal de los casos y presentar los respectivos informes sobre el estado de los procesos. Así mismo, incluir esos informes en las carpetas del archivo del gap y el aula Moodle.

10. Realizar el trabajo de campo, entrevistas, encuestas, estudios de casos $\mathrm{y}$ foros que le sean asignados.

11. A poyar desde la perspectiva ética y de responsabilidad social universitaria la construcción de los casos y la elaboración de los documentos relacionados con los mismos y con otras actividades.

12. Asistir y participar en las reuniones acordadas y convocadas por el equipo supervisor del GAP y elaborar las respectivas actas (o apoyar la elaboración de las mismas).

13. Concurrir puntualmente al lugar donde se desarrolla la práctica jurídica en el GAP y a las demás reuniones y compromisos internos y externos. 
14. Presentar los informes que le solicite el equipo supervisor del GaP e incluirlos en las carpetas del archivo y en el aula Moodle.

15. Las demás que se deriven de las actividades y casos desarrollados por el GAP.

Artículo 21. Selección de los practicantes del GaP. Los practicantes pro bono del GAP serán seleccionados semestralmente mediante concurso público organizado por la coordinación de asuntos pro bono de la Facultad.

\section{TÍTULO V}

Actividades y procedimientos del GAP

Artículo 22. Planeación. El equipo supervisor definirá las actividades semestralmente y las pondrá en consideración de los demás miembros en la reunión plenaria para sugerencias. Dicha planeación corresponderá a las prioridades de atención de casos o tareas de interés para el grupo.

Artículo 23. Recepción y aceptación de casos. Los casos que se conocen en la clínica, pueden llegar por diferentes medios:

1. Por solicitud escrita o verbal del usuario o comunidad al Monitor del GAP.

2. Por propuesta de algún estudiante activo o miembro del equipo supervisor del GAP.

3. Por propuesta de otra clínica jurídica, una ONG u Organización Social, por conducto de cualquiera de los supervisores.

Una vez el caso llega a la clínica, el equipo supervisor adelantará una revisión preliminar a fin de establecer si el caso encaja dentro de los parámetros de competencia y pertinencia académica de la Clínica; en caso de ser procedente, se asignará el caso a los estudiantes que se estime necesario para que adelanten la ficha de viabilidad, la cual será presentada por ellos en la reunión plenaria que indique el equipo supervisor. Los parámetros a revisar en dicha ficha son:

1. Impacto social y/o Jurídico del caso propuesto.

2. Viabilidad de acciones colectivas y/o públicas. 
3. Apoyo de la comunidad en el trámite del caso.

4. Visibilidad del caso.

5. Estudio de estrategias de investigación y acción jurídica.

Realizada la presentación de la ficha de viabilidad, el equipo supervisor realizará la revisión final del caso, a fin de decidir su aceptación por parte de la clínica y aprobará la propuesta sobre las estrategias a seguir en el caso.

Artículo 24. Presentación de informes. Conforme a la programación del consultorio jurídico, los miembros del GAP presentarán informes orales semanales al equipo supervisor en las reuniones de cada comisión y un informe escrito al final del semestre, que será subido a Moodle.

Artículo 25. Criterios de evaluación. Serán tenidos en cuenta los siguientes aspectos a la hora de definir la nota de los diferentes cortes del semestre:

1. Asistencia y participación en las reuniones y actividades del Grupo, así como el trabajo en equipo.

2. Presentación oportuna de informes y demás labores encargadas.

3. Conocimiento y estrategia en el trabajo del grupo correspondiente.

4. Contacto permanente con los usuarios.

5. Seguimiento procesal o de las actividades previstas para el caso.

6. El correspondiente archivo virtual y físico de las actuaciones realizadas.

Artículo 26. Soporte físico. La información relacionada con todas las actividades y casos deberá estar documentada en carpetas físicas que siempre deberán reposar en el archivo físico del GAP, conforme a las exigencias del Consultorio Jurídico (índice, enumeración de hojas, estado de los procesos, etc.). En ningún caso, los documentos originales de los casos que reposen en los archivos del GAP, podrán ser retirados de las instalaciones de la clínica; en caso de requerirse un documento del expediente, deberán tomarse copias del mismo.

Artículo 27. Soporte virtual. La información relacionada con los avances jurídicos así como los documentos producto de la investigación respecto de los diferentes temas manejados por el GAP, constarán en un aula virtual creada 
para tales efectos. El sitio virtual está a disposición de todos los miembros del grupo.

Es obligación de todos y cada uno de los miembros del grupo consignar en los respectivos archivos del aula, la información pertinente relacionada con los casos que a cada uno le corresponden.

Es de especial importancia señalar que la información consignada en el Aula virtual es de estricta confidencialidad y solo está disponible para los miembros del grupo.

Artículo 28. Realización de actas de plenaria. Se levantará un acta de la reunión plenaria por parte de un estudiante asignado, la cual deberá contener los nombres de los asistentes, los temas discutidos, las actividades realizadas, las tareas pendientes y el seguimiento procesal. Esta deberá subirse al aula Moodle una vez finalice la reunión.

Artículo 29. Seguimiento de casos en jurisdicción. Cada estudiante deberá realizar el seguimiento procesal de los casos que le han sido asignados en la respectiva comisión a la que pertenece. Este seguimiento deberá ser constante y dar cuenta de toda actuación procesal que se dé en los casos e informar al supervisor de la comisión y a la plenaria, cuando así lo indiquen los supervisores. De esta manera, todos los miembros de la clínica estarán al tanto del acontecer de cada uno de los casos que lleva esta.

\section{TÍTULO VI}

Tratamiento y protección de datos personales

Artículo 30. Los estudiantes deberán autorizar de manera libre, expresa e informada, al iniciar su año de pertenencia a la clínica, el tratamiento de sus datos personales bajo los términos establecidos en las políticas institucionales de manejo de la información. En ese sentido, la información suministrada al GAP relacionada con sus correos electrónicos, teléfonos, número celular, dirección de domicilio, entre otros datos personales, serán utilizados exclusivamente para el manejo de los asuntos académicos del Grupo. 


\section{TÍTULO VII}

Presupuesto del GAP

Artículo 31. Cada año y teniendo presentes las políticas institucionales y el calendario definido para tales efectos por la Facultad de Jurisprudencia, el GAP elaborará un presupuesto acorde con sus necesidades, que contendrá los rubros necesarios para el desarrollo de actividades priorizadas por el Grupo. Su ejecución dependerá de la disponibilidad de recursos de la Facultad y de su aprobación o modificación por parte de la misma.

\section{TÍTULO VIII}

Causales de retiro del Grupo

Artículo 32. Causales de retiro. Se consideran causales de retiro del grupo las siguientes:

1. Bajo rendimiento en la evaluación según los criterios determinados en el artículo octavo.

2. Incumplimiento de los deberes de confidencialidad, responsabilidad y respeto por la labor de la clínica jurídica y los usuarios del servicio.

3. Descuido y abandono de los casos asignados.

4. Inasistencia injustificada equivalente al $10 \%$ de las reuniones referidas en los artículos anteriores.

5. Incumplimiento de cualquiera de las disposiciones establecidas en el presente documento.

El equipo supervisor informará al estudiante las causales de retiro y escuchará sus descargos, luego de lo cual se tomará una decisión que será comunicada por escrito y quedará en los archivos del GAP.

Parágrafo. No existe retiro voluntario del GAP y la permanencia de los miembros estará sujeta al reglamento y directivas del Consultorio Jurídico. 


\section{Guía para diligenciar la ficha de viabilidad}

\section{Información general}

1. Comisión: colocar el nombre de la comisión del GAP a la cual fue asignado el caso.

2. Ponentes: estudiantes responsables del caso dentro de la Comisión.

Nombre:

Teléfono fijo:

Teléfono celular:

Dirección:

Correo personal:

* Cualquier cambio de información, debe ser notificada al respectivo supervisor y en todo caso al coordinador.

3. Datos del usuario: en este espacio se debe colocar el nombre de la persona que acude al grupo, teléfono, celular, correo electrónico, dirección y ciudad.

4. Fecha de recepción del caso: fecha en la cual el caso fue presentado al Grupo.

\section{Información del caso}

5. Descripción de los hechos: se debe realizar una síntesis de los principales hechos que permita entender el caso. Los hechos deberán ordenarse cronológicamente y estar numerados.

6. Lugar de los hechos: colocar el lugar donde está ocurriendo o puede presentarse la vulneración o amenaza de derechos. 
7. Afectados: corresponde a la identificación de las personas o sujetos de derechos que reclaman su reconocimiento.

8. Derechos vulnerados: se colocan los derechos que, de acuerdo con la presentación del caso por el usuario, se perciben vulnerados.

\section{Parámetros del estudio de viabilidad de las propuestas}

9. Impacto social y/o jurídico del caso propuesto: se refiere al impacto de carácter social y jurídico del caso analizado desde diversas perspectivas, como la particularidad del caso, el interés académico, impacto jurídico, impacto social, las características del grupo afectado, etc.,. Así mismo, se analiza la defensa del interés general y la prevalencia que este conlleva de conformidad con las normas constitucionales y la protección de los derechos humanos.

Esto representa una experiencia académica e investigativa que implica importantes aportes a la formación personal del estudiante, por lo cual, se tendrá en cuenta las consideraciones del estudiante,

10. Condición económica de la comunidad o del particular afectado: teniendo presente el componente social, es importante señalar que en este punto del estudio de viabilidad también se analiza la condición económica del (los) afectado(s), coligiendo las dificultades económicas de este(os) para acudir a los servicios de un abogado. Puede haber casos en que este parámetro no sea factor de decisión, pues por las características del caso, puede ser académicamente interesante y relevante para el Grupo.

11. Conformación del elemento probatorio, sustancial en la investigación: revisión de la calidad, la pertinencia, la conducencia y la eficacia que deben presentar las pruebas con las que se cuenta y que el estudiante considera para la viabilidad del caso, documentos los cuales solo se recibirán copia. Si no se cuenta con este material, el estudiante deberá resaltar su pertinencia y la necesidad de que el usuario recaude algunas de ellas,

12. Recomendación final de la comisión: se coloca la conclusión a la que llegan los estudiantes responsables frente al caso, señalando las razones de procedibilidad en caso de que así sea. 
En el evento en el que se considere que el casi no es viable, se deberá elaborar un concepto al usuario que contenga una breve asesoría jurídica y además manifestar de forma general las razones por las cuales el caso no puede ser llevado por el grupo y algunas propuestas o alternativas de solución.

\section{Elementos para el análisis de viabilidad:}

1. Identificación de la problemática y derechos vulnerados: definición de la situación o problema experimentado ya sea en forma de amenaza, violación, vulneración, como evento justiciable a la luz de los Derechos Humanos ocasionado por la acción u omisión de particulares, de entidades del Estado o de particulares con funciones administrativas. ${ }^{57}$

2. FODA (fortalezas, oportunidades, debilidades, amenazas del caso propuesto): se debe identificar la estrategia que será empleada para lograr la protección y garantía de los derechos humanos como objetivo principal, mediante un ejercicio de ponderación del FODA.

\begin{tabular}{|l|l|l|l|}
\hline Fortalezas & Oportunidades & Debilidades & Amenazas \\
\hline & & & \\
\hline & & & \\
\hline & & & \\
\hline & & & \\
\hline
\end{tabular}

3. Estudio de estrategias de investigación y acción: una vez agotado el ejercicio FODA, mediante un examen de ponderación, el estudiante selecciona la estrategia que a su juicio es las más pertinente y viable para la solución y el logro del objetivo de protección y garantía de los derechos humanos planteada por el grupo.

Las estrategias pueden ser concurrentes en un mismo caso o quizá una por caso; a manera ilustrativa, el estudiante podrá optar por las siguientes posibilidades:

57 "Supone redefinir el hecho empírico presentado por las personas afectadas como necesidad o problema en términos de incumplimiento o vulneración de alguno o varios derechos humano" (Yrigoyen Fajardo, 2007). 
- Estrategia jurídica: consiste en la identificación de la acción jurídica que los estudiantes consideran viable como parte del esquema que se debe diseñar para la búsqueda de una solución en derecho.

De igual forma, se deberá determinar la estrategia de investigación que se adelantará, así como la manera de consolidar sus resultados, pues este será el elemento fundamental, no solo para la argumentación y sustentación de la posible acción, sino también del soporte probatorio.

- Estrategia social: consiste en identificar y buscar los elementos que inciden en la situación ya sea de carácter social o político, que están generando las violaciones a los derechos humanos; de igual forma, deben revisarse los elementos del contexto que rodea el caso (de carácter social, cultural y/o político), que puedan tener incidencia en la solución de la problemática. Esto permitirá una solución orientada a la formulación de políticas públicas que contribuyan a la protección de los derechos humanos en el problema específico, creación de iniciativas legislativas u otro tipo de acciones sociales con alto impacto.

- Estrategia política: consiste en identificar las instituciones o socios estratégicos que pueden servir como aliados para defender la causa. En ese sentido, podrá plantearse una estrategia que permita una acción conjunta, en procura de la defensa del interés público.

- Estrategia pedagógica: consiste en la realización de capacitaciones y cursos a la comunidad -sujeto pasivo en la vulneración de los derechos humanos-, para instruir y empoderar de herramientas, para la defensa de sus derechos

4. Decisión de la plenaria: se debe incluir la decisión de la plenaria frente al caso planteado, las observaciones y sugerencias de los estudiantes. 


\section{Ficha de viabilidad \\ Grupo de Acciones Públicas \\ Universidad del Rosario}

\begin{tabular}{|c|c|}
\hline 1. Comisión & \\
\hline 2. Estudiantes responsables & $\begin{array}{l}\text { Nombre: } \\
\text { Celular: } \\
\text { Email: }\end{array}$ \\
\hline 3.. Datos del usuario & $\begin{array}{l}\text { Nombre: } \\
\text { Celular: } \\
\text { Teléfono: } \\
\text { Dirección: } \\
\text { Ciudad: }\end{array}$ \\
\hline 4. Fecha de recepción del caso & \\
\hline 5. Descripción y lugar de los hechos & \\
\hline 6. Afectados & \\
\hline 7. Derechos vulnerados & \\
\hline $\begin{array}{l}\text { 8. Impacto social y/o jurídico del caso } \\
\text { propuesto }\end{array}$ & \\
\hline 9. Condición económica & \\
\hline 10. Elementos probatorios & \\
\hline $\begin{array}{l}\text { 11. Importancia académica, } \\
\text { investigativa, formativa }\end{array}$ & \\
\hline $\begin{array}{l}\text { 12. Recomendación final de la } \\
\text { Comisión }\end{array}$ & \\
\hline Viabilidad del caso & \\
\hline $\begin{array}{l}\text { 1. Identificación de la problemática y } \\
\text { derechos vulnerados }\end{array}$ & \\
\hline & Fortalezas \\
\hline 2. FODA (Fortalezas, oportunidades, & Oportunidades \\
\hline $\begin{array}{l}\text { debulldades, amenazas dei caso } \\
\text { propuesto) }\end{array}$ & Debilidades \\
\hline & Amenazas \\
\hline & Estrategia Jurídica \\
\hline & Estrategia social \\
\hline $\begin{array}{l}\text { 3. Estudio de estrategias de } \\
\text { investiogción yacción }\end{array}$ & Estrategia política \\
\hline & Estrategia pedagógica \\
\hline & Otras estrategias \\
\hline 4. Decisión de la plenaria & \\
\hline
\end{tabular}




\section{Referencias}

Abramovich, V. (1999). "La enseñanza del derecho en las clínicas legales de interés público. Materiales para una agenda temática”. En Cuadernos de Análisis Jurídico, Santiago de Chile, disponible en: http://www.palermo. edu/derecho/pdf/Bibliografia-clinicas-juridicas/la_ensenanza_del_derecho_en_las_clinicas_legales_de_interes_publico(2).pdf, 1-25.

(2011). "Autonomía y subsidiaridad.El Sistema Interamericano de Derechos Humanos frente a los sistema de justicia nacionales”. En C. E. Rodríguez, El Derecho en América Latina. Buenos Aires: Siglo xxi, pp. 211-230. (1999). "La enseñanza del derecho en las clínicas legales de interés público. Materiales para una agenda temática". En Cuaderno de Análisis Jurídico, Serie Publicaciones Especiales.

Alonso Pérez, M. T. (2013). “La formación en competencias a través de la jurisprudencia en el grado en Derecho de la Universidad de Zaragoza. Situación actual y propuestas de mejora”. En J. García Añón, Transformaciones en la docencia y el aprendizaje del derecho. Valencia: Trotta, p. 45.

Álvarez,A. (2005). “E1 desarrollo de las clínicas jurídicas como proyección social en el Salvador”. En A. Peña-Jumpa, Proyección social del derecho y clínicas jurídicas en las universidades del siglo XXI. Madrid: Dykinson, pp. 61-76.

Arcos, F. (2000). La seguridad jurídica: una teoría formal. Madrid: Dykinson.

Armas-Alvarado, H. P. (2005). "Proyección social del Derecho. Experiencias uniendo a la universidad y a la comunidad en la promoción del acceso a la justicia en Perú”. En A. Peña-Jumpa, Proyección social del derecho y clínicas jurídicas en las universidades de América del siglo XXI. Madrid: Dykinson, pp. 121-142.

Asa, P. (6 de diciembre de 2012). Clínica de migrantes y refugiados Caref-cels. (B. Londoño, entrevistador).

Avella, M.E. (2014). “El Abogado del siglo xxı”. En Clínicas jurídicas iberoamericanas: retos para el siglo Xxi. Bogotá: Universidad del Rosario, p. 35.

Baladrón, M. C. (2013). Clínica jurídica. Buenos Aires: cels. 
Bariff, F. E. (2013). Práctica clínica y litigación estratégica en discapacidad y derechos bumanos. Algunas experiencias de Iberoamérica. Madrid: Dykinson.

Barranco, M. d. (17 de junio de 2013). Clínicas Jurídicas en España. (B. Londoño, Entrevistador)

Blázquez Martín, D. (2006). "La educación jurídica crítica en el contexto del Proceso de Bologna: su aplicabilidad en España”. En Opinión Jurídica, vol. 5, n. ${ }^{\circ} 10$, pp. $161-179$.

(2005/2006). "Apuntes acerca de la educación jurídica clínica”. En Universitas. Revista de Filosofía, Derecho y Politica, n. 3 3, Bogotá, pp. 43-60.

Bloch, F. S. (2013). El movimiento global de clinicas jurídicas. Formando Juristas en la Justicia Social. Valencia: Tirant lo Blanch.

Bonilla, D. (2008). Parejas del mismo sexo. Bogotá: Universidad de Los Andes. (s.f.). El formalismo jurídico, la educación jurídica. En: http:// www.derechoshumanos.udp.c1/wp/wp-content/uploads/2013/05/Bonilla. pdf, 263.

Boueiri, S. (2006). "Acceso a la justicia y servicios jurídicos no estatales en Venezuela”. En El otro derecho. Bogotá, ILsA, n. ${ }^{\circ} 35$, pp. 299-233.

Brunner, J. J. (2000). Bases para un nuevo contrato entre el Estado y la educación superior. Santiago de Chile: s.e.

(2010). La educación superior en Iberoamérica. Santiago de Chile: Universia.

Calamandrei, P.T. (1926). Demasiados abogados. Madrid: s.e.

Carreño, M.T.(2014). Formación en derecho basada en competencias. Bogotá: Editorial Universidad del Rosario.

Carrillo, A. (2011). Clínicas jurídicas de derechos humanos: una alternativa para la educación jurídica y la sociedad. En C. S. Derecho, Clinicas jurídicas de derechos humanos: una alternativa para la educación jurídica y la sociedad. México: Corte Suprema de Justicia.

(2011). "Diferencias entre las clínicas de servicios jurídicos gratuitos y las clínicas de interés público y derechos humanos”. En Corte Suprema de México, Clínicas Jurídicas de Derechos Humanos: Una alternativa para la educación jurídica y la sociedad. México: Corte Suprema de Justicia, pp. 36-49.

Carrillo, A. Y. (2011). "Reimaging Human Rignts Law Clinic”. En Maryland Journal of International Law, vol. 26, pp. 80-112. 
Caso Atala Riffo y niñas vs. Chile (Corte Interamericana de Derechos Humanos, 24 de febrero de 2012).

Castro Buitrago, E. (2006). "La enseñanza clínica, un paso hacia la calidad”. En: Opinión Jurídica, pp. 175-186.

Castro, E. (2012).Análisis de buenas prácticas pedagógicas en las clínicas de Colombia, Chile y Argentina. Santa Marta.

Castro-Buitrago, E. E. (2013). "La educación jurídica clínica en América Latina: hacia el interés público". En F. Bloch, El movimiento global de clínicas jurídicas. Formando juristas en la justicia social. Valencia: Tirant lo Blanch, pp. 137-158.

Clínicas Jurídicas (27 de octubre de 2013). Clínicas jurídicas. Obtenido de www. clinicasjuridicas.org

Colau, A. Y. (2013). Vidas hipotecadas. Barcelona: Lectio Ediciones.

Coral, A. E. (2010). El concepto de litigio estratégico en América Latina:1990-2010. Bogotá: Vniversitas. Obtenido de http://redalyc.uaemex.mx/src/inicio/ ArtPdfRed.jsp?iCve=82518988003, 49-76.

Correa, L. (2013). “Enseñanza clínica del derecho y discapacidad”. En F. Bariffi, Práctica clínica y litigación estratégica en discapacidad y derechos humanos. Algunas experiencias de Iberoamérica. Madrid: Dykinson, pp. 17-35.

(2013). “Enseñanza clínica del derecho y discapacidad”. En F. Bariffi, Práctica clínica y litigación estratégica en discapacidad y derechos humanos. Algunas experiencias de Iberoamérica. Madrid: Dykinson, pp. 17-28. (2009). "Panorama de la protección jurisprudencial a los derechos humanos de las personas con discapacidad en Colombia”. En: Revista Vniversitas, n. ${ }^{\circ} 118$, enero-junio, pp. 115-139.

(2008). "La enseñanza clínica del Derecho: transformando la forma de enseñar y ejercer el derecho". En Revista Studiositas, 3(1), pp.34-40, Obtenido de http://portalweb.ucatolica.edu.co/easyWeb2/files/ studiositas/H_V3_N1_CORREA_Y_VASQUEZ.pdf

Courtis., C. (2005). "El desarrollo del derecho de interés público en la Argentina: avances, obstáculos y desafíos”. En A. Peña-Jumpa, Proyección social del derecho y clínicas jurídicas en las Universidades de América del siglo XXI. Madrid: Dykinson, pp. 161-189.

Cunill Grau, N. (1997). Repensando lo público a través de la sociedad. Caracas: Nueva Sociedad. 
Damaška,M.(1968). "A continental lawyer in an american law school: Trials and tribulations of adjustment". En University of Pennsylvania Law Review, n. ${ }^{\circ} 116$, pp. 1363-1375.

De Pina, R. (1955). “Teoría y práctica en la enseñanza del Derecho”. En Revista de la Facultad de Derecho de México, n. ${ }^{\circ} 17-18$, enero-junio. En: http:// www.juridicas.unam. $m x /$ publica/librev/rev/facdermx/cont/17/dtr/dtr11. $p d f, 261-275$.

Di Matteo, M. F. (2012). “Enseñar y evaluar a través del método de casos”. En J. A. Seda, Difusión de derechos y ciudadania en la escuela. Buenos Aires: Eudeba, pp. 75-90.

Eduardo B, C. (1939). Clínica jurídica y enseñanza práctica. Santa Fe: U. Santa Fe. Efrón, F. (2014). “Clínica Jurídica de Derechos Humanos cELs-Caref-uBA”. En El abogado del siglo xxi. Bogotá: Universidad del Rosario, p. 15.

Fager, N. (2013). "La Ciudad de Bolívar no tiene agua: hacia la justiciabilidad de los derechos colectivos de los menos favorecidos”. En B. E. Londoño, Litigio estratégico y derechos humanos. Bogotá: Editorial Universidad del Rosario.

Fajardo, L. (14 de noviembre de 2012). Educación legal clínica en Colombia. (B. Londoño, entrevistador).

Fajardo, L. A. (2012). "Educación en derecho y clínicas jurídicas". S.P. Santa Marta: III Encuentro de la Red Colombiana de Clínicas Jurídicas.

Fayad, R. (2012). "Elementos a considerar en la discusión sobre la reforma de la educación superior en Colombia”. En C.H. Trujillo García, Contribución de la Universidad del Rosario al debate sobre educación superior en Colombia. Bogotá: Editorial Universidad del Rosario, pp. 345-359.

Flórez Ochoa, R. (1999). Evaluación, pedagogía y cognición. Bogotá: McGraw Hill. Fortunato, M. A. (2012). "Herramientas didácticas y participación ciudadana”. En J. A. Seda, Difusión de derechos y ciudadanía en la escuela. Buenos Aires: Eudeba, pp. 37-55.

Freire, P. (1999). Pedagogía del oprimido. México: Siglo xxi.

Fuller, L. L. (1978). “The forms and limits of adjudication”. En Harvard Law Review, n. $353,92$.

Galiana Saura, A. (7 de julio de 2013). Clínica ambiental en la Universidad de Tarragona. (B. Londoño, entrevistador).

García Añón, M. (25 de junio de 2013a). Clínicas jurídicas en España (B. Londoño, entrevistador). 
García Añón, M. (2013b). Transformaciones en la docencia y el aprendizaje del derecho. Valencia, 11-13 de septiembre de 2013: Unitat d'innovació educativa,Facultat de Dret, Universitat de València, 2013. Obtenido de: www.uv.es/innodret/pub/2013actas_congreso.pdf.

Gardner,J.A.(1980). Imperialismo legal: abogados de América y la ayuda extranjera en América Latina. Madison: University of Winsconsin.

González Morales, F. (15 de febrero de 2013). Litigio estratégico y clínicas jurídicas en Chile. (V. Solano, entrevistador).

(2004). "El trabajo clínico en materia de derechos humanos e interés público en América Latina”. En Cuadernos de Deusto de Derechos Humanos, n. ${ }^{\circ}$ 27, Ediciones del Instituto de Derechos Humanos de la Universidad de Deusto, Bilbao, pp. 1-41.

Goyes, I. (2012). “Retos de la educación jurídica basada en competencias”. En: Advocatus. Edición Especial, n. ${ }^{\circ} 19$. Obtenido de: http://www.unilibrebaq. edu.co/unilibrebaq/revistas2/index.php/advocatus/article/view/278/250, 133-147.

(2013). “Teoría curricular para la formación jurídica en competencias”. En M.T. Carreño Bustamante, Formación en derecho basada en competencias. Bogotá: Editorial Universidad del Rosario, pp. 14-26.

Grandez, P. (11 de mayo de 2013). Clínica Jurídica Universidad de San Marcos en el Perú. (M. Barriga, entrevistador).

Guevara-Paredes, M. (2005). "Metodología de la enseñanza del derecho mediante la interacción con la realidad a través de medios de comunicación masiva”. En A.Peña-Jumpa, Proyección social del derecho y clinicas jurídicas en las universidades de América del siglo XXI. Madrid: Dykinson, pp. 143-158.

Gülco, H. (4 de diciembre de 2012). Entrevista sobre litigio estratégico y educación legal clínica en Argentina. Universidad Torcuato di Tella (B. Londoño, entrevistador).

Hurtado, L.F.(15 de abril de 2013). Clínicas jurídicas en materia de discapacidad (B. Londoño, entrevistador).

Instituto de Educación Superior de la Unesco (2008). "Declaración de la Conferencia Regional de Educación Superior en América Latina y el Caribe”. Cartagena. En: http://www.fvet.uba.ar/institucional/Declaracion.pdf

Lidman, R. (2005). "Proyección social en la Facultad de Derecho de la Universidad de Seattle en los Estados Unidos”. En A. Peña-Jumpa, Proyección 
social del derecho y clínicas jurídicas en las Universidades de América del siglo XXI. Madrid: Dykinson pp. 77-91.

Londoño, B. E. (2013). Educación jurídica en Iberoamérica. S.P. Bogotá, p. 34. Madrid, A. (28 de junio de 2013). Clínicas jurídicas en España (B. Londoño, entrevistador).

Martínez Rizo, F. (2011). “Los rankings de universidades: una visión crítica”. En Revista de la Educación Superior, enero-marzo, vol.xL (1), n. ${ }^{\circ}$ 157,pp.79-97.

Maury, A. (2010). Las clínicas jurídicas y su pertinencia en la formación de abogados. En Justicia, pp. 74-79.

Meraz, A. ( 2007). “El acceso a la información como herramienta para el litigio estratégico. Experiencia Legal de Interés Público del IтAм”. En: Oficina del Alto Comisionado de las Naciones Unidas, El litigio estratégico en México: La aplicación de los derechos bumanos a nivel práctico. México.

Michavila, F. (2011). "El nuevo horizonte europeo de las universidades". En F.M. Michavila, El día después de Bolonia. Barcelona: Tecnos, pp. 19-84.

Minagawa, M. I. (2012). "La enseñanza del derecho y la integración grupal". En J. A. Seda, Difusión de derechos y ciudadanía en la escuela. Buenos Aires: Eudeba,pp. 57-74.

Minteriaga Garaban, A. (2009). Lo público de la educación pública: la reforma educativa de los noventa en Argentina. México: Flacso.

Miranda, E. (2012). “Cooperación académica internacional: entre la política y la gestión universitaria”. En Revista Argentina de Educación Superior, abril, año 4, n.o 4, p. 23. Obtenido de: http://www.untref.edu.ar/raes/documentos/raes_4_miranda.pdf

Montoya,J. (s.f.). “Educación jurídica en América Latina: dificultades curriculares para promover los temas de interés público y justicia social". Obtenido de: http://ilsa.org.co:81/biblioteca/dwnlds/od/elotrdr038/od38-juny.pdf

Morales, D. (2008). La lucha por el derecho. Buenos Aires: Siglo xxı.

(7 de diciembre de 2012). Clínicas jurídicas en Argentina (B. Londoño, entrevistador).

Nino, M. (6 de diciembre de 2012). Entrevista sobre la clínica de interés público de la Universidad de Palermo (B. Londoño, entrevistador).

O’Donnell, G. (2003). Democracia, desarrollo humano y ciudadanía: reflexiones sobre la calidad de la democracia en América Latina. Rosario: Homo Sapiens.

Olea, E. (15 de marzo de 2013). Clínica de Migrantes en la Universidad Diego Portales de Chile (V.Solano, entrevistador). 
Olea,E. (2014). "Interés público y asistencia jurídica: objetivos complementarios en un programa clínico”. En El abogado del siglo xxi. Bogotá: Universidad del Rosario.

Oliver, F. (1918). Enseñanza superior en Alemania. Buenos Aires: s.e.

Orozco Silva, L. (2010). "Calidad académica y relevancia social de la educación superior en América Latina”. En Revista Iberoamericana de Educación Superior, 1. Obtenido de: http://ries.universia.net/index.php/ries/article/ view/, fecha de acceso: 22 de septiembre de 2013.

Ortiz-Sánchez, I. (2005). "La proyección social en las facultades de derecho. Aproximación comparativa en un grupo de universidades de América Latina”. En A. Peña-Jumpa, Proyección Social del derecho y clinicas juridicas en universidades de América del siglo XXI, Madrid: Dykinson, pp. 23-59.

Peces-Barba, G. (2007). Educación para la ciudadanía y derechos humanos. Madrid: Espasa.

Peña-Jumpa, A. (2005). Proyección social del derecho y clinicas jurídicas en las Universidades de América del Siglo XXI. Madrid: Dykinson.

Pérez,H. (2014). “Para qué una clínica de interés público contra la trata de personas?: Aprendizajes y perspectivas. El caso de la Ciudad de México”.El abogado del Siglo xxi. Bogotá: Universidad del Rosario, p. 20.

Posadas, A. (2014). Law Schools, Regulation of Lawyers and Clinical Legal Education in Mexico. Bogotá: Universidad del Rosario (en Proceso Editorial), pp. 1-40.

Puga, M. (2011). "La enseñanza tradicional forma licenciados en derecho, las clínicas forman abogados”. En Derecho Noticias, n. ${ }^{\circ} 14$, pp. 18-1.

(2013). Litigio Estructural. Buenos Aires: S/P.

Rekosh, E. (1997). Reporte del Simposio sobre Derecho de Interés Público en Europa del Este y Rusia. Rusia: Fundación Interés Público.

Rekosh, E. B. (2001). Pursuing the Public Interest. New York: Columbia Law School.

Rodríguez Garavito, C. (2006). "Globalización, reforma judicial y estado de derecho en Colombia y América Latina: el regreso de los programas de derecho y desarrollo". En R. R. Uprimny, ¿̇Justicia para todos? Sistema judicial, derechos sociales y democracia en Colombia. Bogotá: Norma, pp. 405-469. (29 de agosto de 2013). Clínicas jurídicas en México (B. Londoño, entrevistador). 
Seda,J. A. (2006). “La formación docente en la carrera de abogado”. En Cuarto Simposium Internacional de Derechos, Sinaola: Universidad Autónoma de Sinaloa.

(2012).“Extensión universitaria y construcción de ciudadanía”.En J. A. Seda, Difusión de derechos y ciudadanía en la escuela. Buenos Aires: Eudeba, pp. 175-187.

Seijo-Ortiz, B. (2005). "Proyección social de las escuelas de derecho a través de los cursos clínicos: el caso de la Universidad de Puerto Rico”. En A. P. Jumpa, Proyección social del derecho y clinicas jurídicas en las universidades de América del siglo XXI. Madrid: Dykinson, pp. 49-60.

Shalleck, A. (2003). "Pedagogical subversion in Clinical Teaching: The women \& The Law Clinic and the inellectual property clinic as legal archaeology". En Texas Journal of Women E the Law, 13(1), Retrieved from Academic Search Complete database, pp. 113-131.

Tomasevski, K. (2001). Human Rights obligations: making education available, accessible, acceptable and adaptable. Gothenburg: Novum Grafiska Ав.

Torres Villarreal, M. L. (2010). "El abogado al servicio de la sociedad: el papel de la academia en el trabajo pro bono”. En Universidad y Sociedad. Bogotá: Editorial Universidad del Rosario, p. 22.

Torres, M. (2012). Educación legal clínica en Colombia. S.P. Santa Marta: III Encuentro Red Colombiana de Clínicas.

Torres, M. L. (2013). "Herramientas para la protección del interés público: el diseño de un litigio de alto impacto desde la educación legal clínica". En Memorias Iv Encuentro de la Red colombiana de Clínicas Jurídicas. Medellín: Universidad de Medellín, p. 30.

Tuning América Latina. (2007). "Reflexiones y perspectivas de la Educación Superior en América Latina. Informe Final”. Obtenido de: http://tuning. unideusto.org/tuningal/

Unesco (2009). Conferencia Mundial de Educación Superior. Las Nuevas Dinámicas de la Educación Superior y de la Investigación para el Cambio Social y el Desarrollo. Obtenido de: http://www.unesco.org.ve/dmdocuments/ comunicado

Universidad del Rosario - Dirección de Justicia Formal del Ministerio de Justicia (2013). Diagnóstico de la educación legal clínica en Colombia. Bogotá: sin publicar. 
Varela, M. C. (2012). “Formación ciudadana y vínculo pedagógico”. En J. A. Seda, Difusión de derechos y ciudadanía en la escuela. Buenos Aires: Eudeba, pp. 27-36.

Viola de Mestre, I. M. (2013). "La clínica jurídica en derecho inmobiliario y mediación residencial de la Universitat de Barcelona: información para los ciudadanos y formación para los estudiantes". En J. García Añón, Transformaciones en la enseñanza del derecho. Valencia: Unidad de Innovación Pedagógica Universidad de Valencia, pp. 343.

Yrigoyen Fajardo, R. (2007). El litigio estratégico en derechos humanos. Guatemala: F. Soros G. 
Este libro fue compuesto en caracteres Adobe Caslon Pro 11,5 puntos, impreso sobre papel propal de 70 gramos y encuadernado con método hot melt, en julio de 2015, en Bogotá, D. C., Colombia.

Panamericana Formas e Impresos S.A. 